\title{
USER'S GUIDE TO THE CULVERT ANALYSIS PROGRAM
}

by Janice M. Fulford

\section{U.S. GEOLOGICAL SURVEY}

Open-File Report 95-137

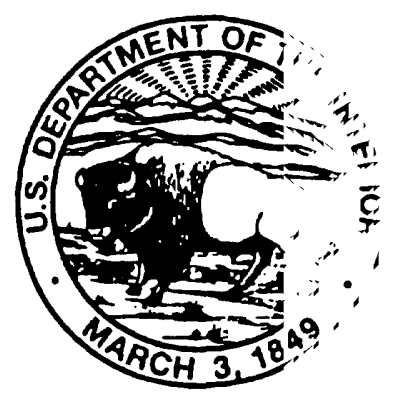

Stennis Space Center, Mississippi 


\section{U.S. DEPARTMENT OF THE INTERIOR}

BRUCE BABBITT, Secretary

U.S. GEOLOGICAL SURVEY

Gordon P. Eaton, Director

USE OF BRAND NAMES IN THIS REPORT IS FOR IDENTIFICATION PURPOSES ONLY AND DOES NOT CONSTITUTE ENDORSEMENT BY THE U.S. GEOLOGICAL SURVEY.

For additional information write to:

Copies of this report can be purchased from:

Chief, Deterministic Models

U.S. Geological Survey

Building 2101

Stennis Space Center, MS 39529
U.S. Geological Survey

Earth Science Information Center

Open-File Reports Section

Box 25286, MS 517

Denver Federal Center

Denver, Colorado 80225 


\section{CONTENTS}

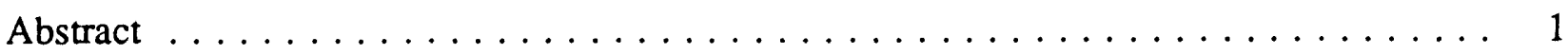

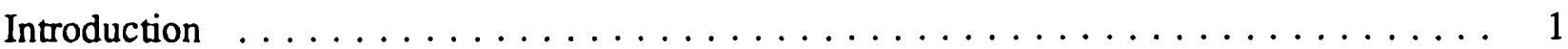

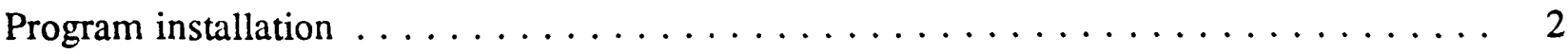

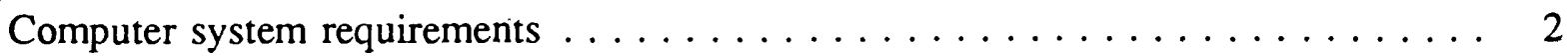

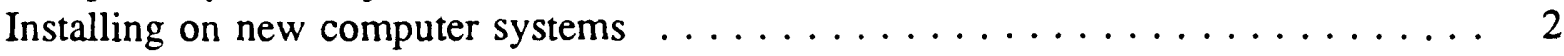

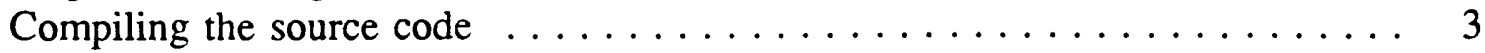

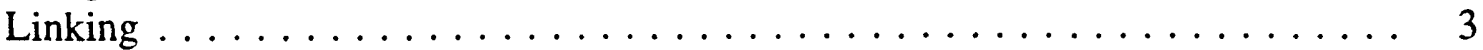

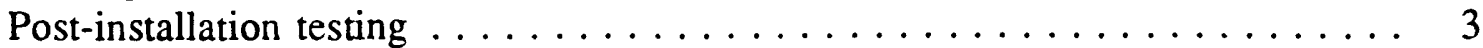

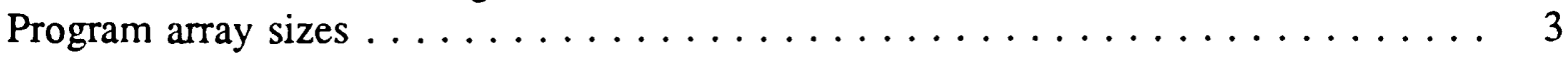

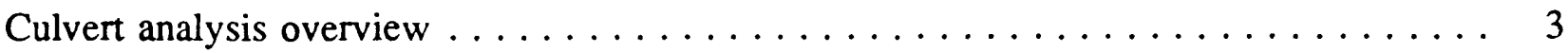

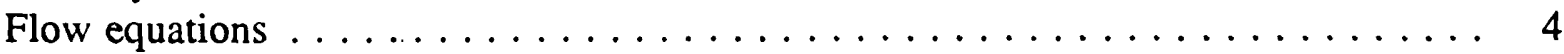

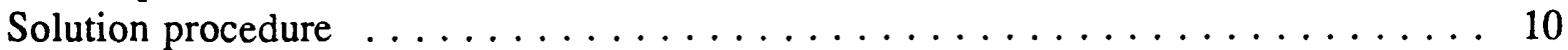

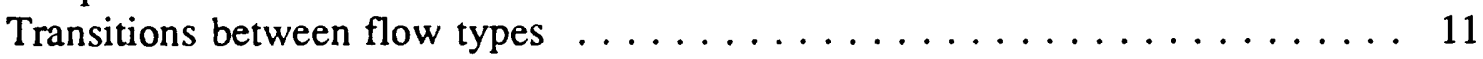

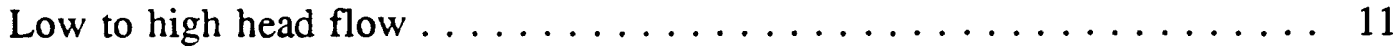

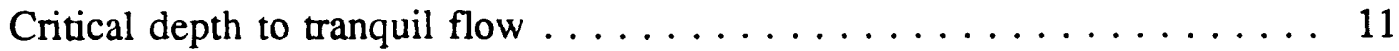

Culvert flowing full and part full $\ldots \ldots \ldots \ldots \ldots \ldots \ldots$

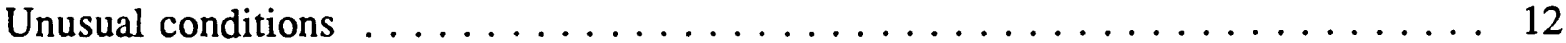

Rating surfaces for culverts ........................ 12

Rating curves for mitered pipe culverts . . . . . . . . . . . . . . . . 14

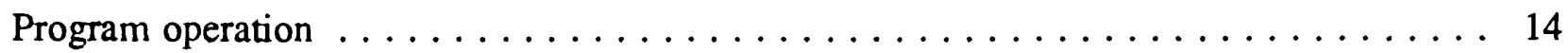

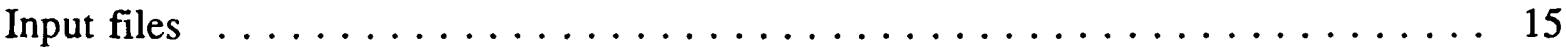

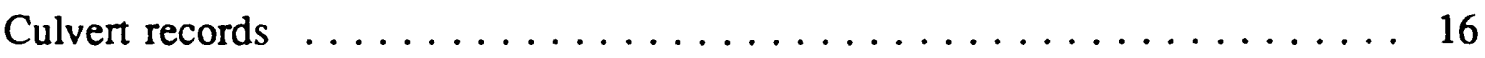

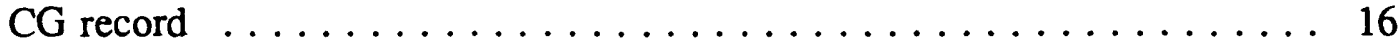

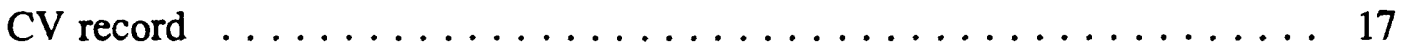

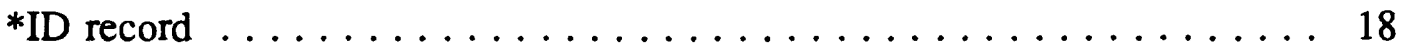

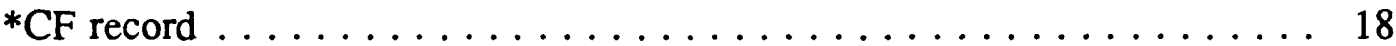

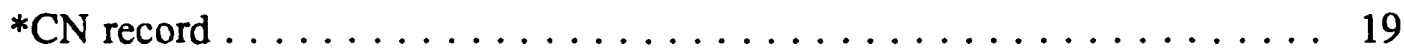

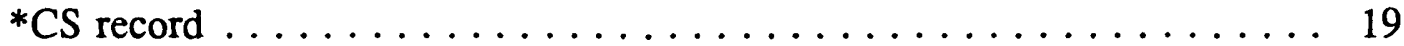

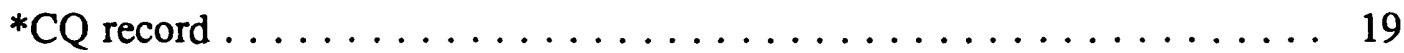

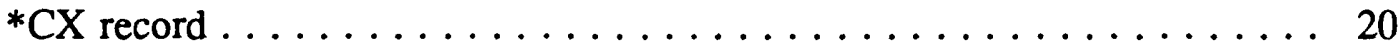

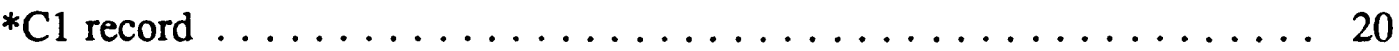

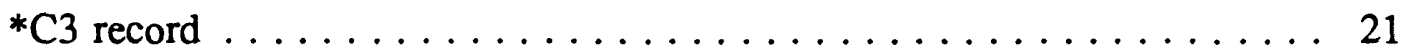

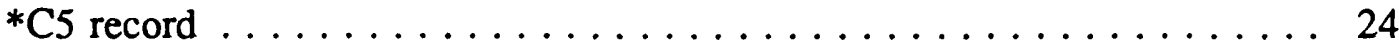

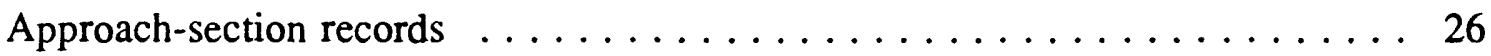

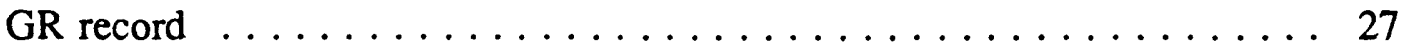

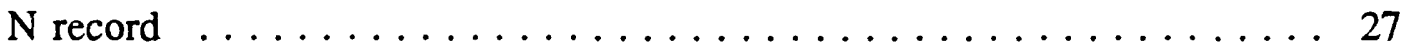

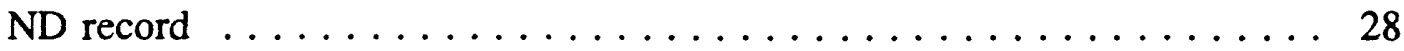

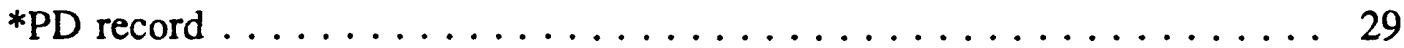

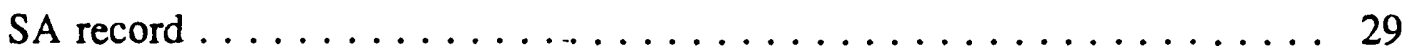

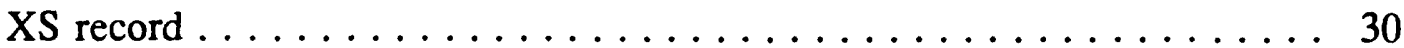

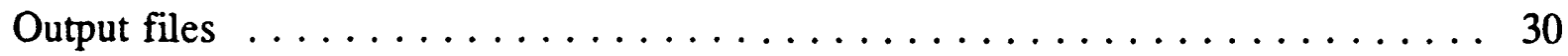




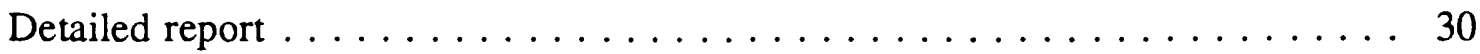

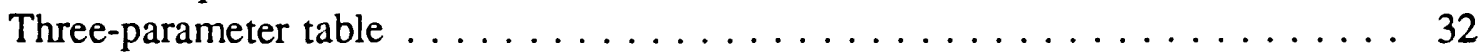

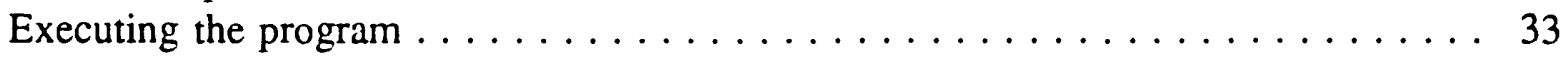

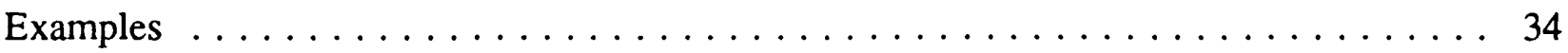

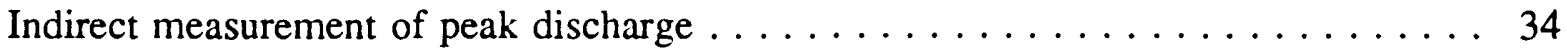

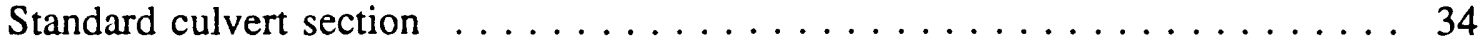

Nonstandard culvert section . . . . . . . . . . . . . . . 40

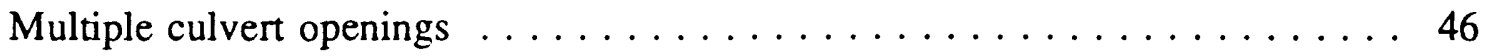

Computation of a three-parameter table $\ldots \ldots \ldots \ldots \ldots \ldots \ldots \ldots \ldots \ldots$

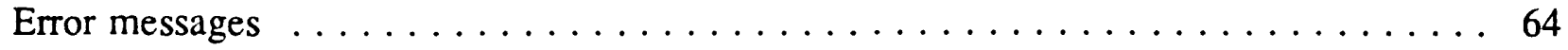

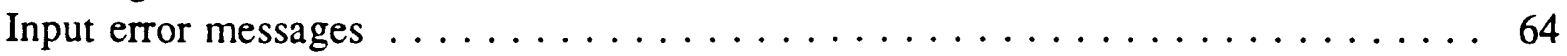

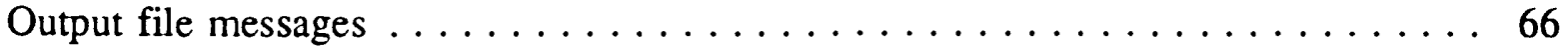

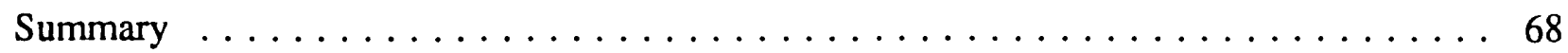

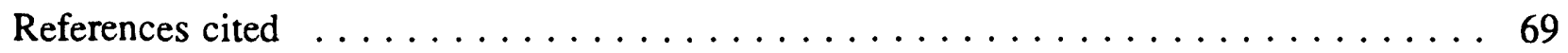




\section{FIGURES}

Figure 1. Definition sketch for a simple stream reach. . . . . . . . . . . . 5

2. Definition sketch for a stream reach with flow through a culvert. . . . . . . 6

3. Rating surface for a rectangular culvert. . . . . . . . . . . . . 13

4. Rating curve for a rectangular culvert with a tailwater depth of 0.5 foot. . . . . 13

5. Distance and elevation relations between the culvert and approach section .... 15

6. Typical data sequence used to describe culvert sections and computations. . . . 17

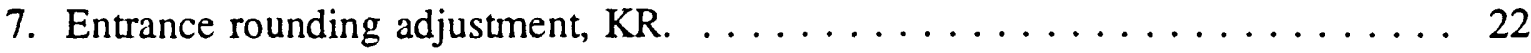

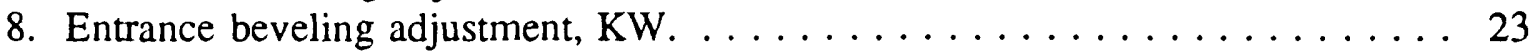

9. Typical sequence of records used to describe the approach section . . . . . . 27

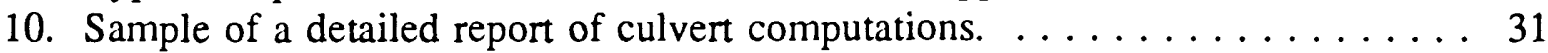

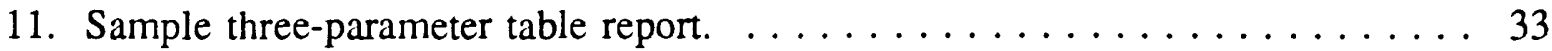

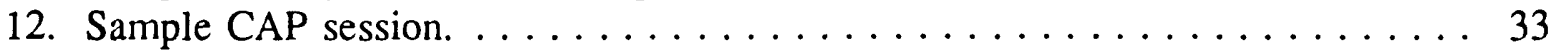

13. Approach section for culvert in tributary to Mercer Creek. . . . . . . . 35

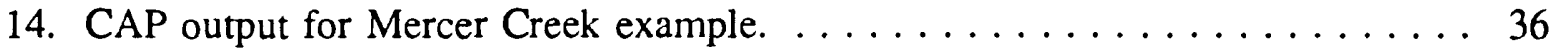

15. Cross-section of Pigeon House Creek culvert. . . . . . . . . . . . 41

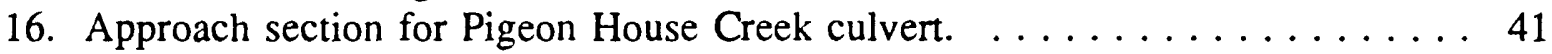

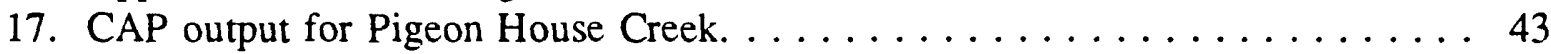

18. Location of dividing points on embankments for multiple culvert sections. . . . 46

19. Approach section for the Rio Grande conveyance channel culvert. . . . . . . . . 47

20. Longitudinal view of barrel 1 of the Rio Grande conveyance channel culvert. . . 48

21. Longitudinal view of barrel 2 of the Rio Grande conveyance channel culvert. . 48

22. CAP output for barrel 1 of Rio Grande conveyance channel culvert. . . . . . . 50

23. CAP output for barrel 2 of Rio Grande conveyance channel culvert . . . . . . 54

24. CAP output for TWRI creek example . . . . . . . . . . . . . . . . 59

25. Tabled output for TWRI creek example. . . . . . . . . . . . 63

26. TWRI creek three-parameter rating surface. . . . . . . . . . . 63 


\section{TABLES}

Table 1. Classification criteria for the six culvert flow types $\ldots \ldots \ldots \ldots \ldots \ldots 10$

2. Values of entrance rounding and beveling for riveted corrugated metal pipe . . 22

3. Adjustment factors, KPROJ, for projecting entrances . . . . . . . . . 23

4. Flow types 4 and 6 discharge coefficients for box or pipe culverts . . . . . . 24

5. Flow type 5 discharge coefficients for flared pipe ends . . . . . . . . 25

6. Type 5 discharge coefficients for box or pipe culverts set flush . . . . . . . 25

7. Flow type 5 discharge coefficients for box culverts with wingwalls . . . . . . 26

8. Fortran formats used by CAP for the three-parameter table report $\ldots \ldots \ldots 32$ 
CONVERSION FACTORS

\begin{tabular}{rll}
\hline Multiply & By & To obtain \\
\hline inch(in) & 25.4 & millimeter \\
foot $(\mathrm{ft})$ & 0.3048 & meter \\
square foot $\left(\mathrm{ft}^{2}\right)$ & 0.09290 & square meter \\
cubic foot per second $\left(\mathrm{ft}^{3} / \mathrm{s}\right)$ & 0.02832 & cubic meter per second \\
\hline
\end{tabular}




\title{
USER'S GUIDE TO THE CULVERT ANALYSIS PROGRAM
}

\author{
by Janice M. Fulford
}

\begin{abstract}
This user's guide contains information on using the culvert analysis program (CAP). The procedure used is based on that presented in Techniques of Water-Resources Investigations of the United States Geological Survey, book 3, chapter A3, "Measurement of Peak Discharge at Culverts by Indirect Methods." The program uses input files that have formats compatible with those used by the Water-Surface Profile (WSPRO) program. The program can be used to compute rating surfaces or curves that describe the behavior of flow through a culvert or to compute discharges from measurements of upstream and downsteam water-surface elevations.
\end{abstract}

\section{INTRODUCTION}

This user's guide contains information on the culvert analysis program (CAP). Users can determine discharges from measured high-water marks or compute rating surfaces or curves that represent the hydraulic behavior of the culvert with CAP. The resulting rating surfaces or curves can be used to simulate culvert hydraulics in other flow models.

The culvert analysis procedure followed by the program computes headwater elevations for specified combinations of tailwater elevations and discharge. The procedure is baset on the U.S. Geological Survey (USGS) method documented by Bodhaine (1968) in Techniques of Water-Resources Investigations (TWRI) book 3, chapter A3, which is based on USGS field investigations (Carter, 1957) and on laboratory investigations made by the USGS, the Bureau of Public Roads, and many universities. The USGS procedure has been adapted to provide solutions that minimize the need for the user to determine the flow regime in the culvert.

The guide contains sections on the installation of the program onto computer syst 'ms; an overview of the culvert analysis procedure used by the program; details of program operation; and examples demonstrating the use of the program. Users should be familirr with basic hydraulic principles. Detailed explanation of the culvert analysis procedure and determination of discharge coefficients is not contained in this guide. Users should refer to the TWRI by Bodhaine to determine discharge coefficients or if they are unfamiliar with culvert analysis.

The program source code, written in Fortran 77, has some routines that are loosely based on an antecedent program, A526 (Matthai and others, 1970?), used by the USGS. The antecedent program was initially written for a Burroughs 220 in BALGOL by W.P. Somers and G.I. Selner of the USGS and was subsequently converted to Fortran IV by J.V. Tarida, O.G. Lara, and H.E. Stull of the USGS. 
Interactive entry and editing of the input data is not supported by CAP. Discha-ges are computed from an input file that is prepared by the user with a text editor before CAP is run. The input file format is based on the Water-Surface Profile (WSPRO) computer program input files.

\section{PROGRAM INSTALLATION}

This section contains information on installing the program. Details on system requirements, transferring the program to new computer systems, and program testing are included.

\section{Computer System Requirements}

The culvert analysis program compiles, links and runs successfully on IBM personal computers and compatibles (PC's), Macintosh personal computers, minicomputers, and mainframe computers. It does not use or require graphics capability, color, or a mous?. Disk space of approximately 250 kilobytes $(\mathrm{K})$ is sufficient for many applications. Source code for the program is approximately $203 \mathrm{~K}$. A typical executable file on a PC is $230 \mathrm{~K}$. Additional disk space is needed for input, output, and temporary files.

\section{Installing on New Computer Systems}

The program installer should copy CAP files from the source media (floppy dis'- or remote computer system) onto the hard disk of the target computer system. CAP files include the following:

README packing list and update information.

CAP.EXE executable file (not available for all computer systems)

CULVERT.FOR source code. Contains the main program, and subroutines that compute culvert flow.

SHYDIE.FOR source code. Contains routines that compute hydraulic properties.

MERCER.DAT test data set, circular culvert with an approach section.

PIGEON.DAT test data set, non-standard culvert section with an approach section.

RIOGRAN.DAT test data set, multiple pipe arches with an approach section.

CULTWRI.DAT test data set, TWRI example with an approach section.

If an executable file is available for the target computer system compiling and linking of the program is not necessary and users can skip to the section on post-installation testing. If an executable file is not available, minimal effort is required to compile CAP source code on most computer systems. The target computer should have a Fortran 77 compiler th at adheres to the American National Standard Institute (ANSI) Fortran 77 standard (American National Standards Institute 1978). Installation requires the installer to compile and link the program on the new system. Familiarity with the Fortran compiler and linker on the computer is necessary before attempting to install the code on a new system. 


\section{Compiling the Source Code}

It is recommended that the installer review the readme file before compiling the source. It contains the latest information on the program. Installers should use the target comp'ter's Fortran compiler to compile all the files except the readme file and the .DAT example input files. The source file name extension .FOR is not compatible with every Fortran compiler and may require modification before compiling.

\section{Linking}

Successfully compiled files can be linked with the computer's linking facility. Compiled files should be linked in the following order: CULVERT, SHYDIE. The so' rce code has been successfully compiled with Microsoft Fortran version 5.0 (DOS), Greentills Fortran-88000 version 1.8.6 (UNIX), and MacFortranII (MAC OS).

\section{Post-Installation Testing}

An executable file can be tested with one of the supplied test data sets. The cormands required to run the program are dependent on the computer system. For a PC or a workstation (such as a Data General Aviion 300), entering the program name CAP will start the program. Enter MERCER.DAT for the culvert file and for the approach file in response to the program's queries. The results for this data set are listed in the Examples section of the guide. File names are case sensitive for UNIX computer systems and other computar operating systems that are case sensitive.

\section{Program Array Sizes}

The default array sizes in CAP allow computations of upstream water elevations for combinations of up to 50 tailwater elevations and 48 discharges through the culvert. Tie approach section is allowed to have up to 20 subareas and 150 coordinates.

\section{CULVERT ANALYSIS OVERVIEW}

The culvert analysis procedure followed by CAP is similar to that described by G.L. Bodhaine (1968) in "Measurement of Peak Discharge at Culverts by Indirect Methods." A few adaptations and modifications have been made to allow solutions to be computed vithout user intervention.

Bodhaine's procedure for computing flow through culverts is cited by numerous texts on hydraulics and classifies culvert flow into six flow types. Equations for the six flow' types are based on continuity and energy equations. Classification depends on whether the culvert inlet or outlet is controlling the flow and whether the culvert barrel flows full. 
The following is a brief overview of the flow equations and solution procedure. Users unfamiliar with the culvert analysis procedure should refer to Bodhaine (1968) for a detailed explanation.

\section{Flow Equations}

The equations for culvert flow are based on the conservation of energy and mass between the approach section and a downstream section in the culvert. The equation for each particular state of flow in the culvert is derived by applying the energy equation (Bernoulli's equation) and continuity equation (mass conservation) between the appropriate downstram culvert section that governs that flow state and the approach section. Depending on the flow regime in the culvert, the downstream section in the culvert is located either at the control section or at the outlet section of the culvert. The control section is the section where the flow changes from subcritical to supercritical flow. For an uncomplicated flow reach of constant shape and slope as illustrated in figure 1, the energy equation for gradually varied flow is

$$
h_{1}+\alpha_{1} \frac{V_{1}^{2}}{2 g}=h_{2}+\alpha_{2} \frac{V_{2}^{2}}{2 g}+h_{f_{1-2}},
$$

where $h_{1}$ is the upstream water surface elevation, $h_{2}$ is the downstream water surface elevation, $V_{1}$ and $V_{2}$ are mean water velocity at sections 1 and $2, g$ is the acceleration of gravity, $\alpha_{1}$ and $\alpha_{2}$ are velocity coefficients at sections 1 and 2 , and $h_{f_{1-2}}$ is the energy loss over the length of the flow reach. The energy loss term in the equation is computed as

$$
h_{f_{1-2}}=\frac{L Q^{2}}{K_{1} K_{2}}
$$

where $Q$ is the discharge, $L$ is the reach length, and $K_{1}$ and $K_{2}$ are the upstream and downstream conveyances, respectively. Conveyance, is defined using Manning's equation as

$$
K=\frac{1.49}{n} A R^{\frac{2}{3}}
$$

where $\boldsymbol{n}$ is Manning's coefficient of roughness, $\boldsymbol{A}$ is cross-sectional area, and $\boldsymbol{R}$ is hydraulic radius. For a detailed derivation of gradually varied flow and conveyance and a discussion of Manning's equation refer to Chow (1959, p. 217-248). 


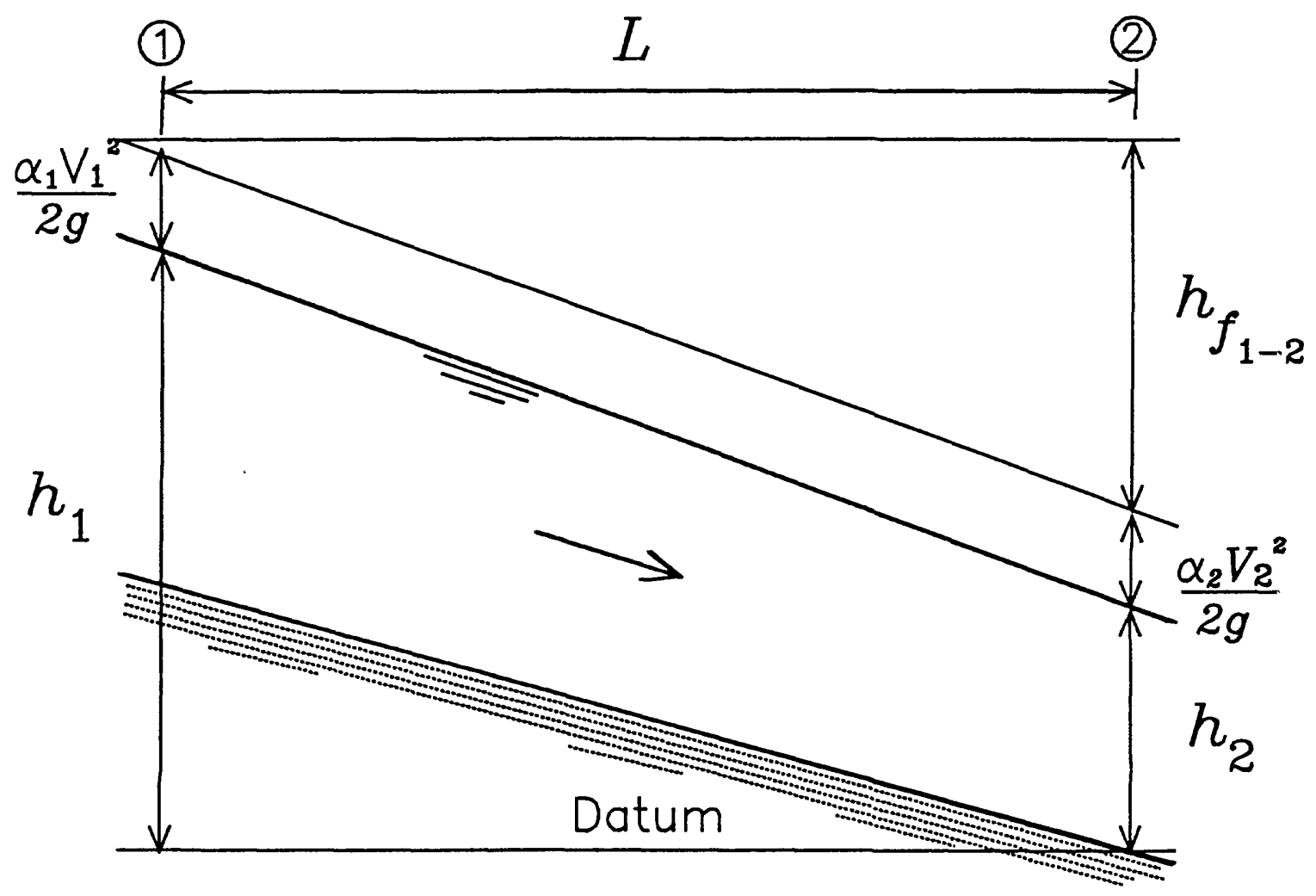

Figure 1. Definition sketch for a simple stream reach. $\boldsymbol{L}$ is reach length; $\boldsymbol{h}_{\boldsymbol{1}}$ and $\boldsymbol{h}_{\mathbf{2}}$ are water-surface elevations; $V_{1}$ and $V_{2}$ are mean velocities; and $\alpha_{1}$ and $\alpha_{2}$ are the velocity head coefficients. Subscripts 1 and 2 denote sections 1 and 2 respectively. $g$ is the acceleration of gravity and $\boldsymbol{h}_{\boldsymbol{f}}$ is the friction loss over the reach length.

The equations for the six culvert flow types-(1) critical depth at inlet, (2) critical depth at outlet, (3) part full culvert barrel and tranquil flow throughout, (4) submerged outlet and inlet, (5) rapid flow at inlet and part full culvert barrel, and (6) full culvert barrel flow. with free outfall-are special cases of the energy equation for gradually varied flow. Because entrance loss is computed in the culvert equations as a function of velocity, the entrance loss and velocity head in the control section are combined into a single velocity head term that contains the discharge coefficient. Energy losses due to the contraction and expansion of flow as it passes through the culvert are also accounted for by the discharge coefficients. This results in discharge coefficients being a function of flow type and approach depth, as well as a function of culvert and entrance geometry. Figure 2 is a definition sketch for culvert flow. 


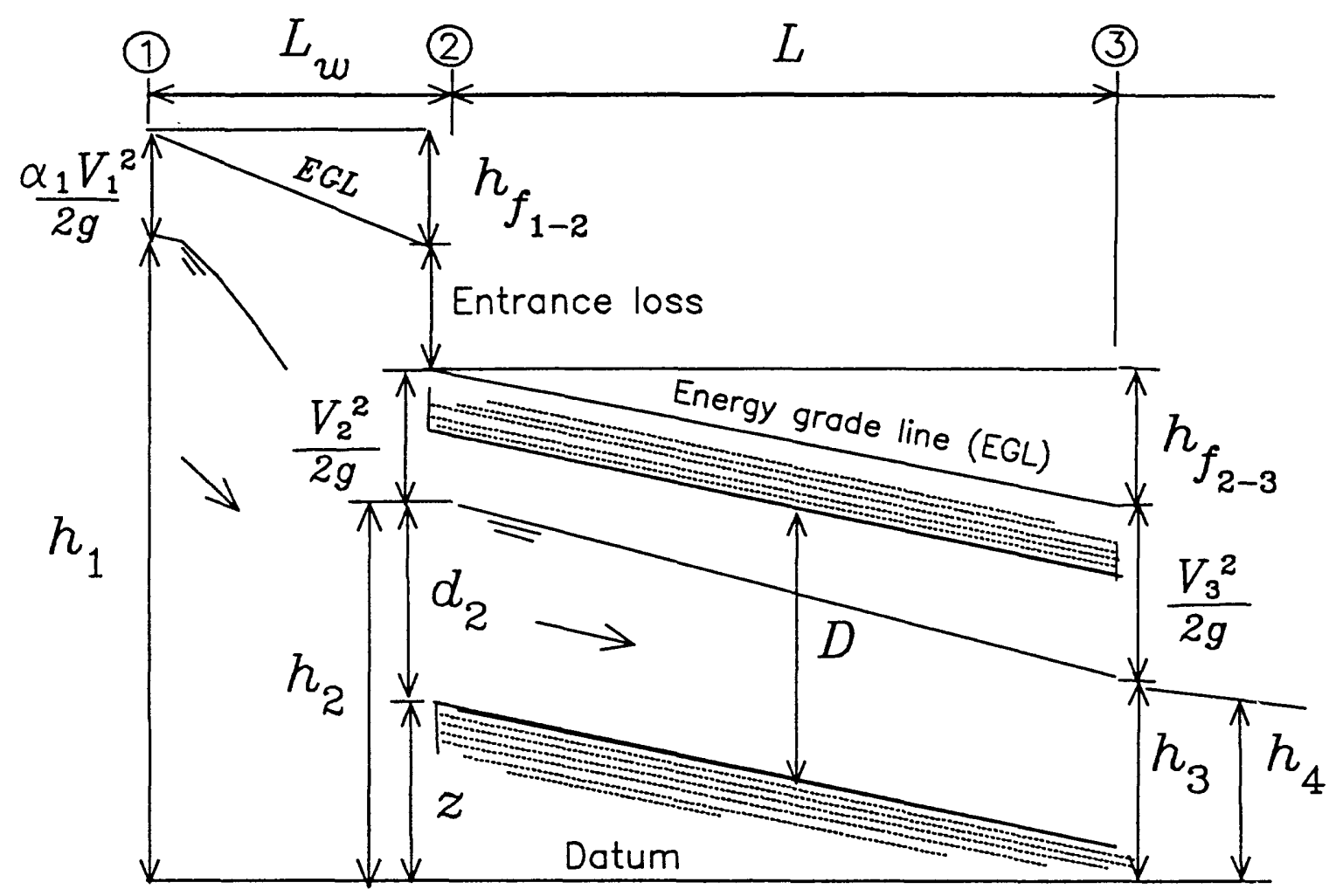

Figure 2. Definition sketch for a stream reach with flow through a culvert. 1 is at the approach section, 2 is at the culvert inlet section, and 3 is at the culvert outlet section. $L_{w}$ is the reach length between sections 1 and 2; $L$ is the culvert barrel length; $D$ is the culvert barrel height; $d_{2}$ the flow depth in the culvert inlet and $z$ is the fall over the culvert lergth. $h$ is the water surface elevation and $V$ is the mean velocity in the section denoted by the numeric subscript. $h_{f}$ is friction loss over $L_{w}$ for subscript 1-2 and over $L$ for subscript 2-3.

For flow type 1, critical depth at inlet, the energy equation is written from the inlet section of the culvert to the approach section. Flow is supercritical in the culvert barrel and tranquil upstream of the culvert inlet. Critical depth is assumed in the inlet section of the culvert. For culvert flow type 1 , the energy equation is

$$
h_{1}+\alpha_{1} \frac{V_{1}^{2}}{2 g}=d_{c}+z+\frac{V_{2}^{2}}{C_{123}^{2} 2 g}+h_{f_{1-2}} .
$$

The discharge coefficient $C_{123}$ is for flow types 1,2 , and 3, where the culvert does not flow full at the inlet, $z$ is the fall of the culvert, and $d_{c}$ is the critical flow depth in the culvert 
for the discharge. The fall of the culvert is computed by subtracting the elevation of the downstream culvert invert from the elevation of the upstream culvert invert. The frictional energy loss term is computed as

$$
h_{f_{1-2}}=\frac{L_{w} Q^{2}}{K_{1} K_{d_{c}}}
$$

where $L_{W}$ is the length of the reach between the approach section and the culvert inlet, and $K_{d_{c}}$ is the conveyance of the culvert at critical flow depth.

For flow type 2, critical depth at the outlet, the energy equations are written from the exit section of the culvert through the inlet and then to the approach section. Flow is tranquil in the culvert barrel. Critical depth is assumed in the outlet section of the culvert. For culvert flow type 2 , the energy equation is

$$
h_{1}+\alpha_{1} \frac{V_{1}^{2}}{2 g}=d_{C}+\frac{V_{3}^{2}}{C_{123}^{2} 2 g}+h_{f_{1-2}}+h_{f_{2-3}} .
$$

The frictional energy losses for type 2 flow are computed as

$$
h_{f_{1-2}}=\frac{L_{w} Q^{2}}{K_{1} K_{2}} \quad \text { and } \quad h_{f_{2-3}}=\frac{L Q^{2}}{K_{2} K_{d_{c}}}
$$

The conveyance of the culvert inlet, $K_{2}$, in equations $7 \mathrm{a}$ and $7 \mathrm{~b}$ requires the determination of the flow depth in the culvert inlet. The flow depth in the inlet is determined by routing the discharge from critical depth at the exit to the inlet using the energy equation.

For flow type 3, part full culvert barrel and tranquil flow throughout, the energy equations are written from the exit section of the culvert through the inlet and then to the approach section. Tranquil flow is assumed throughout the culvert approach, barrel, outlet, and exit sections. For culvert flow type 3 , the energy equation is

$$
h_{1}+\alpha_{1} \frac{V_{1}^{2}}{2 g}=h_{3}+\frac{V_{3}^{2}}{C_{123}^{2} 2 g}+h_{f_{1-2}}+h_{f_{2-3}} .
$$

The frictional energy losses for flow type 3 are computed as

$$
h_{f_{1-2}}=\frac{L_{w} Q^{2}}{K_{1} K_{2}} ; \quad h_{f_{2-3}}=\frac{L Q^{2}}{K_{2} K_{3}} .
$$


The computation of the culvert inlet conveyance, $K_{2}$, in equations $9 \mathrm{a}$ and $9 \mathrm{~b}$ require the determination of the flow depth in the culvert inlet. The flow depth is determined by routing the discharge from the known tailwater elevation at the culvert exit to the inlet using the energy equation.

For flow type 4, submerged outlet and inlet, the energy equation is written from the exit section to the approach section assuming full culvert flow and submerged inlet and outlet conditions. Essentially, the culvert acts as a pipe. In contrast to Bodhaine (1968), por ted conditions (no approach velocity or friction loss) are not assumed in the approach to the culvert inlet. For culvert flow type 4 , the energy equation is

$$
h_{1}+\frac{\alpha_{1} V_{1}^{2}}{2 g}=h_{4}+\frac{V_{o}^{2}}{C_{46}^{2} 2 g}+h_{f_{2-3}}+h_{f_{1-2}} .
$$

The discharge coefficient, $C_{46}$, is for flow types 4 and 6 , where the inlet and culvert b?rrel flows full. The frictional energy losses for flow type 4 are a function of velocity in th: culvert barrel and the approach section and the barrel and approach section roughnesser They are computed as

$$
h_{f_{2-3}}=\frac{V_{O}^{2}}{2 g} 29 n^{2} L R_{O}^{-\frac{4}{3}} ; \quad h_{f_{1-2}}=\frac{L Q^{2}}{K_{1} K_{2}}
$$

where $R_{0}$ is the hydraulic radius for the full culvert barrel.

For flow type 5 and type 6 the approach section water-surface elevation is at least 1.5 times the culvert barrel height above the culvert inlet invert. These flows are categori-od as high head flows. For flow type 5, rapid flow at the inlet and part full culvert, the energy equation is written from the inlet section of the culvert to the approach section. The crlvert acts as a gate in this case. The outlet is not submerged. Ponded conditions in the approach are assumed. For type 5 culvert flow, the energy equation is

$$
h_{1}=z+\frac{V_{o}^{2}}{C_{5}^{2} 2 g} \text {. }
$$

The discharge coefficient, $C_{5}$, is the coefficient used for type 5 flow where the inlet arts as a sluice gate.

For type 6 flow, full culvert barrel flow with free outfall, the energy equation is written from the exit section of the culvert through the inlet to the approach section. This case is similar to type 5 except that the culvert barrel flows full. The culvert acts as an orifice. As for type 5 flow conditions, the outlet is not submerged. For type 6 culvert flow, the energy equation is 


$$
h_{1}=h_{3}+\frac{V_{O}^{2}}{C_{46}^{2} 2 g}+h_{f_{2-3}} \text {. }
$$

To solve this equation, the program uses a functional relation that has been defined by laboratory experiments. This functional relation is documented in the TWRI by Bodhaine (1968, figure 17, p. 34).

The continuity equation, $Q=V A$, is substituted for velocity in the energy equation. CAP solves the six equations for the approach section water-surface elevation. Bodhaire, however, solved for discharge to facilitate hand calculation of discharge, resulting in the following equations where $A_{d c}$ is the culvert area at critical depth, $A_{3}$ is the culvert area at the outlet flow depth and $A_{o}$ is the area of a full culvert;

$$
\begin{gathered}
Q_{t y p e 1}=C_{123} A_{d c} \sqrt{2 g\left(h_{1}-z+\alpha_{1} \frac{V_{1}^{2}}{2 g}-d_{c}-h_{f_{1-2}}\right)} \\
Q_{t y p e 2}=C_{123} A_{d d_{c}} \sqrt{2 g\left(h_{1}+\alpha_{1} \frac{V_{1}^{2}}{2 g}-d_{c}-h_{f_{1-2}}-h_{f_{2-3}}\right)} \\
Q_{\text {type3 }}=C_{123} A_{3} \sqrt{2 g\left(h_{1}+\alpha_{1} \frac{V_{1}^{2}}{2 g}-h_{3}-h_{f_{1-2}}-h_{f_{2-3}}\right)} \\
Q_{\text {trpe4 }}=C_{46} A_{0} \sqrt{\frac{2 g\left(h_{1}-h_{4}\right)}{1+29 C_{46}^{2} n^{2} L R_{0}^{-\frac{4}{3}}}} \\
Q_{t y p e s}=C_{5} A_{0} \sqrt{2 g\left(h_{1}-z\right)} \\
Q_{t y p e 6}=C_{46} A_{0} \sqrt{2 g\left(h_{1}-h_{3}-h_{f_{2-3}}\right)}
\end{gathered}
$$




\section{$\underline{\text { Solution Procedure }}$}

The program solves the appropriate form of the energy equation and the continuity equation for the approach section water-surface elevation by using simple flow routing. Given a discharge and a tailwater elevation (water-surface elevation at the culvert-exit section), the appropriate flow type and equation or equations are determined and solved for the approach-section water-surface elevation using a bisection root solver (Conte and DeBoor, 1980). The appropriate set of equations is determined by applying the criteria used by the USGS culvert method for determining type of flow. These criteria are listed in table 1. For some flow types, such as type 5 or type 6 , the proper flow type is determined in the Frogram by first attempting to solve for the occurrence of type 1,2, or 3 flow. Upon failure to bracket a root, the program then solves for type 5 and/or type 6 flow.

The solution procedure used in either CAP or the preceding culvert program, A526, (Matthai and others, 1970?), is based on using three sections in the computations: the approach, culvert inlet, and culvert outlet. This procedure does not ensure numerical convergence; that is, the solution will not change as a result of increasing the number of sections used in the computations. The procedure used does not use sections other than or in addition to the three sections, except for certain cases noted in the following section. For some solutions, this may result in error in the approach water-surface elevation computed or in the type 3 water-surface elevation being computed somewhat lower than the type 2 watersurface elevations for the same discharge. Users can refer to a discussion of numerical convergence in 1-D steady flow models presented by Thompson and Rogers (1993) for examples of the effects of convergence on the accuracy of the water surface computed.

Table 1. Classification criteria for the six culvert flow types $\left[h_{1}\right.$, elevation of approachsection water-surface; $z$, culvert fall; $D$, culvert height; $h_{4}$, elevation of exit-section watersurface elevation; $d_{c}$, critical flow depth in culvert; $S_{o}$, culvert slope; $S_{c}$, critical slope]

\begin{tabular}{cccc}
\hline \multirow{2}{*}{$\begin{array}{c}\text { Clow } \\
\text { type }\end{array}$} & $\begin{array}{c}\text { Approach depth range } \\
\text { (above upstream invert) }\end{array}$ & $\begin{array}{c}\text { Outlet depth range } \\
\text { (above downstream invert) }\end{array}$ & Culvert slofe \\
\cline { 2 - 4 } Type 1 & $\left(h_{1}-z\right)<1.5 D$ & $h_{4}<\left(d_{C}+z\right)$ & $s_{O}>s_{C}$ \\
Type 2 & $\left(h_{1}-z\right)<1.5 D$ & $h_{4}<\left(d_{C}+z\right)$ & $S_{O}<s_{C}$ \\
Type 3 & $\left(h_{1}-z\right)<1.5 D$ & $h_{4} \leq D, h_{4}>d_{C}+z$ & $S_{0}>S_{C}$ \\
& $\left(h_{1}-z\right)>D$ & $h_{4} \leq D, h_{4}>d_{C}$ & $S_{0}<s_{C}$ \\
Type 4 & $\left(h_{1}-z\right)<1.5 D$ & $h_{4}>D$ & no criteria \\
Type 5 & $\left(h_{1}-z\right) \leq 1.5 D$ & $h_{4} \leq D$ & no criteria \\
Type 6 & & $h_{4} \leq D$ & no criteria \\
\hline
\end{tabular}


Transitions between the various flow type equations are not always smooth and continuous. These transitions are either the result of real flow phenomenon or numerical discontinuity between the flow equations.

\section{Low to high head flow}

Flows with the approach water-surface elevation ranging from $1.2 \mathrm{D}+\mathrm{z}$ to $1.5 \mathrm{D}+\mathrm{z}$ can change dramatically back and forth between low (types 1,2, and 3) and high head (types 5 and 6) flows. Bodhaine (1968) assumes that an instantaneous reduction in discharge does not occur. The transition between type 1 and type 5 flow is approximated by fitting a straight line between the type 1 solution at headwater-diameter ratio of 1.2 and the type 5 solution at a headwater-diameter ratio of 1.5 . For the transition between type 2 and type 6 , flow is approximated by fitting a straight line between type 2 and type 6 solutions at headwaterdiameter ratios of 1.25 and 1.75 respectively. Bodhaine (1968) does not suggest techniques for the other transitions between low head and high head flow types.

CAP uses methodology similar to Bodhaine's to compute low to high head transitions. Transitions between low and high head flows are approximated by fitting a straight line between the low head solution at headwater-diameter ratios of 1.2 for type 1 , and 1.25 for type 2 and 3, and the high head solution at headwater-diameter ratios of 1.5 for type 5 and 1.75 for type 6 . Cases for which critical depth is greater than the culvert height are interpolated between flow type 1 and the high head flow types.

\section{Critical depth to tranquil flow}

The tranquil flow (type 3) equation often can not be solved near the transition between flow types with a critical depth control (types 1 and 2) and tranquil flow (type 3). Flow is tranquil in the culvert exit section. However, the energy equation can not be appropriately solved for the inlet water-surface depth assuming tranquil flow in the culvert barrel. Two flow scenarios are possible when this occurs.

If the culvert barrel is steep, supercritical flow and tranquil flow occur in the barrel, separated by a hydraulic jump. Critical flow depth occurs at the inlet and the approach water-surface elevation is computed from type 1 flow equations.

If the culvert barrel slope is mild, only tranquil flow occurs in the barrel and norrnal depth occurs at the inlet. However, significant water-surface curvature in the culvert makes the assumption of a constant water slope in the barrel invalid. The flow equation is numerically discontinuous and cannot be solved. The discontinuity results from poor sfatial convergence and is analogous to trying to draw an arc with connected straight line segments. One line segment does not look like an arc. Multiple connected line segments, howeve-, can look like an arc. To compute a solution, an additional section in the culvert at which flow parameters can be computed is necessary to account for the water surface curvature. 
Simple routing is used to determine the location in the culvert at which normal depth of flow occurs. The inlet depth is then determined by routing the flow from the location in the culvert at which normal depth occurs to the inlet. The approach water surface elevation is determined using the type 3 flow equation. Friction losses are determined for the culvert by summing the friction lost in the normal depth portion with the friction lost in the remaining portion of the culvert.

\section{Culvert flowing full and part full}

Additional numerical discontinuities between flow types occur when flow types 3 and 4 exist simultaneously in the culvert barrel. The culvert flows full for part of its length and flows tranquilly for the remainder of its length. Simple routing through the culvert is used to determine the length of culvert barrel flowing full or part full.

When the culvert flows part full (type 3) at the entrance and full (type 4) at the exit, the type 4 flow equation is used to determine the length of culvert that is flowing as trpe 3 conditions. The type 3 equation is then solved for approach water surface elevation using this length.

Similarly, when the culvert flows full (type 4) at the entrance and part full (type 3) at the exit, the type 3 flow equation is used to determine the length of culvert flowing as type 4 . The type 4 equation is then solved for approach water surface elevation using this length.

\section{$\underline{\text { Unusual Conditions }}$}

Some culvert conditions are inappropriate for the procedure. These conditions are (1) variation in cross-sectional dimensions or material through the culvert barrel, (2) nonuniform slope or break in slope along the culvert barrel or (3) severe adverse slope.

Additionally, some flow conditions are inappropriate for the procedure. Inappropriate flow conditions include nonponded conditions for type 5 and 6 and supercritical flow in the approach section. When significant approach velocity (nonponded condition) occurs for flow types 5 and 6, flows are not computed accurately because approach velocity head and friction losses are ignored in the procedure. The flow equations cannot be solved for culverts with supercritical flow in the approach section, because of the routing technique used in setting up and solving the equations and because the discharge coefficients assume subcritical flc w conditions in the approach section.

\section{Rating Surfaces for Culverts}

The flow behavior of hydraulic structures such as culverts can be represented by a three-dimensional surface. The surface is described by a set of points with coordinates corresponding to the discharge through the structure, the tailwater elevation, and the approach-section water-surface elevation. An example rating surface is shown in figure 3. The familiar technique of representing discharge ratings as a function of discharge and 


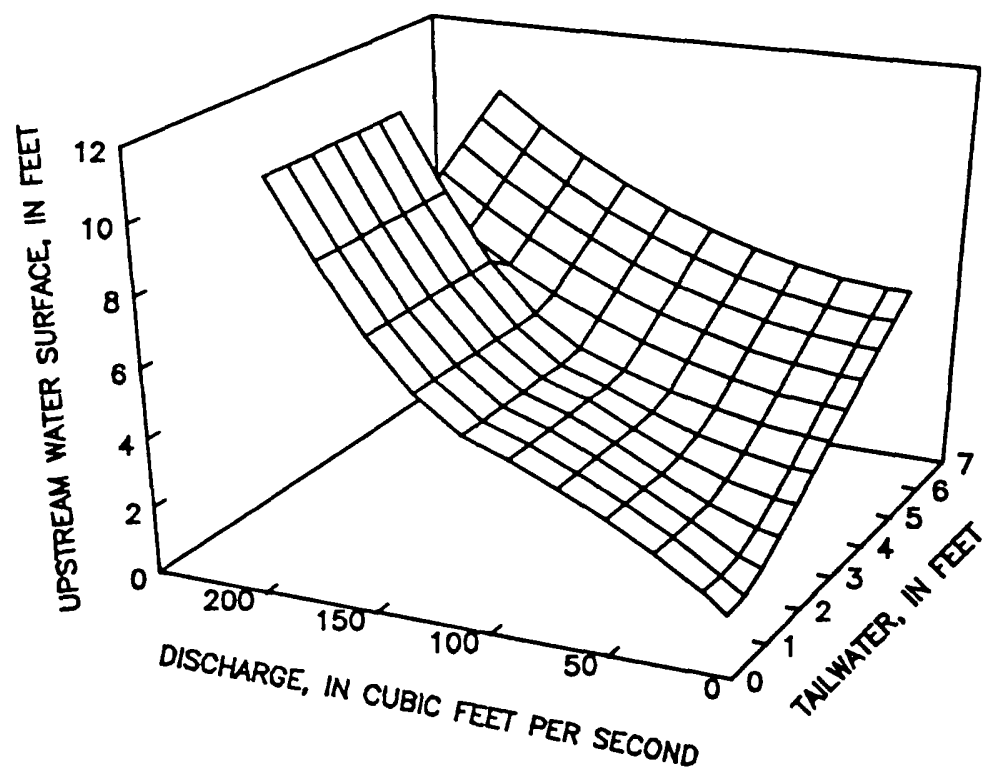

Figure 3. Rating surface for a rectangular culvert.

approach elevation shown in figure 4 requires a curve for each tailwater. Representing flow behavior of hydraulic structures by a three-dimensional surface does not require separate. curves for each tailwater and illustrates the relationship between changing tailwater and discharge and approach water-surface elevation. Numerical surface water flow models often employ tabled values of cross-section hydraulic properties. Tabled values of water-surface elevation, discharge and tailwater elevation for culverts can be produced by CAP to ser'e a similar purpose. Flow models can interpolate intermediate values and gradients from the tabled values.

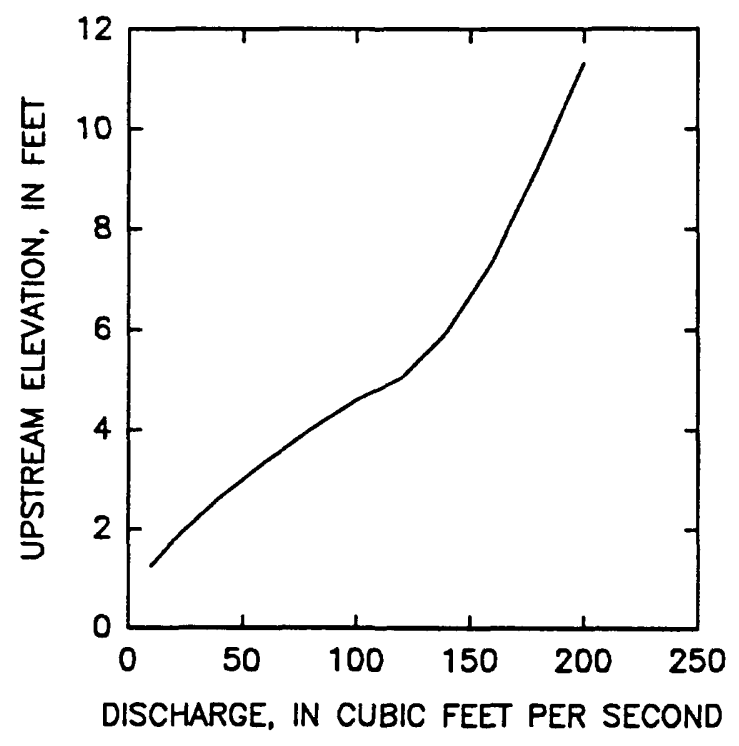

Figure 4. Rating curve for a rectangular culvert with a tailwater depth of 0.5 foo*. 


\section{$\underline{\text { Rating Curves for Mitered Pipe Culverts }}$}

Rating curves for mitered pipes present additional challenges because culvert flow length is a function of flow depth. CAP uses a constant culvert flow length for computation, but rating curves for mitered pipes can be produced by repetitively changing the culvert flow length and executing CAP. For the rating, combinations of discharge, approach water-surface elevation, and tailwater elevation should be selected from the output that has the culvert length that most closely matches the actual flow length in the culvert. Enough runs at various culvert lengths should be made so that the approach water-surface elevation is computed at sufficient accuracy. $L_{\text {miter }}$, the culvert flow length in a mitered pipe, can be estimated form the culvert geometry using

$$
L_{\text {miter }}=L_{\min }+\left(1-\frac{h_{2}}{D}\right) L_{\max }
$$

where $\boldsymbol{h}_{\mathbf{2}}$ is the inlet water elevation, $\boldsymbol{L}$ is the culvert flow length and the subscripts, miter, min, and max denote culvert flow length, minimum flow length (the length between the tops of the culvert barrel ends), and maximum flow length (the length between the inverts $c^{f}$ the culvert barrel ends).

\section{PROGRAM OPERATION}

Culvert computations require data that describe the geometry of the approach section, the geometry of the culvert, roughness parameters, and discharge coefficients. Data for the input file are usually obtained by field survey if the analysis is for an existing culvert. For a discussion of the field surveying requirements see Bodhaine (1968, p.6-9).

Execution of CAP requires first the preparation of an input file, or files, containing the data that describe the culvert, the approach section, and values of tailwater elevation ard discharge. Except for field surveying, input file preparation is normally the most timeconsuming step in the analysis of culvert flow. CAP does not support interactive input of data. A text editor that produces ASCII files is required to create the input files.

The input data files are based on WSPRO (Shearman, 1990) input file formats. The first 10 columns of each record are reserved for fixed-field format. Columns 11 through 80 are available for free-field format. Data items entered in the free-field format area are separated by either a comma, one or more blank spaces or any combination of blanks and a comma. Null values must be specified, unless they occur at the end of the list of data items entered on the record. Null values are specified by either an asterisk or two successive. commas. Data items may be entered in whatever precision is required. Approach-section data formatted for CAP are compatible with the WSPRO program. Use of WSPRO compatible data formats provides users with a simple and well-documented format in vihich to enter data. 


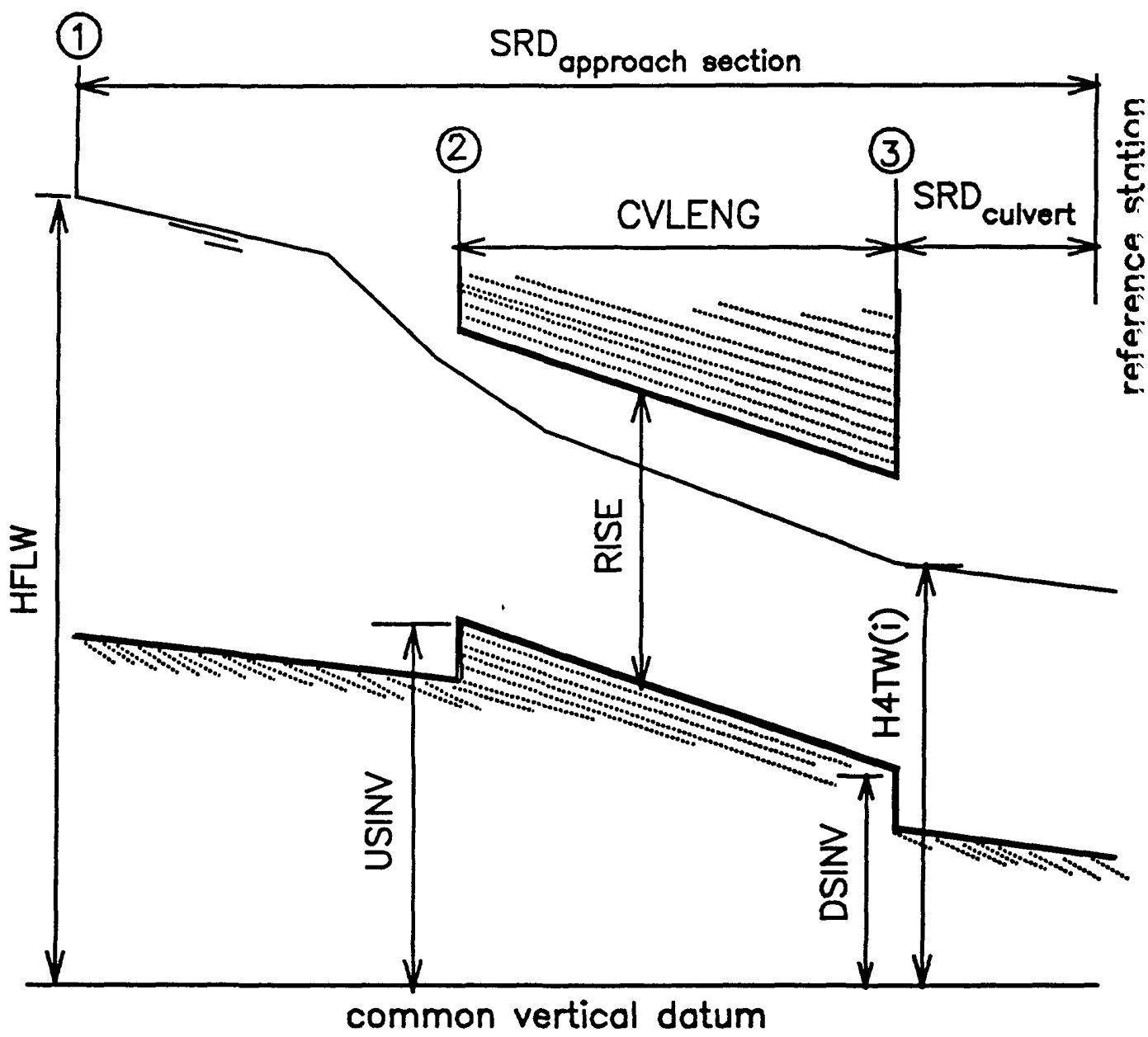

Figure 5. Distance and elevation relations between the culvert and approach section. [Approach section, 1; culvert inlet section, 2; culvert exit section, 3; HFLW, approach section water-surface elevation; USINV, culvert inlet invert elevation; DSINV, culvert outlet invert elevation; H4TW(i), tailwater elevation; RISE, culvert height; CVLENG, culvert length; $S R D_{\text {approach section, }}$ section reference distance for approach section; $S R D_{\text {culver }}$, section reference distance for culvert outlet]

\section{Input Files}

Culvert data may reside in a file either separate from or with the approach-sectior data. The position of the culvert data or the approach-section data in the input file is not important. The culvert and approach section are located in the stream reach by assigning a section reference distance (SRD) to each section. All elevations, including the culvert entrance and exit invert elevations, tailwater elevations and approach section geometry, are referenced to a common datum. The relationships between section reference distances and elevations are shown in figure 5. The following are descriptions of the data records used by CAP. Tl ey are organized into two sections: culvert records, and approach-section records. 


\section{Culvert Records}

Culvert records include data that describe the location of the culvert in the reach. culvert geometry, the culvert barrel roughness, the inlet discharge coefficients, culvert barrel slope, and the tailwater elevation and discharge combinations for which to compute aproachsection water-surface elevations. Formats used by CAP for culvert records include the WSPRO culvert header record, CV; the WSPRO culvert section geometry record, CG; and records specific to CAP. Because WSPRO uses FWHA techniques to compute culvert flow, CAP requires the input of culvert records in addition to those used by WSPRO.

The general order of input records used to describe a culvert is the WSPRO reccrds CV and $\mathrm{CG}$ followed by the $\mathrm{CAP}$ specific records, ${ }^{*} \mathrm{C} 1,{ }^{*} \mathrm{C} 3,{ }^{*} \mathrm{C} 5,{ }^{*} \mathrm{CF},{ }^{*} \mathrm{CX},{ }^{*} \mathrm{CQ}$, and ${ }^{*} \mathrm{CN}$. A typical data sequence describing a culvert is listed in figure 6 . An input file describing a culvert section must have a $\mathrm{CV},{ }^{*} \mathrm{C} 5,{ }^{*} \mathrm{CX},{ }^{*} \mathrm{CQ},{ }^{*} \mathrm{CN}$ and either a ${ }^{*} \mathrm{CS}$ or a $\mathrm{CG}$ record for proper execution. The CG record is used for standard culvert shapes-circular pipes, boxes, and pipe arches; the ${ }^{*} \mathrm{CS}$ record is used for all other shapes. Default values are used if ${ }^{*} \mathrm{C} 1$, ${ }^{*} \mathrm{C} 3$, and ${ }^{*} \mathrm{CF}$ records are not included in the input file. Descriptions of the culvert re:ords used by CAP follow.

\section{CG record}

Purpose: WSPRO culvert geometry record. This record is replaced by *CS records for nonstandard culvert sections. Bracketed variables are optional.

Format:

\begin{tabular}{|c|c|c|}
\hline Column & Format & Contents \\
\hline $1-2$ & A2 & CG \\
\hline $3-10$ & $8 X$ & blanks \\
\hline $11-80$ & free & $\begin{array}{l}\text { ICODE, RISE, / SPAN, BOTRAD, TOPRAD, } \\
\text { CORRAD] }\end{array}$ \\
\hline
\end{tabular}

Definition of variables:

ICODE Three digit culvert code (i.e., IJK) in which the individual digits indicate the following:

I -- Shape code: 1 = box; 2 = circular; 3 = pipe-arch; $4=$ nonstandard section

$\mathrm{J}$-- not used by CAP; enter any single integer

$\mathrm{K}$-- not used by CAP; enter any single integer

RISE The maximum vertical inside dimension, in inches, of the culvert barrel. The rise equals the diameter for circular culverts.

SPAN The maximum horizontal dimension of the culvert barrel, in inches. SPAN must be coded for box and pipe-arch culverts but should not be coded for circular culverts.

BOTRAD, TOPRAD, CORRAD Bottom, top, and corner radii, respectively, of pipe-arch culvert barrel, in inches. If not specified, approximate values of these variables will be computed on the basis of ICODE, SPAN, and RISE. 
$0.98,0,0,0,0$

1.001 .001 .13

$0.87,7.39,0.47,9.39,0.53,13.39,0.58,21.39,0.62$

$1.6,2.0,2.5,3.0,3.5,4.0,4.5,5.0,6.46$

$20,40,60,80,100,125,150,180,210,250$

0.015

Figure 6. Typical data sequence used to describe culvert sections and computations.

\section{CV record}

Purpose: WSPRO culvert header record.

Format:

\begin{tabular}{ccl} 
Column & Format & Contents \\
\hline $1-2$ & A2 & CV \\
$3-5$ & $3 \mathrm{X}$ & blanks \\
$6-10$ & A5 & SECID \\
$11-80$ & free & SRD culver $_{\text {XCTR, CVLENG, DSINV, USINV, }}$ \\
& & NBBL
\end{tabular}

Definition of variables:

SECID Unique cross-section identification code which allows selection of a particular culvert section from a file containing several culvert sections. Even if only one culvert section exists in a file, the culvert section must be identified.

$S R D_{\text {culver }}$ Section reference distance. The SRD for the culvert is referenced from the downstream end of the barrel to the common reference station (figure 5).

$X C T R$ The horizontal stationing of the center of the culvert measured relative to an arbitrary origin on the left bank. This variable is not used by CAP, but an arbitrary value must be included.

CVLENG Length of the culvert barrel in feet. Culvert flow length for mitered pipes is a function of flow depth. CAP does not automatically adjust the effective barrel length for flow depth and requires a constant culvert length for computation.

DSINV Elevation of downstream invert, in feet above the common elevation datum. For nonstandard culvert sections, this is the minimum elevation of the downstream culvert section.

USINV Elevation of upstream invert, in feet above the common elevation datum. For nonstandard culvert sections, this is the minimum elevation of the upstream culvert section.

$N B B L$ The number of culvert barrels. Used by CAP to compute the number of webs for a rectangular culvert. The default value is 1 . For one web in a culvert, enter 2 for $\mathrm{PBBL}$. 
Purpose: Provides input of a 16 character identifier for either a culvert or approach section. Should be placed after the CV record in the input file.

Format:

\begin{tabular}{|c|c|c|}
\hline Column & Format & Contents \\
\hline $1-3$ & A2 & *ID \\
\hline $4-5$ & $3 \mathrm{X}$ & blanks \\
\hline $6-21$ & A5 & $B I G I D$ \\
\hline
\end{tabular}

Definition of variables:

BIGID Unique culvert or approach section identification code of up to sixteen characters.

Used in addition to the SECID on the CV or XS records.

\section{*CF record}

Purpose: Determines how program will handle type 5 and 6 flow conditions. This record is in addition to the standard WSPRO records. If this record is omitted high head f nws will be computed for type 5 and type 6 flow conditions. See pages 30-31 and 47 in Bodhaine (1968) for discussion on determining occurrence of high head flows.

Format:

Column Format Contents

$1-3 \quad$ A3 ${ }^{*} \mathrm{CF}$

11-80 free TFLW, HFLW

Definition of variables:

TFLW integer value for type of high head flow computations.

6 - high head flows are computed using only type 6 computation.

5 - high head flows are computed using only type 5 computation unless HFLW is entered. If HFLW is entered, type 5 is used when the computed approach water-surface elevations using type 5 equations are less than HFLW. Type 6 is used when the computed approach water-surface elevations using type 5 equations are greater than or equal to HFLW.

65 - high head flows are computed twice regardless of HFLW entered, using both type 5 and 6 computations. Use of this value prohibits the output of three parameter tables. Use either TFLW equal 5 or 6 for three parameter tables.

$\boldsymbol{H} \boldsymbol{F L} \boldsymbol{W}$ approach water-surface elevation referenced to the common vertical datum (figure 5) at which computations change from type 5 to type 6 . The approach water-surface elevation used is that from the type 5 computation of approach head and is only used if TFLW is 5. The use of HFLW is applicable for rough pipes and arches. Figure 16 in Bodhaine (1968) can be used to estimate HFLW for pipe culverts with rough barrels. Determine $29 n^{2}\left(h_{l}-z\right) / R_{0}^{4 / 3}$ from plotting on figure 16 in Bodhaine the culvert slope and ratio of culvert length to culvert height. Then solve the equation $H F L W=z+C /\left(29 n^{2} R_{0}^{d / 3}\right)$ for $H F L W$ where $C$ is $29 n^{2}\left(h_{1}-z\right) / R_{0}^{4 / 3}$ determined from figure 16 in Bodhaine, $\boldsymbol{R}_{\boldsymbol{0}}$ is the hydraulic radius of the full culvert barrel, $\boldsymbol{n}$ is the Manning's coefficient of roughness for the culvert barrel and $z$ is the culvert fall. 
Purpose: The culvert roughness, expressed as Manning's roughness coefficient, $n$.

Format:

$\underline{\text { Column }}$ Format $\underline{\text { Contents }}$

$1-3 \quad \mathrm{~A} 3 \quad{ }^{*} \mathrm{CN}$

11-80 free $n$

Definition of variable:

$n$ Manning's coefficient of roughness for the culvert barrel.

\section{*CS record}

Purpose: Coordinate pairs record for describing geometry of nonstandard culvert sectic is.

When used, this record replaces the ${ }^{*} \mathrm{CG}$ record. Coordinates must be entered in counterclockwise order, in feet. The first coordinate and the last coordinate pairs must be the same for closure. The first entered coordinate should be either the highest coordinate pair or the left most pair of the highest coordinate pairs. An example of using the ${ }^{*} \mathrm{CS}$ record is in the Examples section of the user's guide.

Format:

Column Format Contents

1-3 A3 *CS

11-80 free $\quad S C U L(1), G C U L(1), S C U L(2), G C U L(2), \ldots$ $\operatorname{SCUL}(N), G C U L(N)$

Definition of variables:

The parenthetical notation indicates the order number, $\mathrm{i}$, assigned by the model to each $\mathrm{x}, \mathrm{y}$ coordinate pair. For the first pair, $\mathrm{i}=1$, and, for the last pair, $\mathrm{i}=\mathrm{N}$. The number of coordinate pairs, $\mathbf{N}$, must be less than or equal to 150 .

$S C U L(i)$ station, in feet, from an arbitrary horizontal reference station on the left bank (facing downstream) of a point on the culvert section.

$G C U L(i)$ ground elevation, in feet, referenced to the common vertical datum of a point on the culvert section.

\section{*CQ record}

Purpose: Discharges, in cubic feet per second, for which computations of upstream watersurface elevations are made.

Format:

Column Format Contents

1-3 A3 *CQ

11-80 free $Q(1), Q(2), \ldots Q(N)$ 
Definition of variable:

The parenthetical notation indicates the order number, $\mathrm{i}$, assigned by the program to each discharge; $\mathrm{i}=1$ and $\mathrm{i}=\mathbf{N}$ for the first and last discharges. The number of discharges, $\mathbf{N}$, is $\leq$ 48.

$Q(i)$ the discharges at which the culvert computation will be made, in cubic feet per s?cond.

\section{*CX record}

Purpose: Tailwater depths, in feet, for which computations of upstream water-surface elevation are made.

Format:

\begin{tabular}{|c|c|c|}
\hline Column & Format & Contents \\
\hline $1-3$ & A3 & ${ }^{*} \mathrm{CX}$ \\
\hline $11-80$ & free & $H 4 T W(I), H 4 T W(2), \ldots H 4 T W(N)$ \\
\hline
\end{tabular}

Definition of variable:

The parenthetical notation indicates the order number, $\mathrm{i}$, assigned by the program to each tailwater depth; $i=1$ and $i=\mathbf{N}$ for the first and last tailwater elevations. The number of tailwater depths, $\mathbf{N}$, is $\leq 50$.

H4TW(i) tailwater elevations ordered in increasing height for which the culvert computation will be made. Tailwater elevations are referenced to the common vertical datum. A small or zero tailwater elevation may be entered to ensure computation of flow tyาes 1 and 2 .

\section{*C1 record}

Purpose: Culvert discharge coefficients for type 1 to 3 flow. This record is optional. If the record is omitted, the discharge coefficient for type 1 and 2 flow is set equal to 0.95 . Type 3 flow discharge coefficients are computed based on figure 23 in Bodhaine (1968). The discharge coefficient for bellmouth and tongue and groove pipe (inlet=2) is set equal to 0.95 for flow types 1,2 and 3 . The type 1,2 , and 3 discharge coefficients for mitered entrance pipe culverts are computed based on figure 25 in Bodhaine (1968) and on the inlet type specified on the ${ }^{*} \mathrm{C} 3$ record. All other pipes culverts are computed using figure 20 in Bodhaine. The presence of this record overrides the programs coefficient computation. If only CB12 is entered, the graphs from the TWRI will be used for computing coefficients for type 3 flow. All coefficients entered on this record will be appropriately adjusted by CAP for channel contraction effects.

Format:

$\begin{array}{ccl}\frac{\text { Column }}{1-3} & \frac{\text { Format }}{\mathrm{A} 3} & \frac{\text { Contents }}{{ }^{*} \mathrm{C} 1} \\ 11-80 & \text { free } & C B 12, \text { or } \\ & & C P(1), \boldsymbol{H P}(1), \boldsymbol{C P}(2), H P(2), \ldots H P(4), C P(4)\end{array}$


Definition of variables:

The parenthetical notation indicates the order number, $i$, assigned by the program to each pair of discharge coefficients and ratios of approach flow depth and culvert height. For the first pair, $\mathrm{i}=1$, and, for the last pair, $\mathrm{i}=4$. Number of pairs entered is 4 . The first coding opt ${ }^{\text {in }}$ allows the use of single value coefficient for type 1 and 2 flows.

$C B 12$ culvert discharge coefficient for type 1 and 2 flow for culverts with coefficient not dependent on $\left(h_{l}-z\right) / D$. The graphs from Bodhaine (1968) will be used for computing coefficients for type 3 flow. Allowable values, $0.98 \leq \mathrm{CB} 12 \leq 0.85$.

The second coding option varies $C_{123}$ with flow depth in the approach section. $C_{123}$ is linearly interpolated between entered values of $\mathrm{CP}(\mathrm{i})$ for ratios of $\left(h_{1}-z\right) / D$ greater than $\mathrm{HP}(1)$ and less than $\mathrm{HP}(4) . C_{123}$ is equal to $\mathrm{CP}(1)$ for ratios less than or equal to $\mathrm{CP}(1)$ and $\mathrm{CP}(4)$ for ratios greater than or equal to $\mathrm{HP}(4)$.

$\boldsymbol{C P}(i)$ culvert discharge coefficient for type 1,2, and 3 flow when the culvert flows part full at $\mathrm{HP}(\mathrm{i})$. Allowable values, $0.98 \leq \mathrm{CP}(\mathrm{i}) \leq 0.65$.

$\boldsymbol{H P}(i)$ ratios of $\left(h_{1}-z\right) / D$, where $h_{1}$ is the water-surface elevation in the approach section referenced to the culvert outlet elevation, $z$ is the culvert drop, and $D$ is the culvert height.

\section{*C3 record}

Purpose: Adjustment factors for type 1, 2, and 3 flow discharge coefficients. Type 1, 2, and 3 discharge coefficients are appropriately adjusted in the program for the degree of channel contraction. This record is not required and default values are used if this record is omitted. Table 2 lists values of $r / D$ and w/D for standard riveted corrugated metal pipe, and applies only to corrugations with a $1 / 2$ " depth and 2(3/8)" pitch. Padius of entrance rounding, $r$, and bevel width, $w$, must be measured in the field for all other corrugations.

Format:

$\begin{array}{ccl}\frac{\text { Column }}{1-3} & \frac{\text { Format }}{\mathrm{A} 3} & \frac{\text { Contents }}{{ }^{*} \mathrm{C} 3} \\ 11-80 & \text { free } & K R, K W, \text { THETA, INLET, KPROJ }\end{array}$

Definition of variables:

$K R$ entrance-rounding adjustment to discharge coefficient (TWRI, p. 39). Default is KR=1. Determine values from figure 7.

$K W$ entrance-beveling adjustment to discharge coefficient (TWRI, p. 40). Default is $K^{\top /}=1$. Determine values from figure 8.

THETA wingwall angle in degrees. Default is 0 degrees. Equation used to compute adjustment factor derived from Bodhaine (figure 24, p42).

INLET code for program where: 1 vertical headwall flush, 2 mitered, 3 bellmouth, or tongue and groove concrete pipe (TWRI, p. 39-40)

KPROJ projecting-pipe adjustment to discharge coefficient (Bodhaine, pg 42). Default is KPROJ=1. Determine values from table 3. 
Table 2. Values of entrance rounding and beveling for various sizes of standard riveted corrugated metal pipe. This table does not apply to corrugation sizes other than that used in riveted pipes and pipe arches $[D$, pipe diameter in inches; $r D$, ratio of radius of rourding to culvert diameter; w/D, ratio of bevel width to culvert diameter.]

\begin{tabular}{ccc}
\hline $\mathrm{D}$ (inches) & $\mathrm{r} / \mathrm{D}$ & $\mathrm{w} / \mathrm{D}$ \\
\hline 24 & 0.031 & 0.0125 \\
36 & .021 & .0083 \\
48 & .016 & .0062 \\
60 & .012 & .0050 \\
72 & .010 & .0042 \\
\hline
\end{tabular}

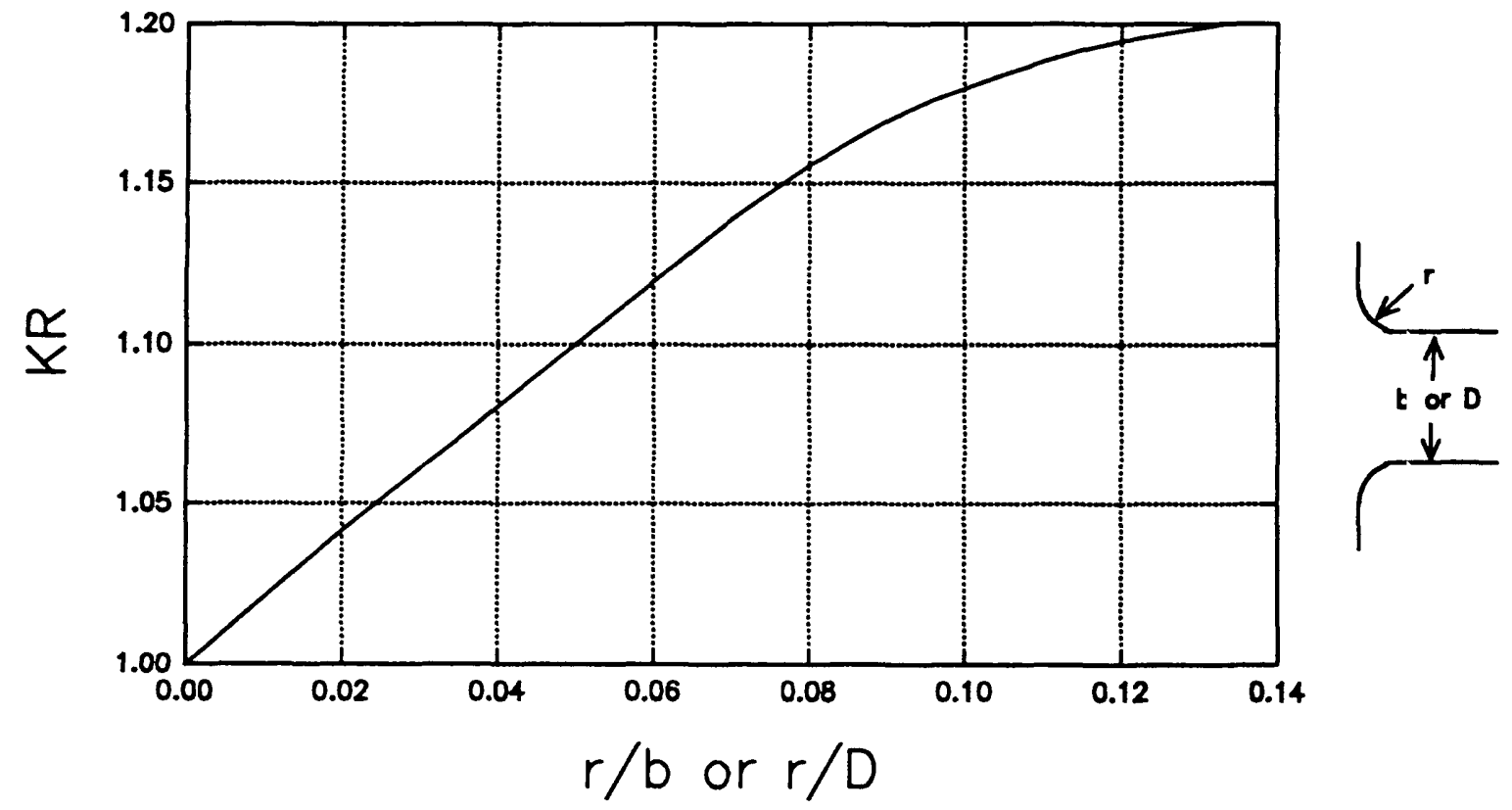

Figure 7. Entrance rounding adjustment, KR, used to adjust the discharge coefficient for entrance rounding. $b$ is the width of the contracted flow section for a box culvert and $D$ is the maximum inside vertical dimension of the culvert barrel. 

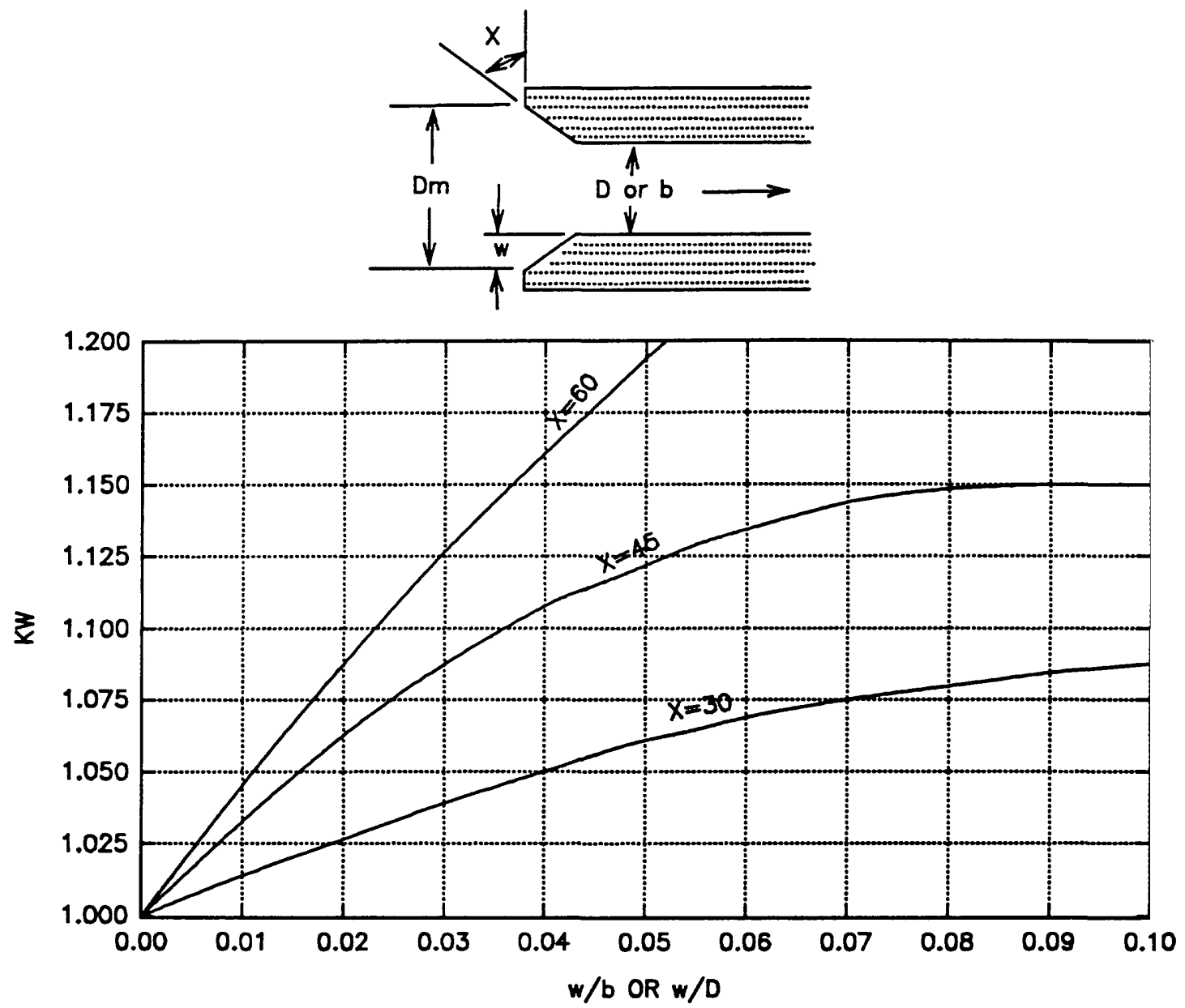

Figure 8. Entrance beveling adjustment, KW, used to adjust the discharge coefficient for beveling.

Table 3. Adjustment factors, KPROJ, for projecting entrances for various values of $L_{p} /$, the length of the culvert projection divided by the culvert height $\left[L_{p}\right.$, length of culvert projection; $D$, culvert diameter]

\begin{tabular}{rr||rr||rr||rr}
\hline \multicolumn{1}{c||}{$\mathrm{L}_{\mathrm{p}} / \mathrm{D}$} & KPROJ & $\mathrm{L}_{\mathrm{p}} / \mathrm{D}$ & KPROJ & $\mathrm{L}_{\mathrm{p}} / \mathrm{D}$ & KPROJ & $\mathrm{L}_{\mathrm{p}} / \mathrm{D}$ & KPROJ \\
\hline 0.00 & 1.00 & 0.05 & 0.96 & 0.10 & 0.92 & 0.6 & $\mathrm{C} .91$ \\
.01 & .99 & .06 & .95 & .2 & .92 & .7 & .91 \\
.02 & .98 & .07 & .94 & .3 & .92 & .8 & .90 \\
.03 & .98 & .08 & .94 & .4 & .91 & .9 & .90 \\
.04 & .97 & .09 & .93 & .5 & .91 & $\geq 1.0$ & .90 \\
\hline
\end{tabular}


Purpose: Culvert discharge coefficients for flow types 4, 5, and 6. This record is required for type 4, 5, and 6 flow computations and must be included with each culvert description.

Format:

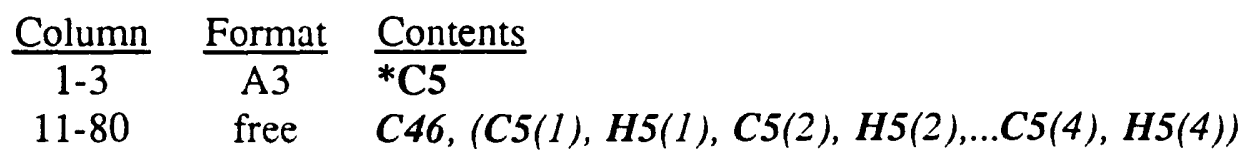

$\underline{\text { Column }} \underline{\text { Format }}$ Contents

$1-3 \quad$ A3 *C5

11-80 free C46, (C5 (1), H5(1),C5(2), H5(2),..C5(4), H5(4))

Definition of variables:

The parenthetical notation indicates the order number, $i$, assigned by the program to erch pair of discharge coefficients and ratios of approach flow depth and culvert height. For the first pair, $\mathrm{i}=1$, and, for the last pair, $\mathrm{i}=4$. Number of pairs entered is $4 . C_{5}$ is linearly interzolated between entered values of $C_{5}$ for ratios of $\left(\mathrm{h}_{1}-\mathrm{z}\right) / \mathrm{D}$ greater than $\mathrm{H} 5(1)$ and less than $\mathrm{H} 5(4)$. $C_{5}$ is equal to $\mathrm{C} 5(1)$ for ratios less than or equal to $\mathrm{H} 5(1)$ and $\mathrm{C} 5(4)$ for ratios greater than or equal to $\mathrm{H} 5(4)$.

C46 culvert discharge coefficient for flow types 4 and 6 . Table 4 lists type 4 and 6 coefficients for box or pipe culverts. Allowable values, $0.98 \leq \mathrm{C} 46 \leq 0.65$.

C5(i) culvert discharge coefficient for type 5 flow at the ratio of H5(i). Table 5 lists type 5 coefficients for flared pipe ends, and tables 6 and 7 list type 5 coefficients for culverts with vertical headwall and wingwalls. Allowable values, $0.75 \leq \mathrm{C} 5(\mathrm{i}) \leq 0.39$.

H5(i) ratios of $\left(h_{1}-z\right) / D$, where $h_{1}$ is the water-surface elevation in the approach section referenced to the culvert outlet elevation, $z$ is the culvert drop, and $D$ is the culvert height.

Table 4. Flow types 4 and 6 discharge coefficients for box or pipe culverts set flush in a vertical headwall $/ r / b$, ratio of radius of rounding to box culvert width; $w / b$, ratio of bevel width to box culvert width; r/D, ratio of radius of rounding to culvert diameter; $w / D$, ratio of bevel width to culvert diameter; $C_{46}$, flow types 4 and 6 discharge coefficients]

\begin{tabular}{cc||cc}
\hline $\begin{array}{c}\mathrm{r} / \mathrm{b}, \mathrm{w} / \mathrm{b}, \mathrm{w} / \mathrm{D}, \\
\text { or } \mathrm{r} / \mathrm{D}\end{array}$ & $\mathrm{C}_{46}$ & $\begin{array}{c}\mathrm{r} / \mathrm{b}, \mathrm{w} / \mathrm{b}, \\
\mathrm{w} / \mathrm{D}, \text { or } \mathrm{r} / \mathrm{D}\end{array}$ & $\mathrm{C}_{46}$ \\
\hline 0. & 0.84 & 0.08 & 0.96 \\
.02 & .88 & .10 & .97 \\
.04 & .91 & .12 & .98 \\
.06 & .94 & & \\
\hline
\end{tabular}


Table 5. Flow type 5 discharge coefficients, $C_{5}$, for flared pipe ends shown in figure 8 of Bodhaine (1968) with ratios of culvert length to culvert height less than 6 and culvert slopes greater than 0.03 . Normally, type 5 flow does not occur for flared pipe end sections. $[D$, culvert height; $\left(h_{1}-z\right)$, depth of water above culvert inlet]

\begin{tabular}{cc||cc}
\hline$\frac{\left(h_{1}-z\right)}{D}$ & $C_{5}$ & $\frac{\left(h_{1}-z\right)}{D}$ & $C_{5}$ \\
\hline 1.4 & 0.48 & 2.0 & 0.57 \\
1.5 & .50 & 2.5 & .59 \\
1.6 & .52 & 3.0 & .61 \\
1.7 & .53 & 3.5 & .63 \\
1.8 & .55 & 4.0 & .65 \\
1.9 & .56 & 5.0 & .66 \\
\hline
\end{tabular}

Table 6. Type 5 discharge coefficients, $C_{5}$, for box or pipe culverts set flush in a vertical headwall with variation of head and entrance rounding or beveling $[r / b$, ratio of radius of rounding to box culvert width; w/b, ratio of bevel width to box culvert width; r/D, ratio of radius of rounding to culvert diameter; w/D, ratio of bevel width to culvert diameter; $\boldsymbol{L}$, culvert height; $\left(h_{1}-z\right)$, depth of water above culvert inlet]

\begin{tabular}{|c|c|c|c|c|c|c|c|}
\hline \multirow{2}{*}{$\frac{\left(h_{1}-z\right)}{D}$} & \multicolumn{7}{|c|}{$\mathrm{r} / \mathrm{b}, \mathrm{w} / \mathrm{b}, \mathrm{r} / \mathrm{D}$, or $\mathrm{w} / \mathrm{D}$} \\
\hline & 0 & 0.02 & 0.04 & 0.06 & 0.08 & 0.10 & 0.14 \\
\hline 1.4 & 0.44 & 0.46 & 0.49 & 0.50 & 0.50 & 0.51 & 0.51 \\
\hline 1.5 & .46 & .49 & .52 & .53 & .53 & .54 & .54 \\
\hline 1.6 & .47 & .51 & .54 & .55 & .55 & .56 & .56 \\
\hline 1.7 & .48 & .52 & .55 & .57 & .57 & .57 & .57 \\
\hline 1.8 & .49 & .54 & .57 & .58 & .58 & .58 & .58 \\
\hline 1.9 & .50 & .55 & .58 & .59 & .60 & .60 & .60 \\
\hline 2.0 & .51 & .56 & .59 & .60 & .61 & .61 & .62 \\
\hline 2.5 & .54 & .59 & .62 & .64 & .64 & .65 & .66 \\
\hline 3.0 & .55 & .61 & .64 & .66 & .67 & .69 & .70 \\
\hline 3.5 & .57 & .62 & .65 & .67 & .69 & .70 & .71 \\
\hline 4.0 & .58 & .63 & .66 & .68 & .70 & .71 & .72 \\
\hline 5.0 & .59 & .64 & .67 & .69 & .71 & .72 & .73 \\
\hline
\end{tabular}


Table 7. Flow type 5 discharge coefficients, $C_{s}$, for box culverts with wingwalls with variation of head and wingwall angle, theta $(\theta)\left[D\right.$, culvert height; $\left(h_{1}-z\right)$, depth of water above culvert inlet; ${ }^{\circ}$, degree]

\begin{tabular}{cccccc}
\hline \multirow{2}{*}{$\left(h_{1}-z\right)$} & \multicolumn{5}{c}{ Wingwall angle, $\theta$} \\
\cline { 2 - 6 }$D$ & $30^{\circ}$ & $45^{\circ}$ & $60^{\circ}$ & $75^{\circ}$ & $99^{\circ}$ \\
\hline 1.3 & 0.44 & 0.44 & 0.43 & 0.42 & 0.39 \\
1.4 & .46 & .46 & .45 & .43 & .41 \\
1.5 & .47 & .47 & .46 & .45 & .42 \\
1.6 & .49 & .49 & .48 & .46 & .43 \\
1.7 & .50 & .50 & .48 & .47 & .44 \\
1.8 & .51 & .51 & .50 & .48 & .45 \\
1.9 & .52 & .52 & .51 & .49 & .46 \\
2.0 & .53 & .53 & .52 & .49 & .46 \\
2.5 & .56 & .56 & .54 & .52 & .49 \\
3.0 & .58 & .58 & .56 & .54 &. .7 \\
3.5 & .60 & .60 & .58 & .55 &. .2 \\
4.0 & .61 & .61 & .59 & .56 &. .3 \\
5.0 & .62 & .62 & .60 & .58 &. .4 \\
\hline
\end{tabular}

\section{Approach-Section Records}

The approach-section data include data that describe the location of the approach section in the reach, approach-section geometry, and roughness parameters. The approach section is located sufficiently upstream from the culvert opening, before the region of drawdown. Usually the approach section is located one opening width from the culvert entrance or, if wingwalls exist, a distance upstream from the end of the wingwalls equal to the width between the wingwalls at their upstream end.

The following sections present the descriptions of the XS, GR, N, ND, and SA W'SPRO records and the *PD records used by CAP. Shearman (1990) presents a complete description of all WSPRO records and instructions on using those records to describe cross-section geometry. The approach-section data file follows the same basic format as WSPRO valley sections. A typical sequence of records describing a culvert approach section is shown in figure 9 . The *PD record must be included in the file containing the approach-section records. 


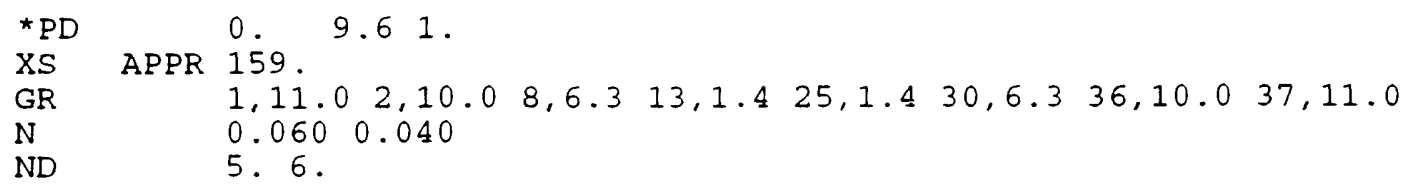

Figure 9. Typical sequence of records used to describe the approach section.

\section{$\underline{\text { GR record }}$}

Purpose: Specifies the $x, y$ coordinates that define the shape of the cross-section. This is a WSPRO record. The cross-section side (or sides) are extended vertically if the watersurface elevation exceeds either (or both) the ground elevation of the leftmost or the Format: rightmost coordinate pairs entered.

$\begin{array}{ccl}\frac{\text { Column }}{1-2} & \text { Format } & \text { Contents } \\ \text { A2 } & \text { GR } \\ 11-10 & 8 \mathrm{X} & \text { blank } \\ 11-80 & \text { free } & X(1), Y(1), X(2), Y(2), \ldots X(N), Y(N)\end{array}$

Definition of variables:

The parenthetical notation indicates the order number, $i$, assigned by the model to each $x, y$ coordinate pair. For the first pair, $\mathrm{i}=1$, and, for the last pair, $\mathrm{i}=\mathbf{N}$. The number of coordinate pairs, $\mathbf{N}$, must be less than or equal to 150 . Coordinates are ordered from left to right in a counterclockwise direction.

$X(i)$ Station, in feet, from an arbitrary horizontal reference station on the left bank (facing downstream) specified for the ith station.

$Y(i)$ Ground elevation of the ith elevation, specified in feet above the common vertical datum.

\section{$\underline{N \text { record }}$}

Purpose: Specifies Manning's coefficient of roughness, $n$, for the approach section. Proper selection of Manning's coefficient of roughness is explained by Chow (1959), Benron and Dalrymple (1967), Arcement and Schneider (1989), and Jarrett (1985). Barnes (1967), and Hicks and Mason(1991) present photos and verified Manning's n for a variety of reaches. This is a WSPRO record.

Format:

$\begin{array}{ccl}\frac{\text { Column }}{1-2} & \text { Format } & \text { Contents } \\ 3-10 & 8 \mathrm{X} & \mathrm{N} \\ 11-80 & \text { blank } & \text { either } N V A L(1)[, N V A L(2) \ldots N V A L(n s a)] \text { or } \\ & & \text { BOTN }(1), \operatorname{TOPN}(1)[, B O T N(2), \operatorname{TOPN}(2) \ldots \\ & & \operatorname{BOTN}(\text { nsa }), \operatorname{TOPN}(\text { nsa })]\end{array}$


Definition of variables:

The parenthetical notation indicates the subarea to which the roughness coefficient is applicable. For the left-most subarea, $i=1$, and for the right-most subarea, $i=n s a$ (number of subareas). The first coding option must be used when the value does not vary with depth. Only one roughness coefficient value is needed for each subarea.

NVAL(i) Roughness coefficient (Manning's coefficient of roughness, $\mathrm{n}$ ) applicable to the full depth of the ith subarea.

The second coding option is used when the values vary with depth. ND records specifying the depths must be coded when this option is used. A pair of roughness coefficients is coded for each subarea.

BOTN $(i)$ Roughness coefficient applicable to the depths equal to and less than the bottom hydraulic depth specified for the ith subarea on the ND record.

TOPN(i) Roughness coefficient applicable to the depth equal to and greater than the bottom hydraulic depth specified for the ith subarea on the ND record.

\section{ND record}

Purpose: Specifies the hydraulic depth breakpoints for vertical variation of roughness coefficients (Manning's coefficient of roughness, $n$ ). This is a WSPRO record.

Format:

Column $\underline{\text { Format }}$ Contents

$1-2 \quad$ A3 ND

3-10 $8 \mathrm{X}$ blank

11-80 free $\quad B O T D(1), \operatorname{TOPD}(1)[, \operatorname{BOTD}(2), \operatorname{TOPD}(2) \ldots$ BOTD(nsa), TOPD(nsa)]

Definition of variables:

The parenthetical notation indicates the subarea to which the depths are applicable: $i=1$ for the left most subarea and $i=n s a$ for the right most subarea (nsa $\leq 20)$.

BOTD(i) Hydraulic depth (area divided by top width) in the ith subarea at or below which the roughness coefficient BOTN (specified for the ith subarea in the $\mathrm{N}$ record) is applicable.

TOPD(i) Hydraulic depth in the ith subarea at or above which the roughness coefficient of TOPN(i) (specified for the ith subarea in the $\mathrm{N}$ record) is applicable.

Values of roughness for the depths between BOTD and TOPD are determined by straight line interpolation. 


\section{*PD record}

Purpose: Specifies the computation of depths over a range of values for which the hydraulic properties are computed at 25 depths. This record is included with the approach sections records and is used for all sections in the file. Only one *PD record is permitted per file.

Format:

\begin{tabular}{|c|c|c|}
\hline Column & Format & Contents \\
\hline$\frac{1-2}{1-2}$ & A2 & *PD \\
\hline $3-10$ & $8 \mathrm{X}$ & blank \\
\hline $11-80$ & free & DMIN, DMAX, RATIO \\
\hline
\end{tabular}

Definition of variables:

DMIN minimum depth at which to compute approach section hydraulic properties. Must be 0 when running CAP.

DMAX maximum depth at which to compute hydraulic properties. The depth entered should be greater than or equal to 2 times the culvert height. If it is less than 1.5 times the culvert height, the program will fail to execute. Depending on the tailwater elevations entered on the ${ }^{*} \mathrm{CX}$ record and the minimum ground elevation in the approach sectinn, it may be necessary to input a DMAX greater than 2 times the culvert depth.

RATIO the common ratio used to compute depths as a geometric progression between minimum and maximum areas. Ratio must be greater than 0 . If a value less than or equal to zero or no value is entered, the program defaults to a ratio of 1 . A ratio value of 1 computes equally spaced areas. Ratios less than 1 result in the intervals between depths decreasing as depth increases. Ratios greater than 1 result in the intervals between depths increasing as depth increases.

\section{SA Record}

Purpose: Specifies the horizontal breakpoints for subdivision of cross section for roughness variation. This record is only necessary for subdivided approach sections. This is a WSPRO record.

Format:

$\frac{\text { Column }}{1-2} \frac{\text { Format }}{\text { A2 }}$ Contents

3-10 $8 \mathrm{X}$ blank

11-80 free $X S A(1), X S A(2) \ldots X S A(n s a-1)$

Definition of variables:

The parenthetical notation indicates the subarea number, $\mathrm{i}$, assigned by the program to each subarea of a cross section. $i=1$ for the left most subarea and $i=n s a$ for the rightmost sul area (nsa $\leq 20)$. The number of breakpoints entered is always one less than the total number of subareas in the cross section and are located at the boundaries between subareas.

$X S A(i)$ The horizontal coordinate, or station in feet, of the rightmost limit of the $i$ th sul area. 


\section{$\underline{X S \text { record }}$}

Purpose: Required; header record for unconstricted approach cross section. This is a WSPRO record.

Format:

\begin{tabular}{ccll} 
Column & Format & & Contents \\
\cline { 1 - 2 } $1-3$ & A2 & XS \\
$4-5$ & $2 \mathrm{X}$ & blank \\
$6-10$ & A5 & & SECID \\
$11-80$ & free & & $S R D_{\text {approach }}$
\end{tabular}

Definition of variables:

$S E C I D$ Unique cross-section identification code.

$S R D_{\text {approach }}$ Section reference distance, in feet. Cumulative distance along the stream measured from the common reference station (figure 5). The difference between the SRD values of culvert outlet and the approach is the flow distance between those sections (figure 5).

\section{Output Files}

Two outputs are available from CAP. A detailed report that summarizes the culve't computations is always produced. An additional table of the discharges, tailwaters, and upstream water-surface elevations computed is produced optionally for use with other computer programs.

\section{Detailed Report}

The detailed report can be used to determine discharge for an indirect measurement or a rating for a culvert. It includes input data for the selected approach and culvert section (always listed on page 0); computed hydraulic properties for the culvert section and the approach section; and a summary of the culvert computations. The summary of the culvert computations lists for each combination of discharge and tailwater elevation the discharge, flow type, and water-surface elevation at the approach, culvert inlet, culvert outlet, and exit sections. It also lists the discharge coefficient, the velocity head, velocity coefficient $(\alpha)$, and Froude number computed for the approach section, the specific energy and Froude number computed for the control section, and the fall and losses computed for various sections. The discharge coefficients listed includes the effect of all adjustments entered on the ${ }^{*} \mathrm{C} 3$ record and the adjustment for channel contraction effects.

Two falls, entry and effective, are listed on the detailed report. The entry fall is the difference in water-surface elevation between the approach section and the downstream section that governs the flow state. The effective fall is the energy loss between the approach section and the downstream section that governs the flow state. For full culvert flow, type 4, the effective fall is equal to the entry fall because zero velocity is assumed in the approach and exit sections for the effective fall computation. For type 5 flow, the effective fall is the 
difference between the approach water-surface elevation and the invert elevation of the culvert outlet. For type 6 flow, the effective fall is the velocity head in the culvert barrel. The losses, entry, (1-2), and (2-3), listed on the detailed report are the entrance losses, friction loss in the reach between the approach section and culvert inlet, and the friction losses in the culvert barrel respectively.

A sample detailed report of culvert computations is shown in figure 10. The flow type is usually a single integer $1,2,3,4,5$, or 6 . However, in cases where the upstream watersurface elevation is linearly interpolated from two flow types, the entry has two digits representing the flow types from which the water-surface elevation is interpolated. When critical depth exceeds the culvert height, type 1 flow is always used for the low head value because type 2 flow is not possible in all culverts. In these cases, the low head flow type is designated by a zero to distinguish it from the other low head flow cases. The first digit represents the flow type in the upstream end of the culvert and the second digit the flow type in the downstream end of the culvert.

If an approach elevation cannot be computed for a combination of discharge and tailwater elevation, a -1.00 is printed in the column for the approach elevation. An error

CAP -USGS culvert analysis program VER $94-5$

page 4

TEST CULVERT 1 WALNUT CRK

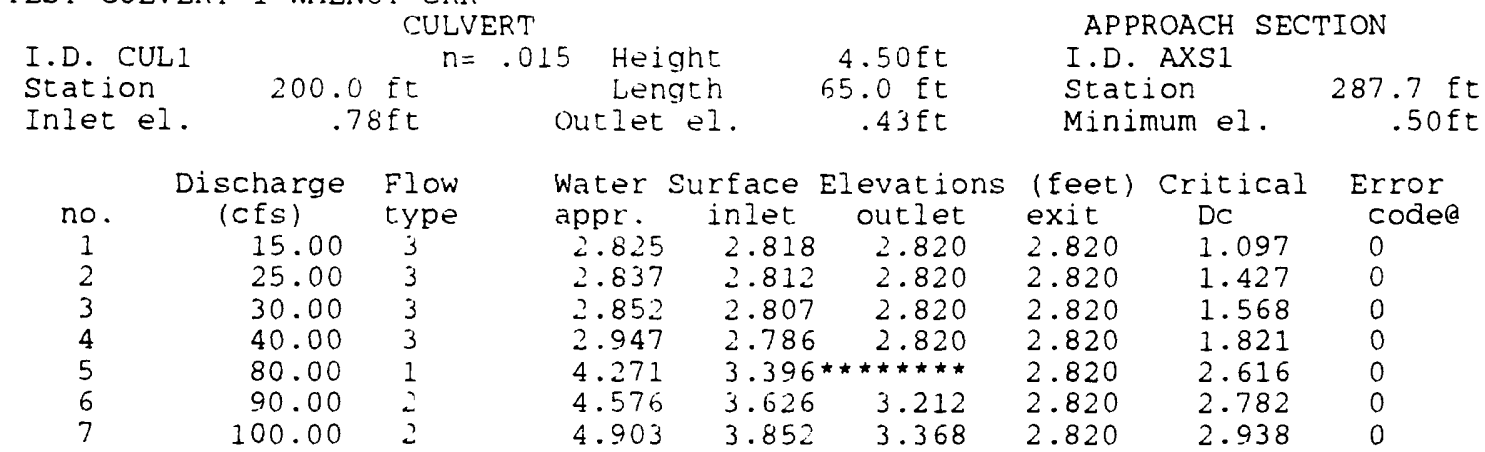

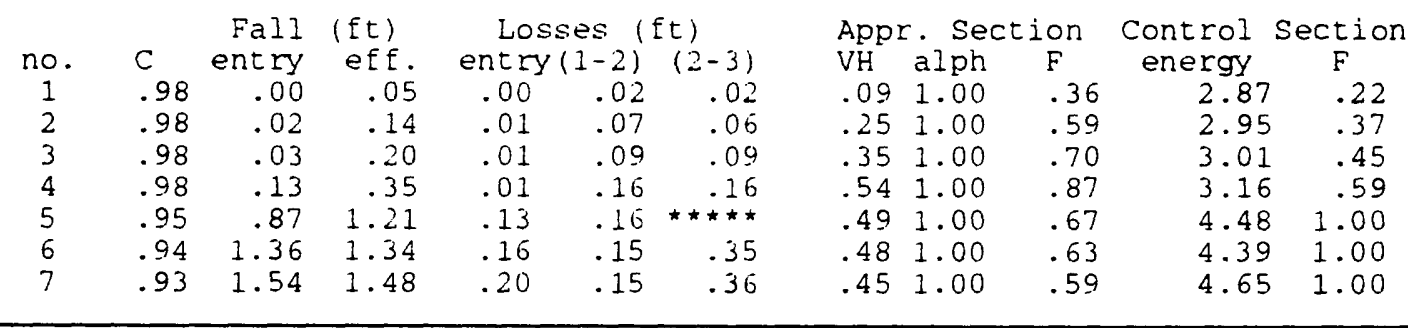

Abrevs. used: appr.-approach C-discharge coefficient eff.-effective VH-velocity head alph-velocity coefficient n-Manning's roughness coef. energy-specific energy F-Froude number entry, (1-2), (2-3)-part of reach

aError codes: $-1,1-7$ fatal error; 8-11 warning; 0 no error

Figure 10. Sample of a detailed report of culvert computations. 
number is printed in the error code column and the error message is printed in the section where the Fall and Losses are normally printed for that computation. Warning messages are printed at the end of the detailed report.

\section{Three-Parameter Table}

The three-parameter table report can be used as input to another flow modeling pringram or graphics program. It provides less information than the detailed report; the discharge, tailwater elevation, water-surface elevation at the approach, a datum elevation, and a culvert identification string.

The table is formatted to facilitate its use by computer programs that can interpolate the tabulated values, draw a rating surface for the culvert, or that need to include the culvet effects in a flow model. The format used by the table is listed in table 8. A sample table report is shown in figure 11. Elevations printed in the table are referenced to the culvert outlet invert, the reference datum for the table. If an approach elevation can not be computed for a given combination of discharge and tailwater elevation, a -1.00 is printed in the trble for the approach water-surface elevation.

The table is generated by responding appropriately to a prompt. The eight digit table number is entered by the user during program execution and allows the use of an eight digit station number as the table number. If ${ }^{*} \mathrm{CF}$ records are used with TFLW $=65$ or no ${ }^{*} \mathrm{C}$ " record is entered, the three parameter table will not be produced. The table report is always printed to a file named TABLES30.DAT and users should rename or delete the file prior to creating new table reports.

Table 8. Fortran formats used by CAP to generate output for the three-parameter table report

\begin{tabular}{|c|c|c|}
\hline $\begin{array}{l}\text { Record } \\
\text { number }\end{array}$ & Fortran format & Content description \\
\hline 1 & $\mathrm{~A} 12$ & Table file identifier, always TABLES30.DAT \\
\hline 2 & A3 & Start of table for culvert flag, always TAB \\
\hline 3 & $\mathrm{I} 8, \mathrm{I} 2,2 \mathrm{I} 3$ & $\begin{array}{l}\text { Eight-digit table number, two-digit number for } \\
\text { table type, number of tailwater depths, number } \\
\text { of discharges }\end{array}$ \\
\hline 4 & F9.3 & Reference datum for table \\
\hline $4-k$ & $12 \mathrm{~F} 7.2$ & Tailwater depths \\
\hline$k-m$ & $10 \mathrm{~F} 8.0$ & Discharges \\
\hline $\mathrm{m}-\mathrm{n}$ & $11 \mathrm{~F} 7.2$ & Computed upstream water-surface elevations \\
\hline
\end{tabular}


$\mathrm{TAB}$

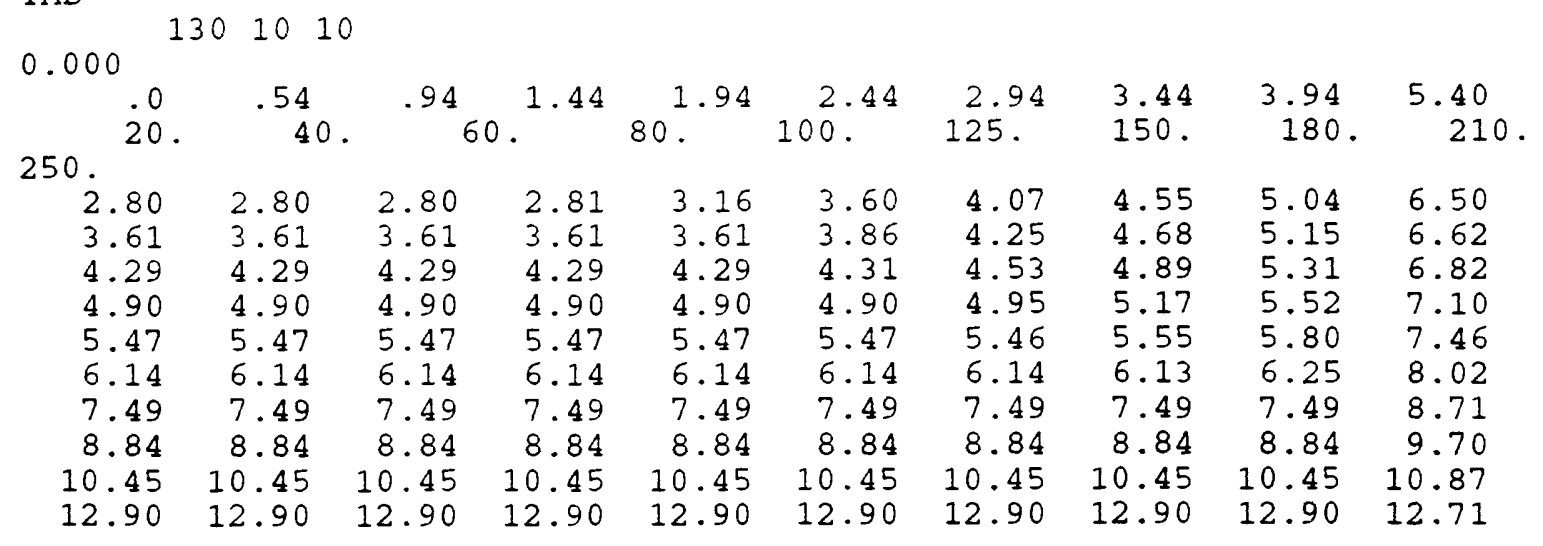

Figure 11. Sample three-parameter table report.

\section{Executing the Program}

The commands required to run the program are dependent on the computer system. On most systems, however, entering the program name, CAP, will start the program. The user is then queried for the output file name, a header title, the culvert data file name, and culvert section id (SECID), and the approach section file name and approach section id (SECIL). The header title allows users to enter descriptive text of up to 80 characters that is print $=d$ on all output pages except for page 0 . Depending on the computer operating system, the input file names may be case sensitive. Section id (SECID) is always case sensitive. Several culvert sections and approach sections may be included in the file or files. Figure 12 is an example of a typical session running the program.

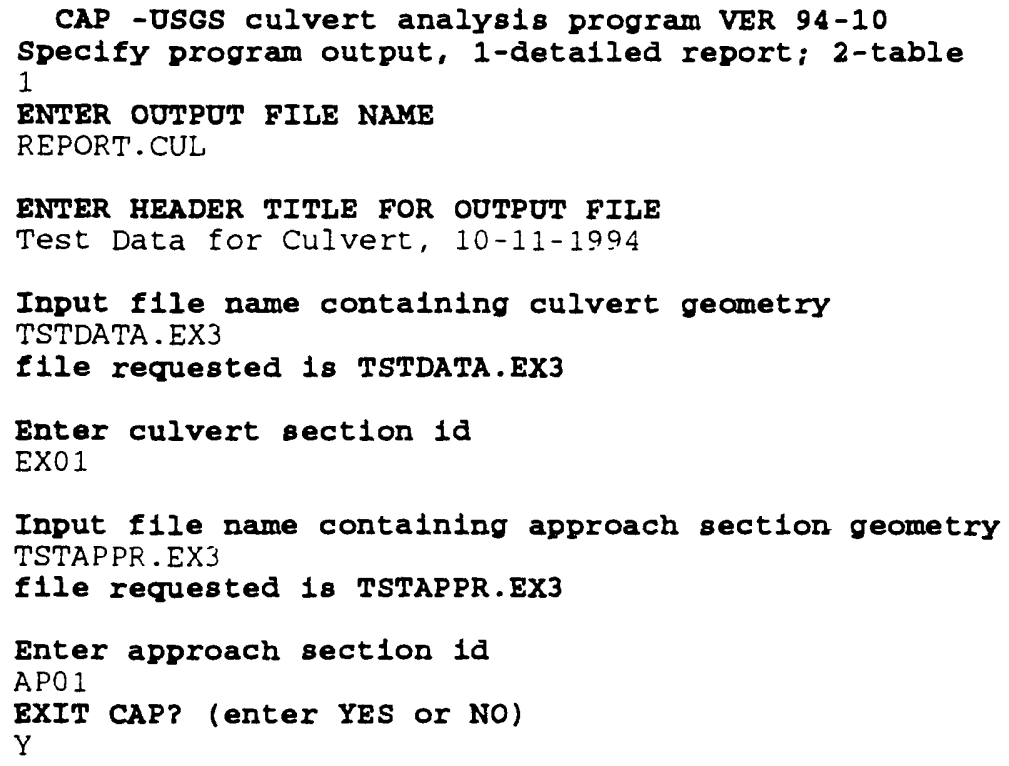

Figure 12. Sample CAP session. [Screen prompts and messages issued by the program are shown in bold type. Other text is entered by user.] 


\section{EXAMPLES}

This section contains four examples that demonstrate how to use CAP. The examples are separated into two subsections, indirect measurement of peak discharge from field data for a specific flow event and computation of a three-parameter table.

\section{Indirect Measurement of Peak Discharge}

Three example problems are presented in this section. The first example is a simple rectangular (box) culvert and demonstrates the basic operation of CAP. The second example is a nonstandard culvert section, and the third is a multiple culvert example.

\section{Standard Culvert Section}

Standard culvert sections are either rectangular, circular, or pipe arch in shape. T'ase culverts are not silted up and the effective shape of the culvert section is unchanged throughout the culvert length. Discharge coefficients have been determined for standard culvert sections by laboratory investigations.

Location: Tributary to Mercer Creek near Bellevue Washington.

Culvert section description: 30 -inch-diameter pipe of smooth concrete with a bell-morth inlet. Culvert length is 41 feet. Manning's coefficient of roughness, $n$, is estimated at 0.015. Elevation of downstream invert is 6.05 feet and upstream invert 6.28 feet. Top of upstream invert is 8.78 feet and top of downstream invert is 8.14 feet. Culvert bevel width is 2.4 inches.

Approach section description: Approach located 6.4 feet from upstream invert of culvart. Manning's coefficient of roughness, $n$, is estimated at 0.025 . Coordinates of approach section are plotted in figure 13.

High-water marks: High-water mark elevations are 8.65 feet in the approach and 8.14 feet downstream of culvert outlet.

The user is required to determine the appropriate discharge coefficients for types 4 and 6 flows when building the input file. In this example, both the culvert section and approach section are in the same file. Initially, discharges from 10 to 50 cubic feet per second were entered with the measured tailwater elevation $(8.14 \mathrm{ft})$. After running CAP, new discrarges were entered over a smaller range and increment to get the desired upstream water-surface elevation. The input file for this example follows. 


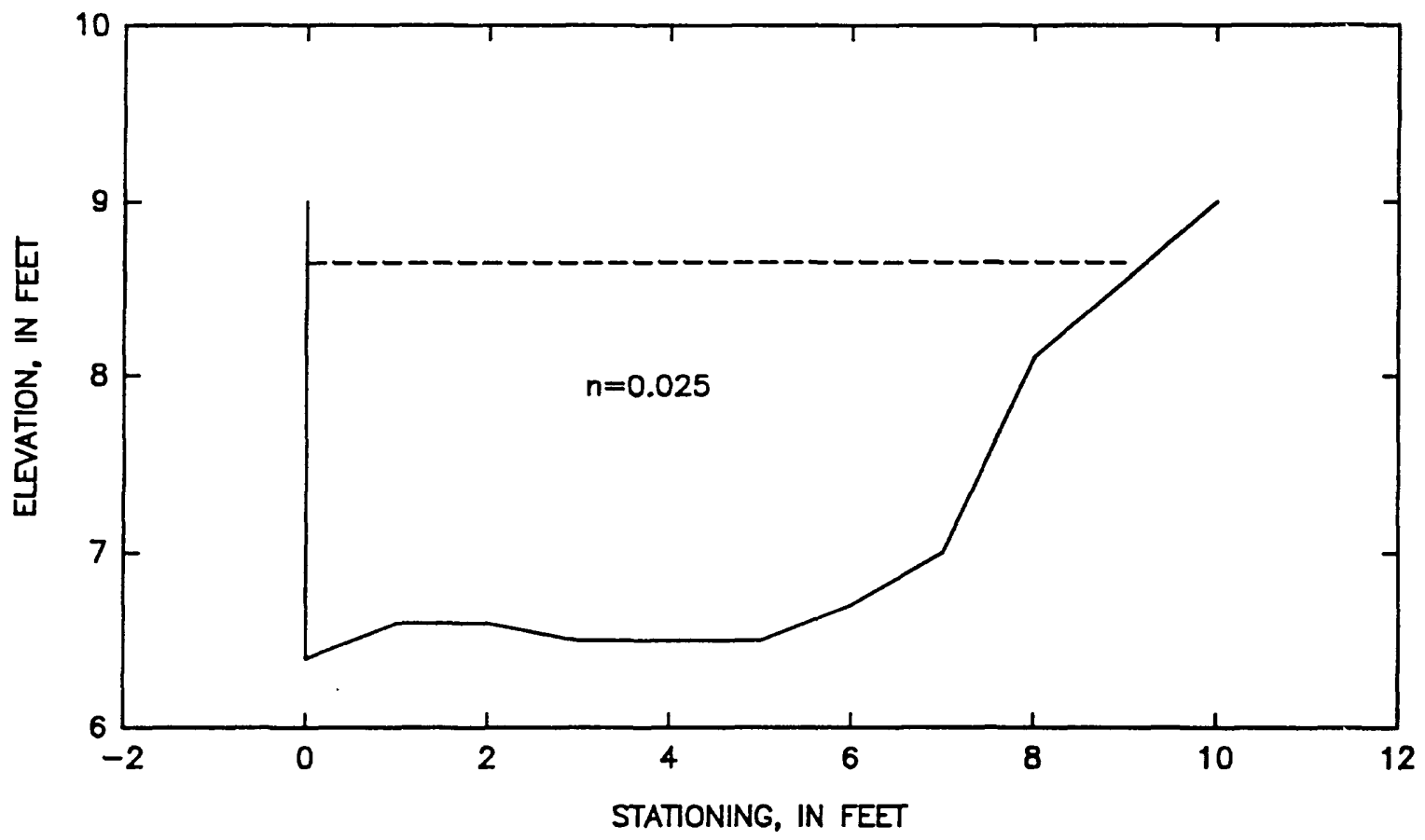

Figure 13. Approach section for culvert in tributary to Mercer Creek near Bellevue Washington.

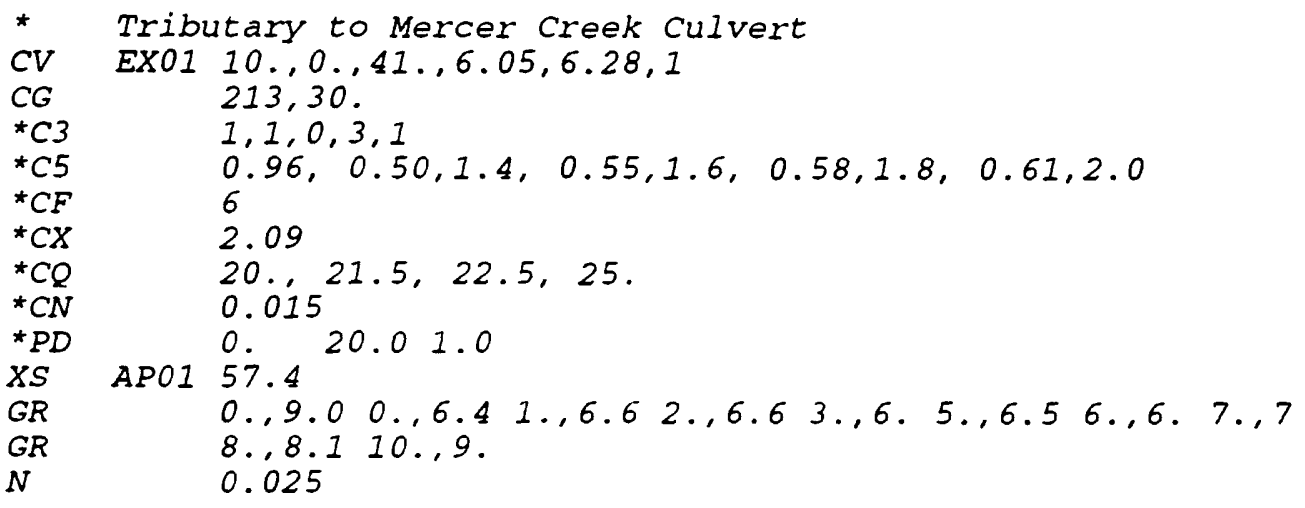

The output from this input file is in figure 14. Note that the upstream water-surface elevation is bracketed by discharges of 20 and 21.5 cubic feet per second. This example is based on a culvert verification done in the 1950's by USGS personnel. The measured discharge (by current meter) was 21.5 cubic feet per second. Linear interpolation from the output gives the discharge as 21.25 cubic feet per second, a difference of about one percent. Alternatively, discharge could have been bracketed during the first execution of the prosram by using smaller increments over the same range of discharge. This technique may not be successful for all culverts. 
CAP -USGS culvert analysis program VER 94-10

CV EX01 $10,0 ., 41,6.05,6.28,1$

CG 213,30 .

*C3 $1,1,0,3,1$

${ }^{*} \mathrm{C} 5$

${ }^{*} \mathrm{CF}$

${ }^{\star} \mathrm{CX}$

${ }^{\star} \mathrm{CQ}$

${ }^{\star} \mathrm{CN}$

${ }^{\star} \mathrm{PD}$

XS

GR

GR

$\mathrm{N}$

$0.96,0.50,1.4,0.55,1.6,0.58,1.8,0.61,2.0$

6

8.14

$20 ., 21.5,22.5,25$.

0.015

$0.20 .0 \quad 1.0$

AP01 57.4

$0 ., 9.0 ., 6.4 \quad 1.6 .6 \quad 2 \ldots 6.6 \quad 3 ., 6.5 \quad 5.6 .5 \quad 6.6 .7 \quad 7.7$

$8 ., 8.110 . .9$.

0.025

Figure 14. CAP output for Mercer Creek example. [ft, feet; sq.ft, square feet; cfs, cubic feet per second] 
Mercer Creek Culvert example, 10-11-1994

CULVERT SECTION PROPERTIES - ID: EXO1

$\begin{array}{ccccc}\text { KR } & \mathrm{KW} & \text { Ktheta } & \mathrm{n} & \text { Inlet } \\ 1.00 & 1.00 & 1.00 & .015 & 3 \\ \text { < User supplied discharge coefficients >> } \\ \text { CB12 }=\text {.00 } & \text { C46 } & .96 \\ \text { For typei23 flow } & \text { For type } 5 \text { flow } \\ \text { C } & (\mathrm{h} 1-\mathrm{z}) / \mathrm{D} & \mathrm{C} & (\mathrm{h} 1-\mathrm{z}) / \mathrm{D} \\ .00 & .00 & .50 & 1.40 \\ .00 & .00 & .55 & 1.60 \\ .00 & .00 & .58 & 1.80 \\ .00 & .00 & .61 & 2.00\end{array}$

Barrel
depth
(ft)
.00
.08
.17
.25
.33
.42
.50
.58
.67
.75
.83
.92
1.00
1.08
1.17
1.25
1.33
1.42
1.50
1.58
1.67
1.75
1.83
1.92
2.00
2.08
2.17
2.25
2.33
2.42
2.50

Area
(sq.ft)
.0
.1
.1
.3
.4
.5
.7
.9
1.1
1.2
1.4
1.6
1.8
2.0
2.2
2.5
2.7
2.9
3.1
3.3
3.5
3.7
3.9
4.0
4.2
4.4
4.5
4.7
4.8
4.9
4.9

Conveyance
(cfs)
.0
.7
3.2
7.4
13.6
21.5
31.2
42.6
55.5
69.8
85.4
102.3
120.1
138.8
158.3
178.2
198.5
219.0
239.5
259.7
279.4
298.4
316.5
333.2
348.4
361.6
372.3
379.9
383.4
380.7
356.4

$\begin{array}{cc}\begin{array}{c}\text { Top } \\ \text { width } \\ \text { (ft) }\end{array} & \begin{array}{c}\text { Wetted } \\ \text { perimeter } \\ .00\end{array} \\ \text { (ft) } \\ .90 & .0 \\ 1.25 & .9 \\ 1.50 & 1.3 \\ 1.70 & 1.6 \\ 1.86 & 1.9 \\ 2.00 & 2.1 \\ 2.11 & 2.3 \\ 2.21 & 2.5 \\ 2.29 & 2.7 \\ 2.36 & 2.9 \\ 2.41 & 3.1 \\ 2.45 & 3.3 \\ 2.48 & 3.4 \\ 2.49 & 3.6 \\ 2.50 & 3.8 \\ 2.49 & 3.9 \\ 2.48 & 4.1 \\ 2.45 & 4.3 \\ 2.41 & 4.4 \\ 2.36 & 4.6 \\ 2.29 & 4.8 \\ 2.21 & 5.0 \\ 2.11 & 5.1 \\ 2.00 & 5.3 \\ 1.86 & 5.5 \\ 1.70 & 5.8 \\ 1.50 & 6.0 \\ 1.25 & 6.2 \\ .90 & 6.5 \\ .00 & 6.9 \\ & 7.9\end{array}$

Figure 14. CAP output for Mercer Creek example-continued. Lft, feet; sq.ft, square feet; $c f s$, cubic feet per second] 
Mercer Creek Culvert example, 10-11-1994

APPROACH SECTION PROPERTIES - ID: AP01

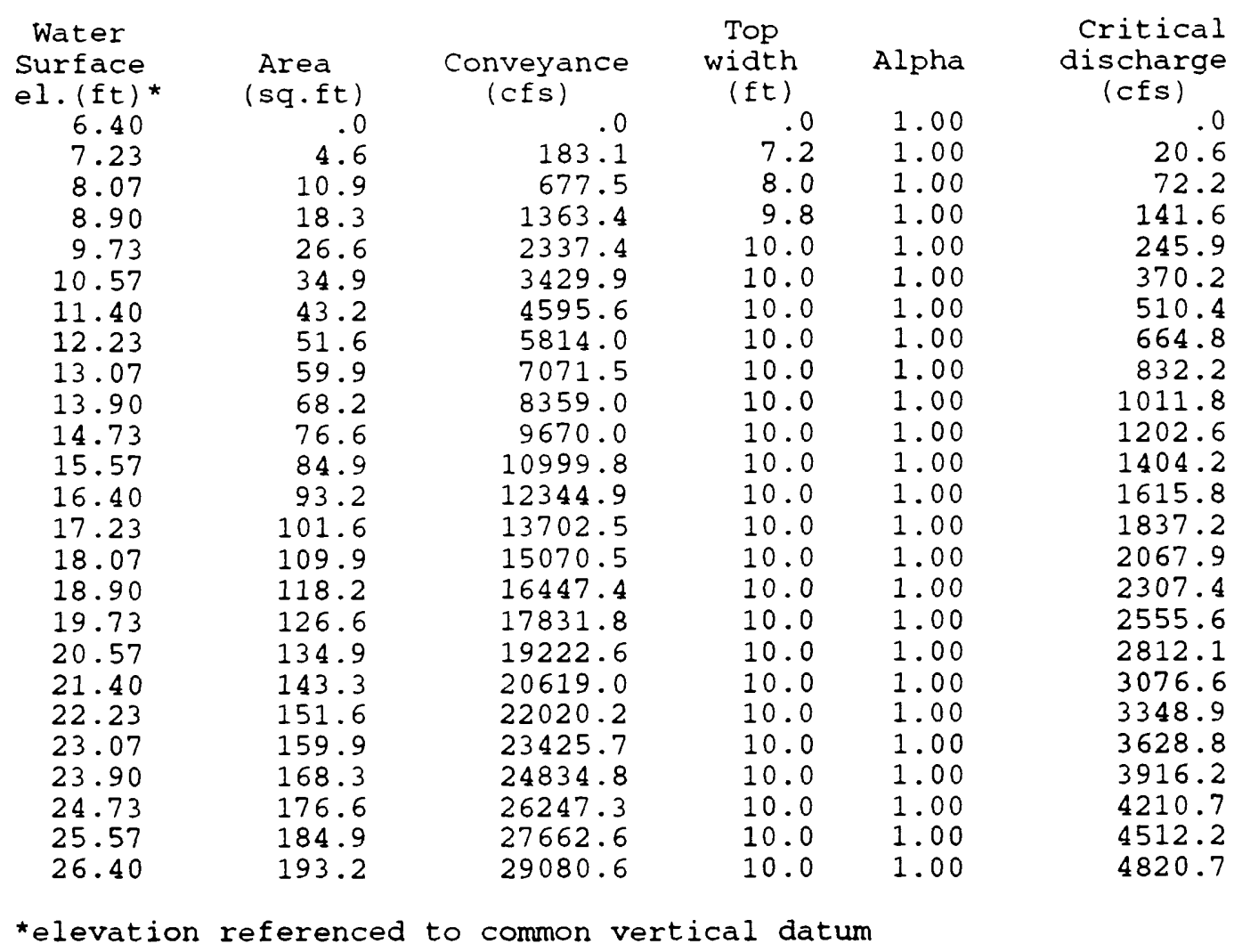

Figure 14. CAP output for Mercer Creek example-continued. [ft, feet; sq.ft, square feet; $c f s$, cubic feet per second] 
Mercer Creek Culvert example, 11-29-1994

CULVERT

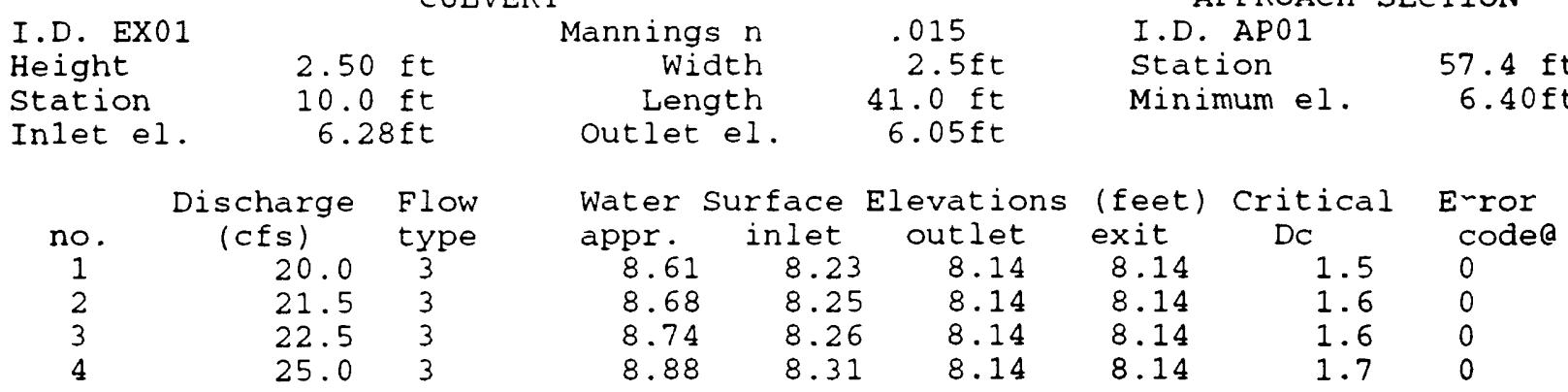

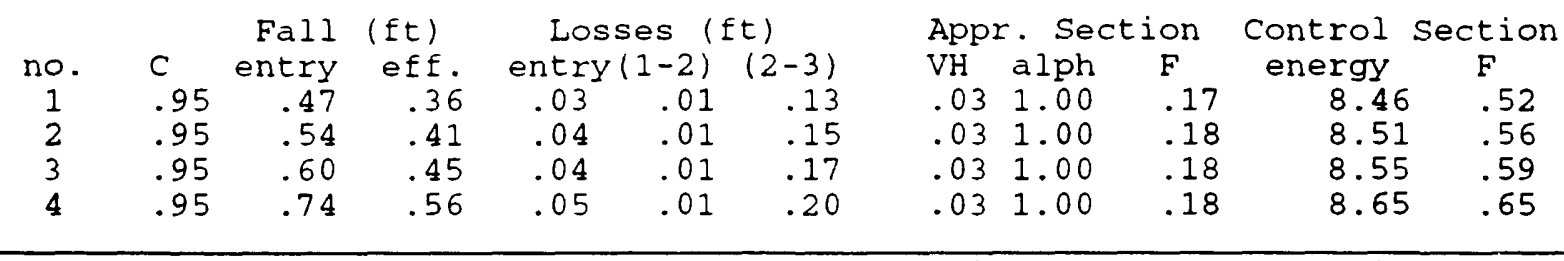

Abrevs. used: appr.-approach C-discharge coefficient eff.-effective $\mathrm{VH}-\mathrm{velocity}$ head alph-velocity coefficient n-Manning's roughness coef. energy-specific energy F-Froude number entry, (1-2), (2-3)-part of reach

aError codes: $-1,1-7$ fatal error; 8-14 warning; 0 no error

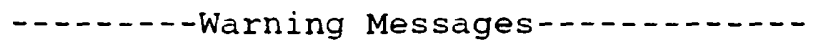

Figure 14. CAP output for Mercer Creek example-continued. [ft, feet; sq.ft, cfs, cubic feet per second] 
Nonstandard culvert sections are sometimes encountered. These culverts may have been built from nonstandard sections (not pipe, rectangular, or pipe arch), or they may be standard sections that have silted up to a uniform depth. These culverts do not have standard tables of discharge coefficients measured for them, so judgment must be used to determine the discharge coefficients.

Location: Pigeon House Creek at Cameron Village at Raleigh, North Carolina.

Culvert section description: 10-foot-diameter corrugated metal pipe cut in half anc atop a rectangular section 9.25 foot by 1.0 foot. The culvert length is 53 feet. Manning's coefficient of roughness, $\mathrm{n}$, is estimated as 0.015 and 0.034 for the rectangular and pipe parts of the culvert section. The inlet has a flat vertical face. The minimum elevation of the upstream invert is $0.55 \mathrm{foot}$, and the minimum elevation of the downstream invert is 0.22 foot. Discharge coefficients for types 1,2 , and 3 flows are estimated to be 0.95 . The culvert section is illustrated in figure 15 . The ratio $\mathrm{r} / \mathrm{D}$ is 0.02 .

Approach section description: The approach is located 15.8 feet from the inlet of the culvert. Manning's coefficient of roughness, $n$, varies from 0.04 to 0.03 by the flow denth and subarea. The approach section is illustrated in figure 16.

High-water marks: The tailwater elevation does not affect the discharge (type 3 not possible). The approach section high water mark is 1.50 feet.

Because the culvert is not affected by the downstream water elevation, the tailwator depth used is small enough to ensure either type 1 or type 2 flow. The culvert-section coordirates are input carefully in counterclockwise order, and the first and last coordinate pairs are the same, closing the figure. The CG record is not included and would have caused a fatal erro- in the program had it been entered. Because this is a nonstandard culvert section, discharge coefficients are estimated and entered on the ${ }^{*} \mathrm{Cl}$ record. Estimated discharge coefficients can be computed from direct discharge measurements. However, the coefficients in this example were extimated from values given in Bodhaine (1968). Below 1. $\mathrm{ft}$ depth in the box shaped portion of the culvert section a discharge coefficient of 0.95 is used. Above $1 . \mathrm{ft}$ depth of flow, the co fficient $^{-}$ is computed as a depth weighted average of the box section coefficient with the appropriate pipe section coefficient. The pipe discharge coefficients used are for flow depths that fill the pipe section half full and greater. These coefficients better account for the effects of the tos shape of the pipe on the flow. Type 5 flow coefficients are from table 6.

Culvert roughness varies with flow depth. The roughness value used in the input file for the culvert is estimated for a flow depth of $1.5 \mathrm{ft}$ by weighing each $\mathrm{n}$ value by its rernective wetted perimeter. 


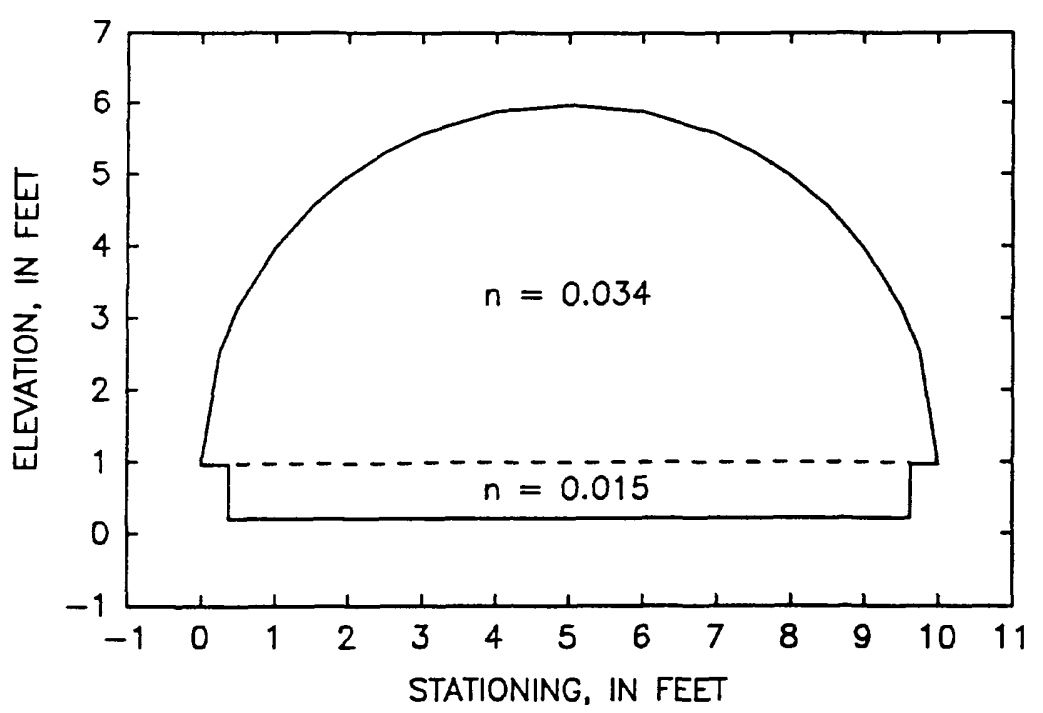

Figure 15. Cross-section of Pigeon House Creek culvert.

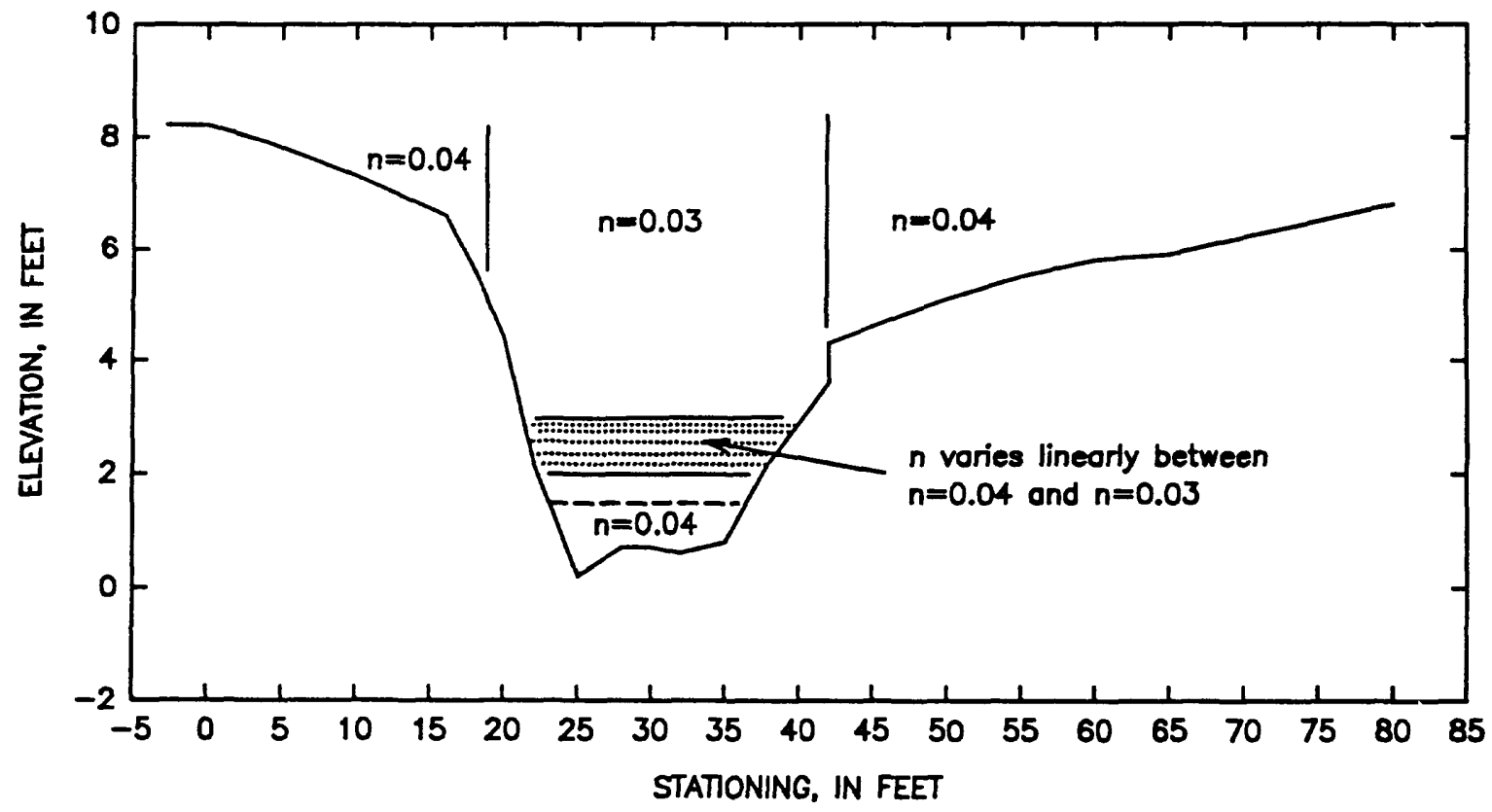

Figure 16. Approach section for Pigeon House Creek culvert. 
As in the Mercer Creek example, both the approach-section and culvert-section data are entered in the same file. The ranges of discharges are run first and then the discharger are changed until the upstream head agrees with the measured high-water mark. The input file follows:

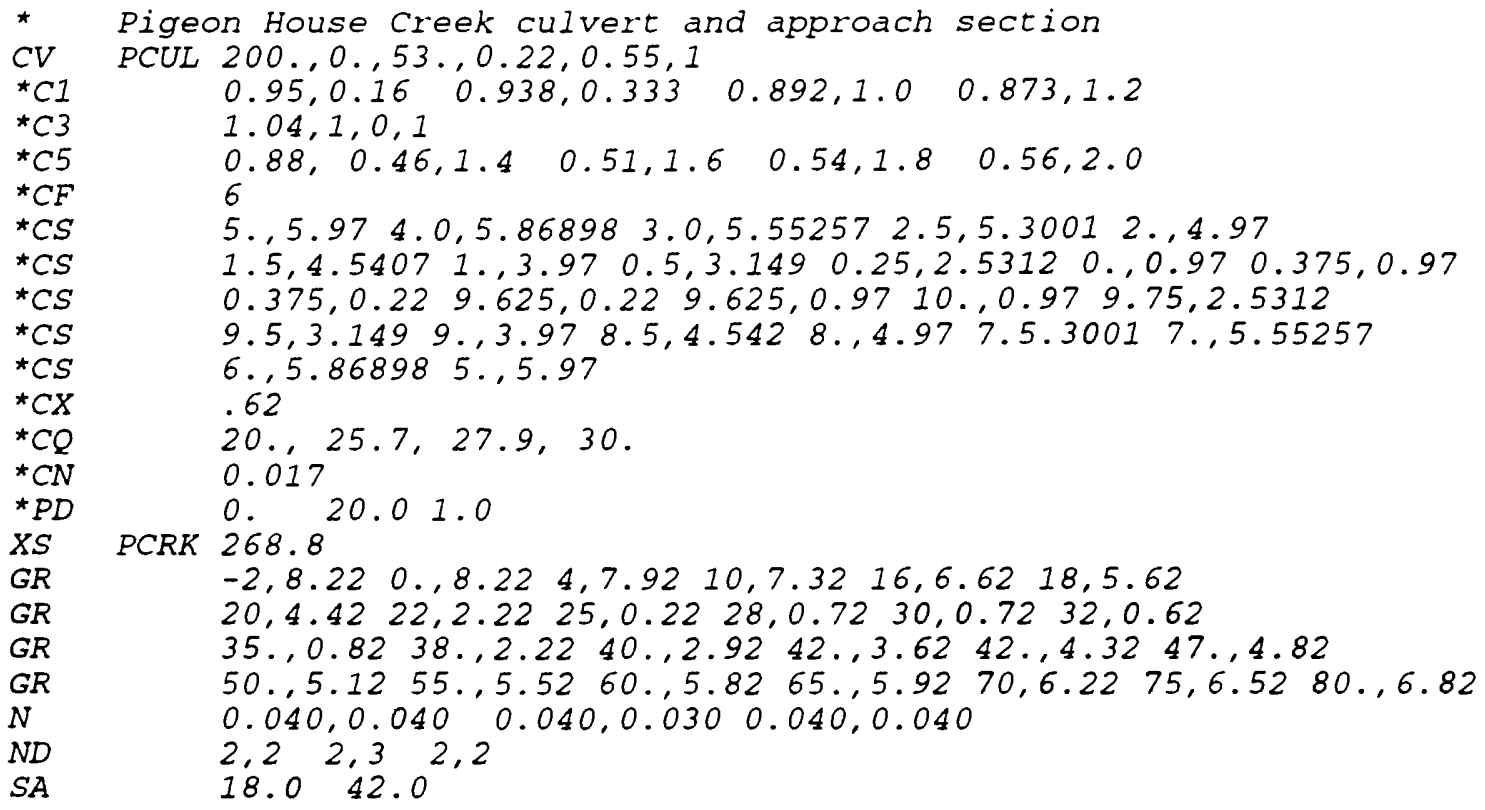

The output from this input file, except for page 0 , is shown in figure 17. Page 0 echoes the input data listed previously. Note that the upstream water-surface elevation is bracketed by discharges of 25.70 and 27.90 cubic feet per second. Linear interpolation from the output gives the discharge as 27.46 cubic feet per second. If the computed approach water-surface elevation had been significantly different from the estimated 1.5ft the Manning's coefficient of roughness, $n$, would be recomputed for that flow depth and the program run with the new $\mathrm{n}$ value to verify the computed water-surface elevation. 
Pigeon Creek Culvert example, 10-11-1994

$$
\text { CULVERT SECTION PROPERTIES - ID: PCUL }
$$

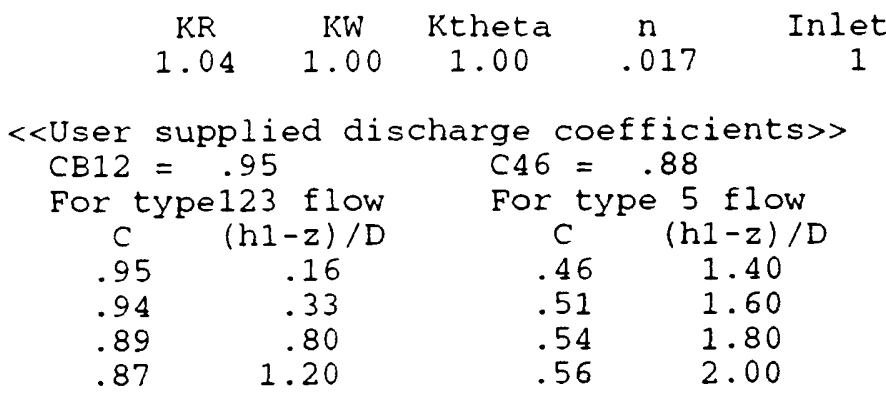

$\begin{array}{ccccc}\begin{array}{c}\text { Barrel } \\ \text { depth } \\ \text { (ft) }\end{array} & \begin{array}{c}\text { Area } \\ \text { (sq.ft) }\end{array} & \begin{array}{c}\text { Top } \\ \text { (conveyce } \\ \text { (c) }\end{array} & \begin{array}{c}\text { width } \\ \text { (ft) }\end{array} & \begin{array}{c}\text { Wetted } \\ \text { perimeter } \\ \text { (ft) }\end{array} \\ .19 & 1.0 & 50.3 & .00 & .0 \\ .38 & 3.5 & 155.5 & 9.25 & 9.6 \\ .58 & 5.3 & 298.1 & 9.25 & 10.0 \\ .77 & 7.1 & 450.8 & 9.25 & 10.4 \\ .96 & 9.0 & 655.7 & 9.99 & 11.5 \\ 1.15 & 10.9 & 882.5 & 9.93 & 11.9 \\ 1.34 & 12.8 & 1127.6 & 9.87 & 12.3 \\ 1.53 & 14.7 & 1387.9 & 9.75 & 12.7 \\ 1.73 & 16.5 & 1661.1 & 9.69 & 13.1 \\ 1.92 & 18.4 & 1945.3 & 9.63 & 13.5 \\ 2.11 & 20.2 & 2238.7 & 9.56 & 13.9 \\ 2.30 & 22.1 & 2540.0 & 9.50 & 14.3 \\ 2.49 & 23.9 & 2843.2 & 9.35 & 14.6 \\ 2.68 & 25.6 & 3147.7 & 9.20 & 15.1 \\ 2.88 & 27.4 & 3452.2 & 9.04 & 15.5 \\ 3.07 & 29.1 & 3751.1 & 8.83 & 15.9 \\ 3.26 & 30.8 & 4043.0 & 8.60 & 16.3 \\ 3.45 & 32.4 & 4328.3 & 8.37 & 16.8 \\ 3.64 & 34.0 & 4606.3 & 8.13 & 17.2 \\ 3.83 & 35.5 & 4871.2 & 7.85 & 17.7 \\ 4.03 & 37.0 & 5117.3 & 7.52 & 18.1 \\ 4.22 & 38.4 & 5349.3 & 7.18 & 18.6 \\ 4.41 & 39.7 & 5559.6 & 6.80 & 19.2 \\ 4.60 & 41.0 & 5742.6 & 6.35 & 19.7 \\ 4.79 & 42.2 & 5901.1 & 5.87 & 20.3 \\ 4.98 & 43.2 & 6020.0 & 5.29 & 20.9 \\ 5.18 & 44.2 & 6098.6 & 4.62 & 21.6 \\ 5.37 & 45.0 & 6119.0 & 3.78 & 22.4 \\ 5.56 & 45.6 & 6040.0 & 2.57 & 23.3 \\ 5.75 & 45.9 & 5710.4 & .00 & 24.6 \\ & & & & 27.2\end{array}$

Figure 17. CAP output for Pigeon House Creek example of a non-standard culvert section. [ft, feet; sq.ft, square feet; cfs, cubic feet per second] 
Pigeon Creek Culvert example, 10-11-1994

APPROACH SECTION PROPERTIES - ID: PCRK

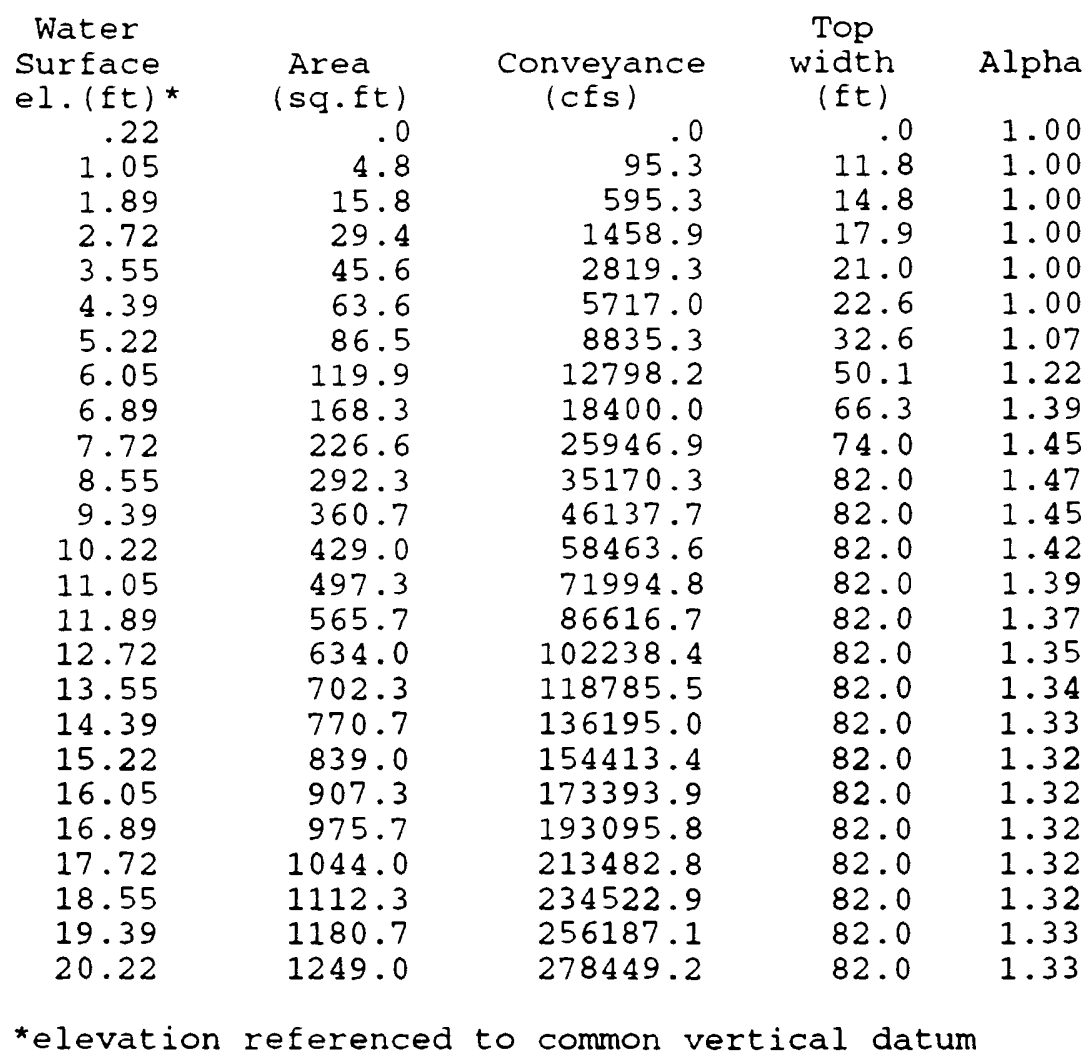

Critical discharge (cfs)

*elevation referenced to common vertical datum

Figure 17. CAP output for Pigeon House Creek example of a non-standard culvert sentioncontinued. [ft, feet; sq.ft, square feet; cfs, cubic feet per second] 
Pigeon Creek Culvert example, 11-29-1994

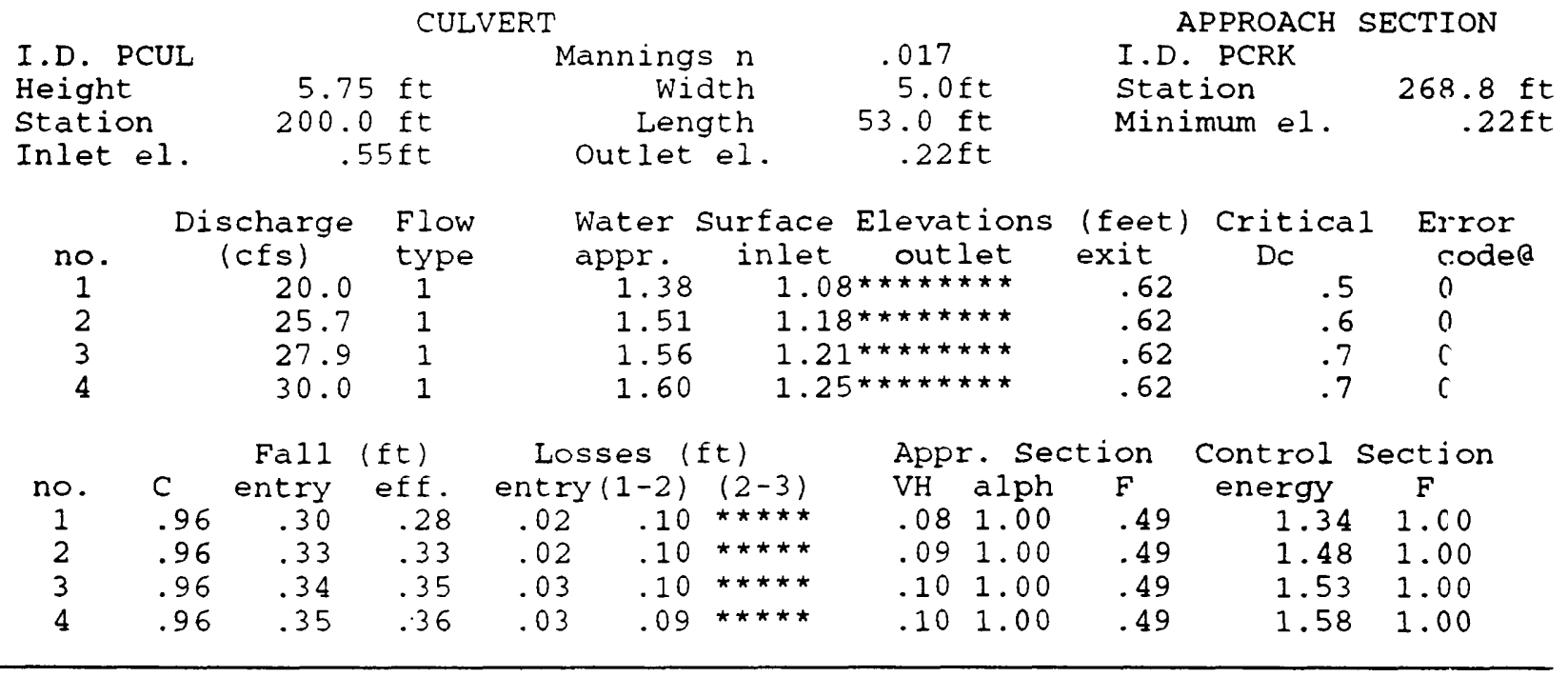

Abrevs. used: appr.-approach C-discharge coefficient eff.-effective VH-velocity head alph-velocity coefficient n-Manning's roughness coef. energy-specific energy F-Froude number entry, (1-2), (2-3)-part of reach

aError codes: $-1,1-7$ fatal error; 8-14 warning; 0 no error

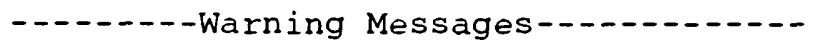

Figure 17. CAP output for Pigeon House Creek example of a non-standard culvert sectioncontinued. [ft, feet; sq.ft, cfs, cubic feet per second] 


\section{Multiple Culvert Openings}

Computations can be made for two or more culverts that share a common approach cross section. The culverts may be of different or similar geometry but must be located far enough apart so that the space between them cannot be considered as a web. However, excep+ for ponded conditions in the approach, the energy and continuity equations are insufficient for the number of unknowns that occur for a multiple opening reach. An additional equation is required for nonponded approach conditions.

Typically, the additional equation is for apportioning the approach section. Each culvert is then treated separately by dividing the approach section between the culverts and assigning the appropriate portion of the approach section to each culvert. If the velocity is near zero (ponded conditions) in the approach section, the approach section should not be subdivided.

Several techniques can be used to apportion the approach section. These techninues are somewhat arbitrary and each technique yields somewhat different results. The technique demonstrated requires the user to manually apportion the approach section. The technique assumes that the approach section can be divided rationally into strips corresponding to each culvert by proportioning the discharge through the culverts and the approach section. Each appropriate portion of the divided approach section is used as an approach section for corresponding culvert.

The dividing point between the strips is located a weighted distance from the right edge of the left opening. The weighted distance is equal to the length of embankment between the culverts multiplied by the ratio of the left opening flow area to the total flow area of thth openings. For the culverts in figure 18, the dividing points (stagnation points) located on the embankment between the culverts are computed from,

$$
x_{d_{2-3}}=L_{1-2} \frac{A_{c 1}}{A_{1,2}} ; \quad x_{d_{2-3}}=L_{2-3} \frac{A_{c 2}}{A_{2,3}}
$$

where $A_{1,2}$ and $A_{2,3}$ are the sum of the opening areas of the two culverts adjacent to the embankment, $A_{c 1}$ and $A_{c 2}$ are the opening area of one of the adjacent culverts, $L_{1-2}$ and $L_{2-3}$

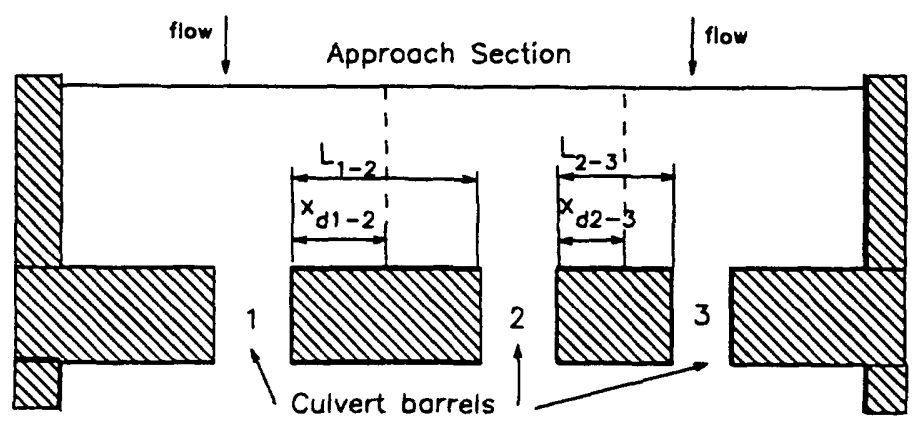

Figure 18. Location of dividing points on embankments for multiple culvert sections. 
are the embankment lengths between the adjacent culverts, and $\mathrm{x}_{\mathrm{d} 1-2}$ and $\mathrm{x}_{\mathrm{d} 2-3}$ are the location of the dividing points referenced to the edge of the adjacent culvert. Numeric subscript: indicate the appropriate culvert. From the dividing points on the embankment, lines are projected upstream parallel to the mean direction of flow to the approach section.

Location: Rio Grande conveyance channel near San Acacia, New Mexico.

Culvert section description: Two-barrel multiplate pipe-arch culverts made from corrug 'ted metal. Manning's coefficient of roughness, $n$, is estimated as 0.032 . The inlet and outlets are mitered and set flush with the slope embankments. Each barrel is 50.0 feet long. Pipe arch dimensions are 15 -foot 4 -inch by 9 -foot 3 -inch nominal and 15 -foot 6 inch by 8 -foot 10 -inch actual. The elevation of the upstream invert for barrel 1 is 1.00 foot and the downstream invert is 0.62 foot. The elevation of the upstream invert for barrel 2 is 0.94 foot and the downstream invert is 0.65 foot.

Approach section description: The approach section is located 60 feet before barrel 1 and 59 feet before barrel 2. The reach is straight and Manning's roughness coefficient, $n$, is estimated as 0.035 . The approach section is illustrated in figure 19 .

High-water marks: For barrel 1, the approach section high-water mark is 9.03 feet and the tailwater mark is 5.41 feet. For barrel 2, the approach-section high-water mark is 9.03 feet and the tailwater mark is 5.24 feet. Figures 20 and 21 are longitudinal views of the water surface and culvert geometry for each barrel.

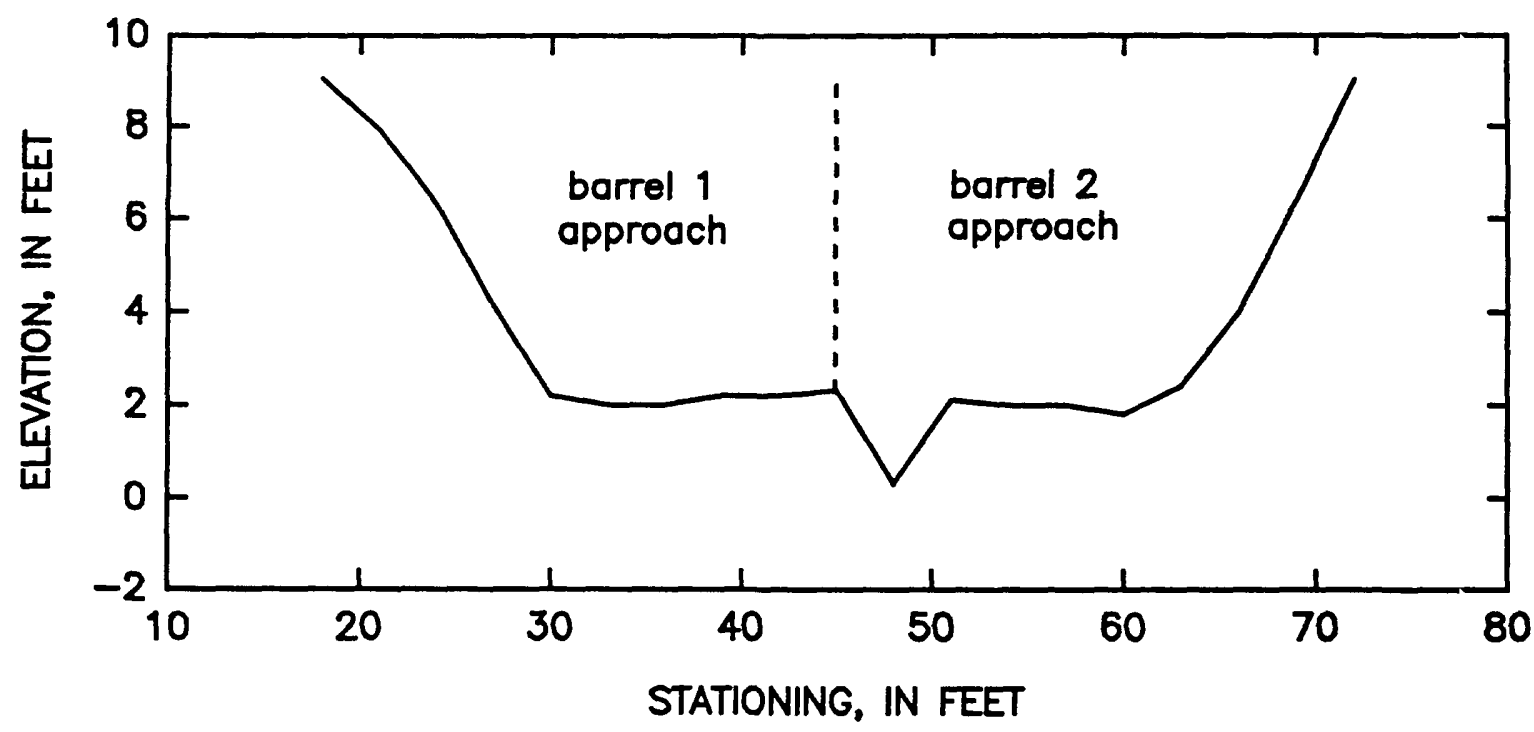

Figure 19. Approach section for the Rio Grande conveyance channel culvert. 


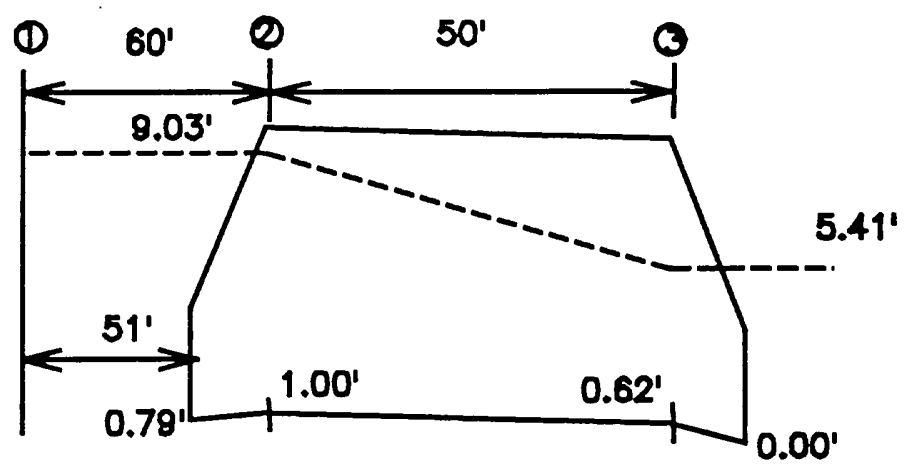

Figure 20. Longitudinal view of barrel 1 of the Rio Grande conveyance channel culvert.

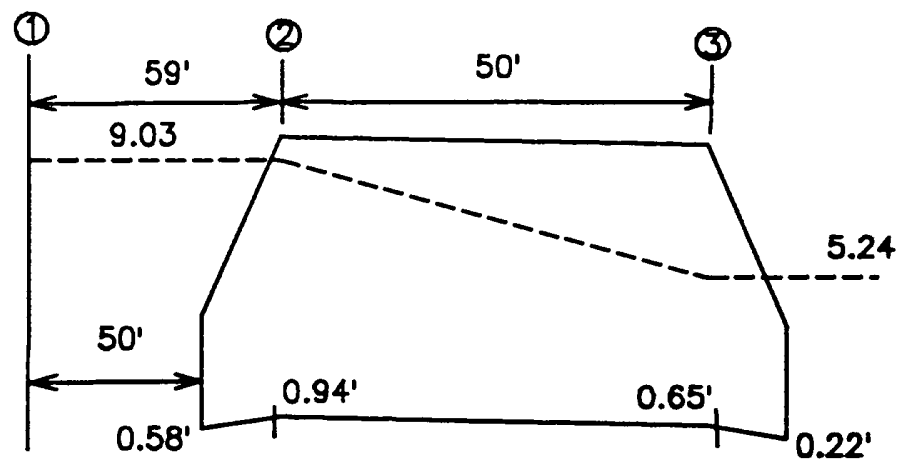

Figure 21. Longitudinal view of barrel 2 of the Rio Grande conveyance channel culvert.

Because the pipe-arches are mitered at the ends, the actual length of the barrels ( 69.5 feet) is not used in the computations. The effective length of a mitered pipe is a functinn of the flow depth in the pipe. The program does not automatically adjust effective pipe length for flow depth. For this example, the effective length is approximated by the length of pipe between the top of the inlet and outlet inverts (50 feet) and is entered as the culvert length. Bodhaine (1968, p. 8) describes in detail the proper computation of pipe length.

The default discharge coefficients for mitered pipes are used for flow types 1, 2, and 3 by setting the inlet equal to 2 on the ${ }^{*} \mathrm{C} 3$ record. Other discharge coefficients are entered on the ${ }^{*} \mathrm{C} 5$ record.

Each barrel has a separate set of input records that describe geometry and roughness and the tailwater and discharges for which to compute the approach-section water-surface elevation. Each barrel also has the appropriate portion of the approach section coded is a separate approach section. The entire approach section was initially coded (the APPR section) and then copied and edited into the approach section for barrel 1 (APP1) and barrel 2 (APP2). For reference purposes, the entire approach section was left in the input file b't is not used. The culvert program is executed twice, once for each barrel using the same strategy as used in the two previous examples. One *PD record is used for APP1 and APP2. Only 
one *PD record can be included in the file containing the approach sections. The input file follows:

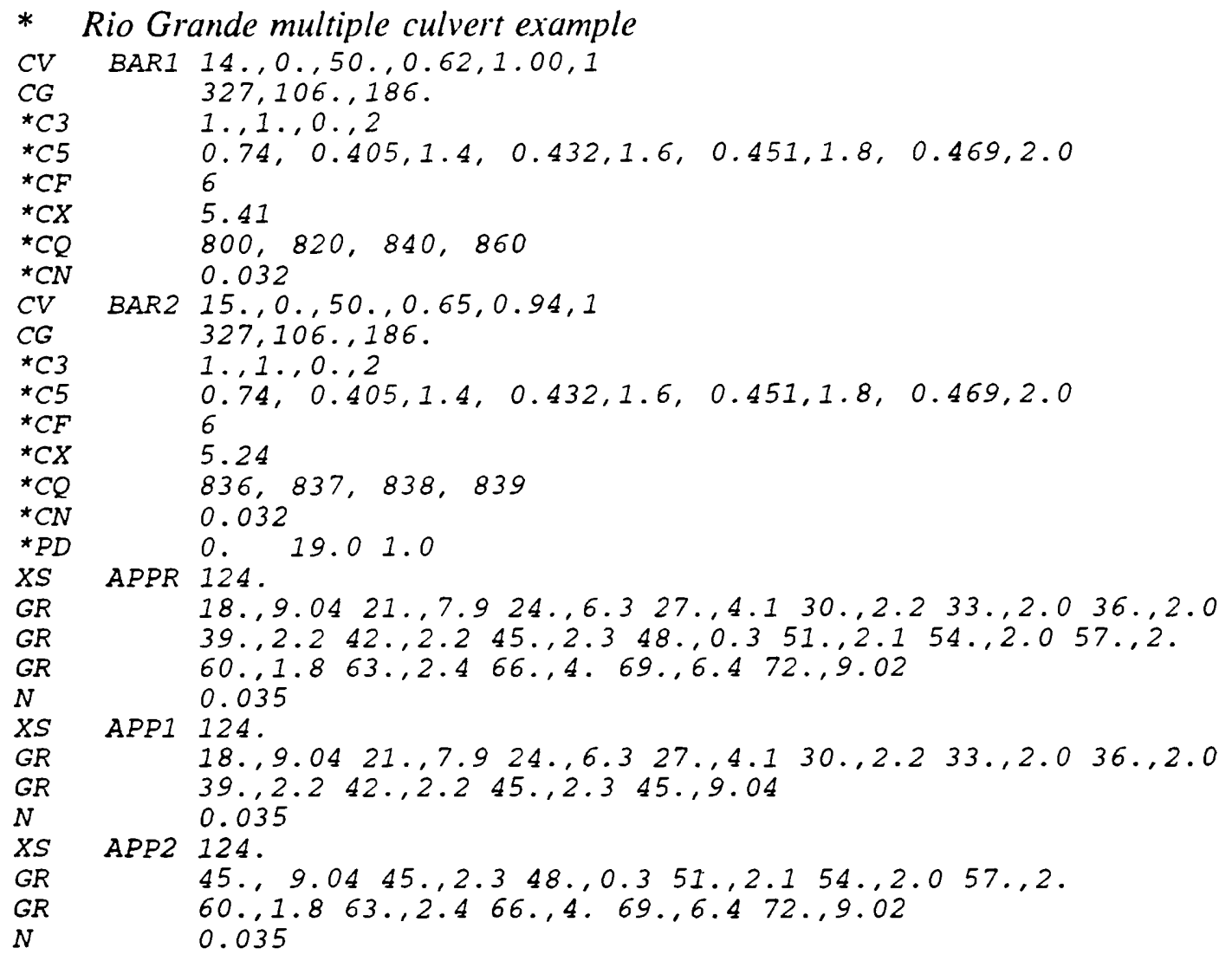

The output from this input file for barrel 1 is in figure 22 and for barrel 2 is in figure 23. The computed discharges for which the computed upstream water-surface elevation matches the measured water-surface elevation of 9.03 feet are 860 cubic feet per second for barrel 1 (BAR1) and 836 cubic feet per second for barrel 2 (BAR2). The total computed discharge (the discharge computed for barrel 1 plus the discharge computed for barrel 2) is 1,696 cubic feet per second. These data are from a verification done in 1961 by USGS personnel. The current-meter-measured discharge for both barrels was 1,743 cubic feet per second. The computed discharge differs from the measured discharge by less than 3 pe-cent. 
CV BAR1 $14,0,50 \ldots 0.62,1.00,1$

CG $327,106 \ldots, 186$.

${ }^{\star} \mathrm{C} 3 \quad 1 ., 1 ., 0 ., 2$

${ }^{\star}$ C5 $\quad 0.74,0.405,1.4,0.432,1.6,0.451,1.8,0.469,2.0$

${ }^{\star} \mathrm{CF} \quad 6$

${ }^{\star} \mathrm{CX} \quad 5.41$

${ }^{*} \mathrm{CQ} \quad 800,820,840,860$

${ }^{\star} \mathrm{CN} \quad 0.032$

XS APP1 124.

GR $\quad 18,9.04 \quad 21,7.9 \quad 24 ., 6.3 \quad 27 \ldots 4.130,2.2 \quad 33 ., 2.0 \quad 36 ., 2.0$

GR

$\mathrm{N}$

$39 ., 2.242 ., 2.2 \quad 45 \ldots 2.3 \quad 45 ., 9.04$

0.035

Figure 22. CAP output for barrel 1 of Rio Grande conveyance channel culvert. [ft, feet; sq.ft, square feet; cfs, cubic feet per second] 
CAP -USGS culvert analysis program VER 94-10

Rio Grande Conveyance Channel multi-culvert barrel 1, 10-11-1994

CULVERT SECTION PROPERTIES - ID: BAR1

$\begin{array}{ccccc}\mathrm{KR} & \mathrm{KW} & \text { Ktheta } & \mathrm{n} & \text { Inlet } \\ 1.00 & 1.00 & 1.00 & .032 & 2 \\ \text { Pipe arch radii: } & 301.0 \text { (bottom) } & 93.2 \text { (top) } & 18.0 \text { (corner) }\end{array}$

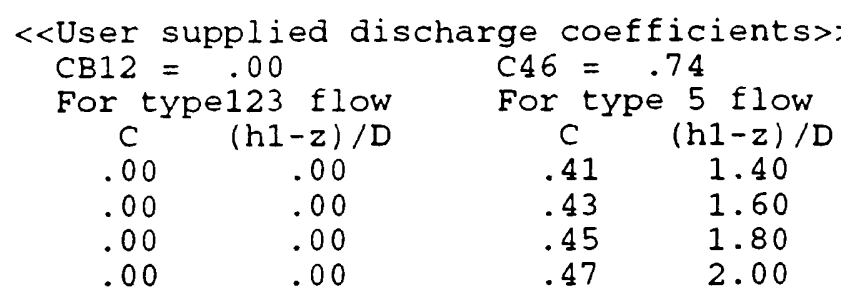

$\begin{array}{ccccc}\begin{array}{c}\text { Barrel } \\ \text { depth } \\ \text { (ft) }\end{array} & \begin{array}{c}\text { Area } \\ \text { (sq.ft) }\end{array} & \begin{array}{c}\text { Conveyance } \\ \text { (cfs) }\end{array} & \begin{array}{r}\text { Top } \\ \text { width } \\ \text { (ft) }\end{array} & \begin{array}{c}\text { Wetted } \\ \text { perimeter } \\ \text { (ft) }\end{array} \\ .29 & .0 & .0 & .00 & .0 \\ .59 & 1.5 & 23.6 & 7.66 & 7.7 \\ .88 & 4.3 & 105.8 & 10.81 & 10.9 \\ 1.18 & 7.8 & 253.7 & 13.20 & 13.4 \\ 1.47 & 11.9 & 480.9 & 14.39 & 14.7 \\ 1.77 & 16.2 & 778.2 & 14.94 & 15.5 \\ 2.06 & 20.7 & 1133.2 & 15.27 & 16.2 \\ 2.36 & 25.2 & 1537.4 & 15.45 & 16.8 \\ 2.65 & 29.8 & 1982.1 & 15.50 & 17.4 \\ 2.94 & 34.3 & 2457.7 & 15.21 & 18.0 \\ 3.24 & 38.8 & 2947.2 & 15.08 & 18.6 \\ 3.53 & 43.2 & 3452.5 & 14.92 & 19.2 \\ 3.83 & 47.6 & 3969.0 & 14.73 & 19.8 \\ 4.12 & 51.9 & 4492.0 & 14.52 & 20.4 \\ 4.42 & 56.1 & 5017.5 & 14.28 & 21.1 \\ 4.71 & 60.3 & 5541.1 & 14.02 & 21.7 \\ 5.01 & 64.4 & 6058.9 & 13.72 & 22.4 \\ 5.30 & 68.3 & 6566.8 & 13.39 & 23.1 \\ 5.59 & 72.2 & 7060.7 & 13.03 & 23.7 \\ 5.89 & 76.0 & 7536.5 & 12.62 & 24.5 \\ 6.18 & 79.7 & 7989.9 & 12.18 & 25.2 \\ 6.48 & 83.2 & 8416.2 & 11.69 & 26.0 \\ 6.77 & 86.5 & 8810.5 & 11.14 & 26.8 \\ 7.07 & 89.7 & 9167.5 & 10.54 & 27.6 \\ 7.36 & 92.7 & 9480.9 & 9.86 & 28.5 \\ 7.66 & 95.5 & 9743.3 & 9.10 & 29.5 \\ 7.95 & 98.1 & 9945.1 & 8.22 & 30.5 \\ 8.24 & 100.4 & 10073.2 & 7.20 & 31.7 \\ 8.54 & 102.3 & 10106.1 & 5.93 & 33.1 \\ 8.83 & 103.8 & 9997.8 & 4.24 & 34.9 \\ & 104.7 & 9380.3 & .00 & 39.2\end{array}$

Figure 22. CAP output for barrel 1 of Rio Grande conveyance channel culvert-continued. [ft, feet; sq.ft, square feet; cfs, cubic feet per second] 
Rio Grande Conveyance Channel multi-culvert barrel 1, 10-11-1994

APPROACH SECTION PROPERTIES - ID: APPI

\begin{tabular}{|c|c|c|c|c|c|}
\hline $\begin{array}{l}\text { Water } \\
\text { Surface } \\
\text { el.(ft)* }\end{array}$ & $\begin{array}{l}\text { Area } \\
(\mathrm{sq} \cdot f t)\end{array}$ & $\begin{array}{c}\text { Conveyance } \\
\text { (cfs) }\end{array}$ & $\begin{array}{l}\text { Top } \\
\text { width } \\
\text { (ft) }\end{array}$ & Alpha & $\begin{array}{c}\text { Critical } \\
\text { discharge } \\
\text { (cfs) }\end{array}$ \\
\hline 2.00 & .0 & .0 & 3.0 & 1.00 & .0 \\
\hline 2.79 & 10.2 & 313.8 & 15.9 & 1.00 & 46.3 \\
\hline 3.58 & 23.3 & 1142.0 & 17.2 & 1.00 & 154.1 \\
\hline 4.38 & 37.4 & 2331.6 & 18.4 & 1.00 & 302.8 \\
\hline 5.17 & 52.4 & 3833.1 & 19.5 & 1.00 & 487.7 \\
\hline 5.96 & 68.2 & 5614.3 & 20.5 & 1.00 & 705.4 \\
\hline 6.75 & 84.9 & 7633.6 & 21.8 & 1.00 & 950.5 \\
\hline 7.54 & 102.8 & 9913.7 & 23.3 & 1.00 & 1224.9 \\
\hline 8.33 & 121.9 & 12423.9 & 25.1 & 1.00 & 1524.1 \\
\hline 9.13 & 142.7 & 15264.4 & 27.0 & 1.00 & 1860.9 \\
\hline 9.92 & 164.0 & 18715.7 & 27.0 & 1.00 & 2294.4 \\
\hline 10.71 & 185.4 & 22328.3 & 27.0 & 1.00 & 2757.2 \\
\hline 11.50 & 206.8 & 26079.6 & 27.0 & 1.00 & 3247.4 \\
\hline 12.29 & 228.2 & 29951.0 & 27.0 & 1.00 & 3763.7 \\
\hline 13.08 & 249.5 & 33927.4 & 27.0 & 1.00 & 4304.8 \\
\hline 13.88 & 270.9 & 37996.1 & 27.0 & 1.00 & 4869.6 \\
\hline 14.67 & 292.3 & 42146.5 & 27.0 & 1.00 & 5457.2 \\
\hline 15.46 & 313.7 & 46369.6 & 27.0 & 1.00 & 6066.6 \\
\hline 16.25 & 335.0 & 50657.6 & 27.0 & 1.00 & 6697.2 \\
\hline 17.04 & 356.4 & 55003.9 & 27.0 & 1.00 & 7348.2 \\
\hline 17.83 & 377.8 & 59402.8 & 27.0 & 1.00 & 8019.0 \\
\hline 18.63 & 399.2 & 63849.3 & 27.0 & 1.00 & 8709.1 \\
\hline 19.42 & 420.5 & 68338.9 & 27.0 & 1.00 & 9418.0 \\
\hline 20.21 & 441.9 & 72867.9 & 27.0 & 1.00 & 10145.0 \\
\hline 21.00 & 463.3 & 77432.8 & 27.0 & 1.00 & 10889.9 \\
\hline
\end{tabular}

Figure 22. CAP output for barrel 1 of Rio Grande conveyance channel culvert-continued. [ft, feet; sq.ft, square feet; cfs, cubic feet per second] 
Rio Grande Conveyance Channel multi-culvert barrel 1, 11-29-1994

\begin{tabular}{|c|c|c|c|c|c|c|c|c|c|}
\hline \multirow{4}{*}{\multicolumn{2}{|c|}{$\begin{array}{l}\text { I.D. BAR1 } \\
\text { Height } \\
\text { Station } \\
\text { Inlet el. }\end{array}$}} & \multicolumn{5}{|c|}{ CULVERT } & \multicolumn{3}{|c|}{ APPROACH SECTION } \\
\hline & & \multirow{3}{*}{\multicolumn{2}{|c|}{$\begin{array}{c}8.83 \mathrm{ft} \\
14.0 \mathrm{ft} \\
1.00 \mathrm{ft}\end{array}$}} & \multirow{3}{*}{\multicolumn{2}{|c|}{$\begin{array}{r}\text { Mannings } n \\
\text { Width } \\
\text { Length } \\
\text { outlet el. }\end{array}$}} & .032 & \multirow{3}{*}{\multicolumn{2}{|c|}{$\begin{array}{l}\text { I.D. APP1 } \\
\text { Station } \\
\text { Minimum el. }\end{array}$}} & \\
\hline & & & & & & $\begin{array}{l}15.5 \mathrm{ft} \\
50.0 \mathrm{ft}\end{array}$ & & & $\begin{array}{r}124.0 \mathrm{ft} \\
2.00 \mathrm{ft}\end{array}$ \\
\hline & & & & & & $.62 \mathrm{ft}$ & & & \\
\hline $\begin{array}{c}\text { no. } \\
1 \\
2 \\
3 \\
4\end{array}$ & \multicolumn{2}{|c|}{$\begin{array}{r}\text { Discharge } \\
(\text { cfs) } \\
800.0 \\
820.0 \\
840.0 \\
860.0\end{array}$} & $\begin{array}{l}\text { Flow } \\
\text { type } \\
3 \\
2 \\
2 \\
2\end{array}$ & \multicolumn{2}{|l|}{$\begin{array}{l}\text { Water } \\
\text { appr. } \\
8.54 \\
8.72 \\
8.87 \\
9.02\end{array}$} & $\begin{array}{c}\text { Elevations } \\
\text { out let } \\
5.41 \\
5.43 \\
5.50 \\
5.57\end{array}$ & $\begin{array}{l}\text { (feet) } \\
\text { exit } \\
5.41 \\
5.41 \\
5.41 \\
5.41\end{array}$ & $\begin{array}{l}\text { Critical } \\
\text { DC } \\
4.7 \\
4.8 \\
4.9 \\
5.0\end{array}$ & $\begin{array}{l}\text { Error } \\
\text { codea } \\
0 \\
0 \\
0 \\
0\end{array}$ \\
\hline $\begin{array}{c}\text { no. } \\
1 \\
2 \\
3 \\
4\end{array}$ & $\begin{array}{l}\mathrm{C} \\
.93 \\
.92 \\
.92 \\
.92\end{array}$ & $\begin{array}{r}\text { Fall } \\
\text { entry } \\
3.13 \\
3.28 \\
3.37 \\
3.45\end{array}$ & $\begin{array}{l}(f t) \\
\text { eff. } \\
2.71 \\
2.84 \\
2.91 \\
2.99\end{array}$ & $\begin{array}{rr}\text { Losses } \\
\text { entry } \\
.39-2) \\
.42 & .37 \\
.45 & .37 \\
.47 & .36\end{array}$ & $\begin{array}{rr}(f t) \\
) \\
7 & (2-3) \\
7 & .66 \\
7 & .68 \\
6 & .69 \\
6 & .69\end{array}$ & 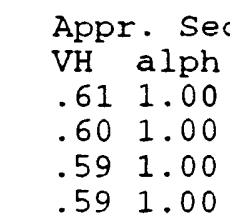 & $\begin{array}{l}\text { etion } \\
\text { F } \\
.50 \\
.49 \\
.48 \\
.47\end{array}$ & $\begin{array}{r}\text { Control s } \\
\text { energy } \\
7.73 \\
7.85 \\
7.97 \\
8.08\end{array}$ & $\begin{array}{c}\text { Section } \\
\text { F } \\
.98 \\
1.00 \\
1.00 \\
1.00\end{array}$ \\
\hline
\end{tabular}

Abrevs. used: appr.-approach C-discharge coefficient eff.-effective VH-velocity head alph-velocity coefficient n-Manning's roughness coef. energy-specific energy F-Froude number entry, (1-2), (2-3)-part of reach

@Error codes: $-1,1-7$ fatal error; 8-14 warning; 0 no error

Figure 22. CAP output for barrel 1 of the Rio Grande conveyance channel culvert-continued. [ft, feet; sq.ft, cfs, cubic feet per second] 
CAP -USGS culvert analysis program VER 94-10

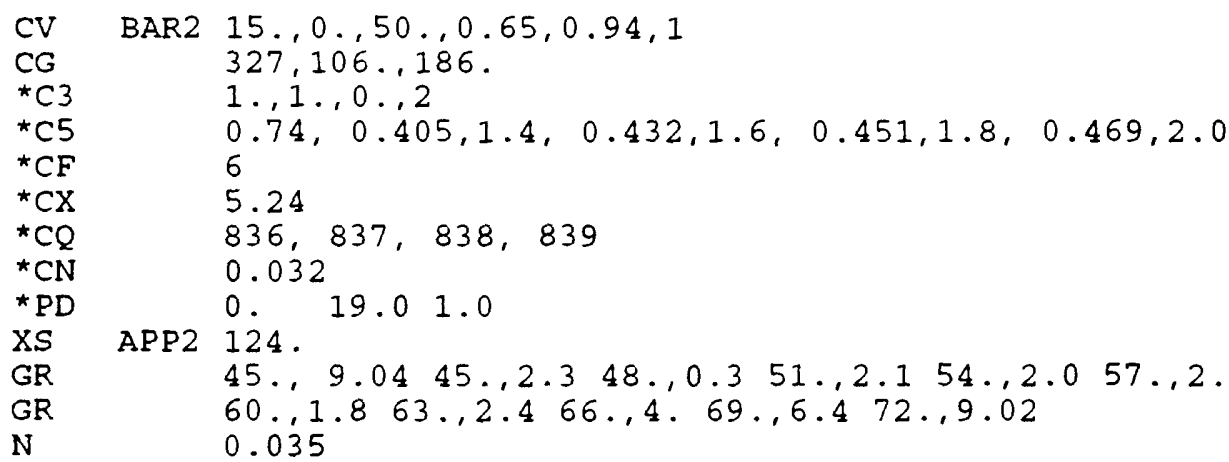

Figure 23. CAP output for barrel 2 of Rio Grande conveyance channel culvert. [ft, feet; sq.ft, square feet; cfs, cubic feet per second] 
Rio Grande Conveyance Channel multi-culvert barrel 2, 10-11-1994

CULVERT SECTION PROPERTIES - ID: BAR2

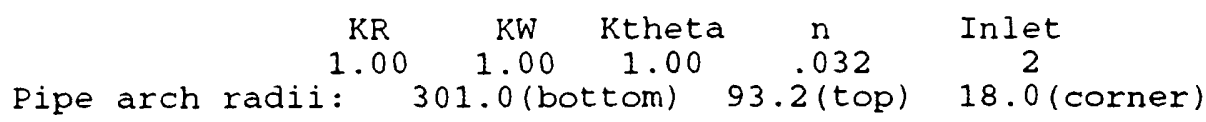

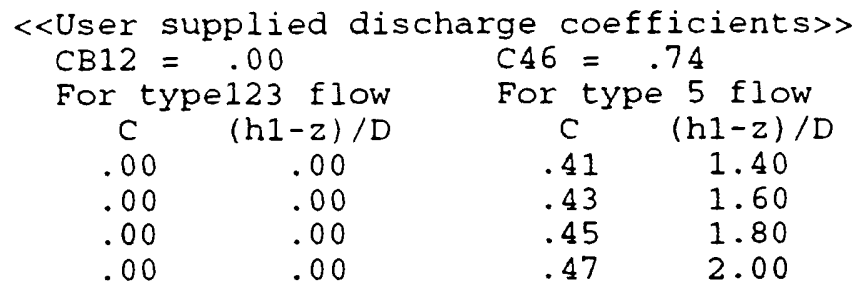

$\begin{array}{ccccc}\begin{array}{c}\text { Barrel } \\ \text { depth } \\ (\mathrm{ft})\end{array} & \begin{array}{c}\text { Area } \\ (\mathrm{sq} . \mathrm{ft})\end{array} & \begin{array}{c}\text { Top } \\ \text { Conveyance } \\ (\mathrm{cfs})\end{array} & \begin{array}{r}\text { width } \\ (\mathrm{ft})\end{array} & \begin{array}{r}\text { Wetted } \\ \text { perimeter } \\ (\mathrm{ft})\end{array} \\ .00 & 1.0 & 23.0 & .00 & .0 \\ .59 & 1.5 & 105.8 & 10.66 & 7.7 \\ .88 & 7.3 & 253.7 & 13.20 & 10.9 \\ 1.18 & 11.8 & 480.9 & 14.39 & 13.4 \\ 1.47 & 16.2 & 778.2 & 14.94 & 14.7 \\ 1.77 & 20.7 & 1133.2 & 15.27 & 15.5 \\ 2.06 & 25.2 & 1537.4 & 15.45 & 16.2 \\ 2.36 & 29.8 & 1982.1 & 15.50 & 16.8 \\ 2.65 & 34.3 & 2457.7 & 15.21 & 17.4 \\ 2.94 & 38.8 & 2947.2 & 15.08 & 18.0 \\ 3.24 & 43.2 & 3452.5 & 14.92 & 18.6 \\ 3.53 & 47.6 & 3969.0 & 14.73 & 19.2 \\ 3.83 & 51.9 & 4492.0 & 14.52 & 19.8 \\ 4.12 & 56.1 & 5017.5 & 14.28 & 20.4 \\ 4.42 & 60.3 & 5541.1 & 14.02 & 21.1 \\ 4.71 & 64.4 & 6058.9 & 13.72 & 21.7 \\ 5.01 & 68.3 & 6566.8 & 13.39 & 22.4 \\ 5.30 & 72.2 & 7060.7 & 13.03 & 23.1 \\ 5.59 & 76.0 & 7536.5 & 12.62 & 23.7 \\ 5.89 & 79.7 & 7989.9 & 12.18 & 24.5 \\ 6.18 & 83.2 & 8416.2 & 11.69 & 25.2 \\ 6.48 & 86.5 & 8810.5 & 11.14 & 26.0 \\ 6.77 & 89.7 & 9167.5 & 10.54 & 26.8 \\ 7.07 & 92.7 & 9480.9 & 9.86 & 27.6 \\ 7.36 & 95.5 & 9743.3 & 9.10 & 28.5 \\ 7.66 & 98.1 & 9945.1 & 8.22 & 29.5 \\ 7.95 & 100.4 & 10073.2 & 7.20 & 30.5 \\ 8.24 & 102.3 & 10106.1 & 5.93 & 31.7 \\ 8.54 & 103.8 & 9997.8 & 4.24 & 33.1 \\ 8.83 & 104.7 & 9380.3 & .00 & 34.9 \\ & & & & 39.2\end{array}$

Figure 23. CAP output for barrel 2 of Rio Grande conveyance channel culvert-continued. [ft, feet; sq.ft, square feet; cfs, cubic feet per second] 
Rio Grande Conveyance Channel multi-culvert barrel 2, 10-11-1994

APPROACH SECTION PROPERTIES - ID: APP2

\begin{tabular}{|c|c|c|c|c|c|}
\hline $\begin{array}{l}\text { Water } \\
\text { Surface } \\
\text { el.(ft)* }\end{array}$ & $\begin{array}{l}\text { Area } \\
(s q . f t)\end{array}$ & $\begin{array}{c}\text { Conveyance } \\
\text { (cfs) }\end{array}$ & $\begin{array}{l}\text { Top } \\
\text { width } \\
(f t)\end{array}$ & Alpha & $\begin{array}{l}\text { Critical } \\
\text { discharge } \\
\text { (cfs) }\end{array}$ \\
\hline .30 & .0 & .0 & .0 & 1.00 & .0 \\
\hline 1.09 & 1.0 & 20.4 & 2.5 & 1.00 & 3.5 \\
\hline 1.88 & 4.0 & 112.7 & 6.7 & 1.00 & 17.8 \\
\hline 2.68 & 16.6 & 619.6 & 18.5 & 1.00 & 89.0 \\
\hline 3.47 & 31.8 & 1701.1 & 20.0 & 1.00 & 227.7 \\
\hline 4.26 & 48.2 & 3185.2 & 21.3 & 1.00 & 411.4 \\
\hline 5.05 & 65.5 & 5032.6 & 22.3 & 1.00 & 636.7 \\
\hline 5.84 & 83.5 & 7190.7 & 23.3 & 1.00 & 897.7 \\
\hline 6.63 & 102.4 & 9644.8 & 24.3 & 1.00 & 1193.3 \\
\hline 7.42 & 122.0 & 12385.2 & 25.2 & 1.00 & 1523.1 \\
\hline 8.22 & 142.2 & 15393.8 & 26.1 & 1.00 & 1885.0 \\
\hline 9.01 & 163.2 & 18665.3 & 27.0 & 1.00 & 2278.3 \\
\hline 9.80 & 184.6 & 22281.8 & 27.0 & 1.00 & 2739.5 \\
\hline 10.59 & 206.0 & 26039.3 & 27.0 & 1.00 & 3228.7 \\
\hline 11.38 & 227.4 & 29917.3 & 27.0 & 1.00 & 3744.1 \\
\hline 12.18 & 248.7 & 33900.3 & 27.0 & 1.00 & 4284.3 \\
\hline 12.97 & 270.1 & 37975.8 & 27.0 & 1.00 & 4848.2 \\
\hline 13.76 & 291.5 & 42132.8 & 27.0 & 1.00 & 5434.9 \\
\hline 14.55 & 312.9 & 46362.5 & 27.0 & 1.00 & 6043.5 \\
\hline 15.34 & 334.2 & 50657.0 & 27.0 & 1.00 & 6673.3 \\
\hline 16.13 & 355.6 & 55009.6 & 27.0 & 1.00 & 7323.6 \\
\hline 16.93 & 377.0 & 59414.7 & 27.0 & 1.00 & 7993.7 \\
\hline 17.72 & 398.4 & 63867.2 & 27.0 & 1.00 & 8683.1 \\
\hline 18.51 & 419.7 & 68362.7 & 27.0 & 1.00 & 9391.3 \\
\hline 19.30 & 441.1 & 72897.4 & 27.0 & 1.00 & 10117.7 \\
\hline
\end{tabular}

Figure 23. CAP output for barrel 2 of Rio Grande conveyance channel culvert-continued. [ft, feet; sq.ft, square feet; cfs, cubic feet per second] 


\section{Computation of a Three-Parameter Table}

One example of a three-parameter table is presented in this section. It is based or examples 3 and 5 in the TWRI on culverts. In this example, a rating surface is computed for a range of discharges and tailwaters. The output table can be used either to plot a rating surface that depicts the hydraulic behavior of the culvert or as inputs into other flow models.

Location: TWRI creek

Culvert section description: 10-foot-diameter corrugated-metal pipe set in vertical headwall.

Manning's coefficient of roughness, $n$, is estimated as 0.024 and $r / D$ is 0.006 . The elevation of the upstream and downstream inverts is 1.6 feet.

Approach section description: Ponded conditions exist.

Computation requirement: Compute upstream water-surface elevations for discharges ranging from 220 to 280 cubic feet per second and tailwaters from 2.00 to 5.00 feet.

Because ponded conditions exist, the adopted cross section must give approach velocities near zero. The input file used follows.

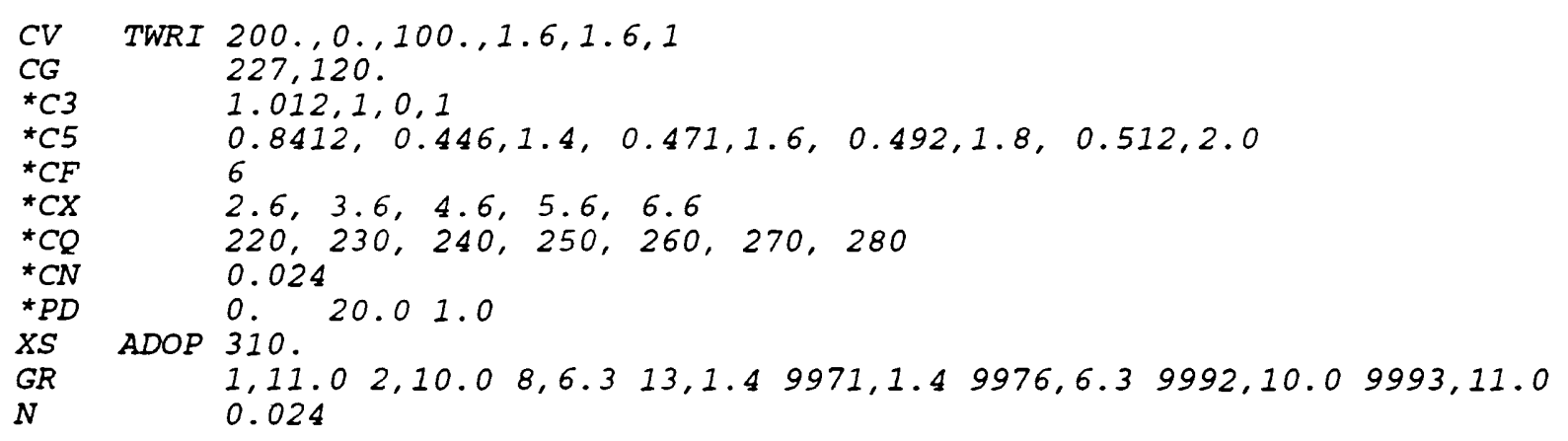

The summary output from this file, except for page 0 containing the echoed input, is shown in figure 24 . The three-parameter table is output to a file named by default as TABLES30.DAT. This output is shown is figure 25. From this table, discharge, upstraam water-surface elevation, and downstream water-surface elevation can be interpolated given any two of the parameters. A rating surface that visually describes the flow behavior for this culvert is shown in figure 26 . The figure was produced with a commercially available 3-D plotting program. 
Rio Grande Conveyance Channel multi-culvert barrel 2, 11-29-94

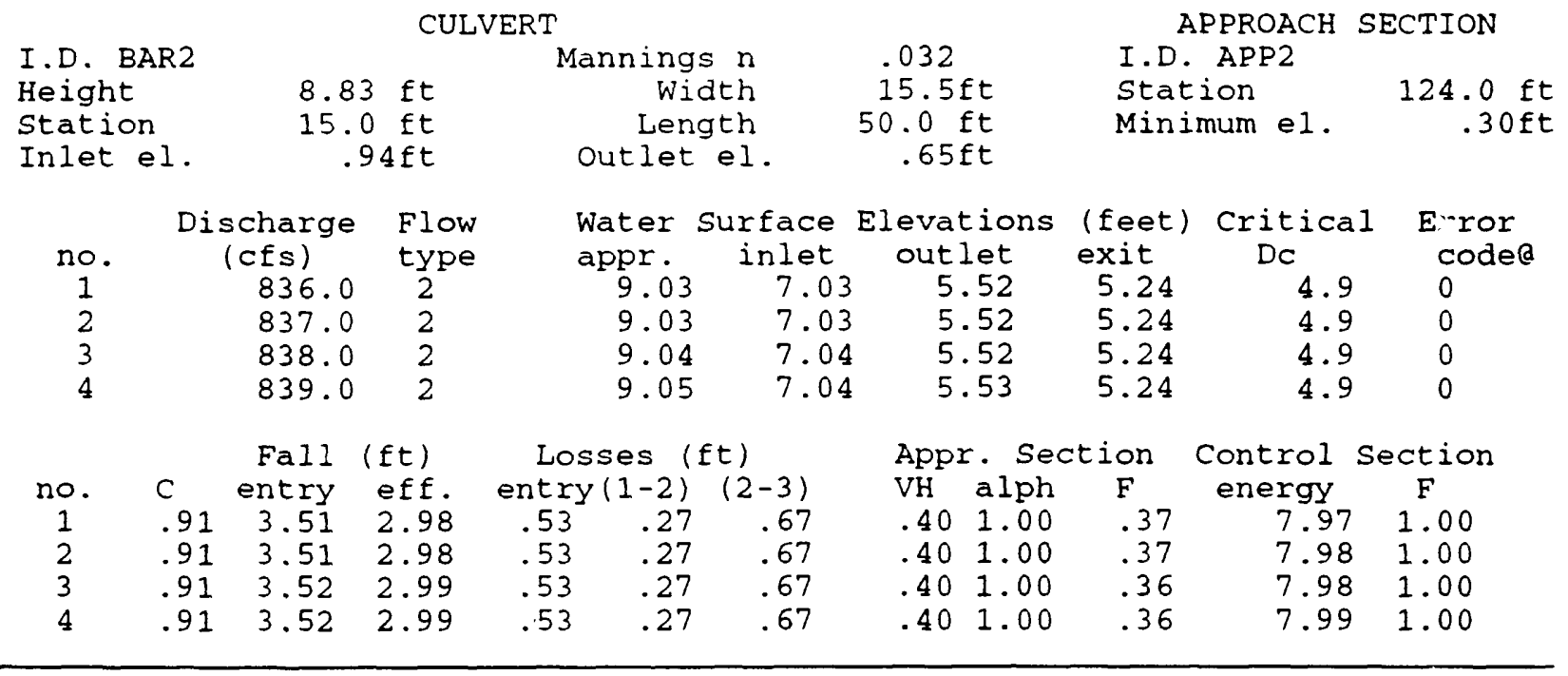

Abrevs. used: appr.-approach C-discharge coefficient eff.-effective VH-velocity head alph-velocity coefficient n-Manning's roughness coef. energy-specific energy F-Froude number entry, $(1-2),(2-3)$-part of reach @Error codes: $-1,1-7$ fatal error; 8-14 warning; 0 no error

Figure 23. CAP output for barrel 2 of Rio Grande conveyance channel culvert-continued. [ft, feet; sq.ft, cfs, cubic feet per second] 
Example using 3 parameter table output

APPROACH SECTION PROPERTIES - ID: ADOP

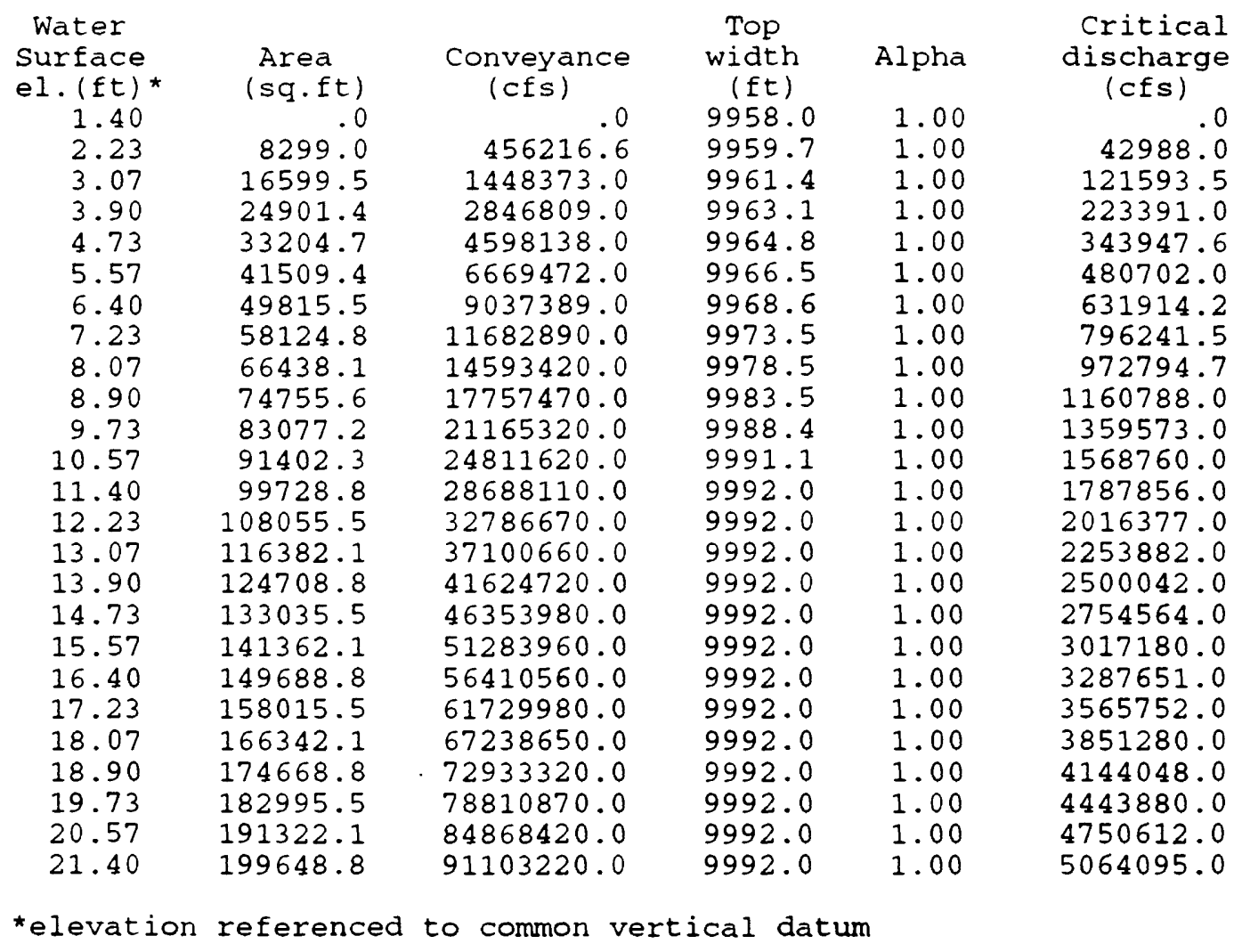

Figure 24. CAP output for TWRI creek example problem using three-parameter table outputcontinued. [ft, feet; sq.ft, square feet; cfs, cubic feet per second] 
Example using 3 parameter table output

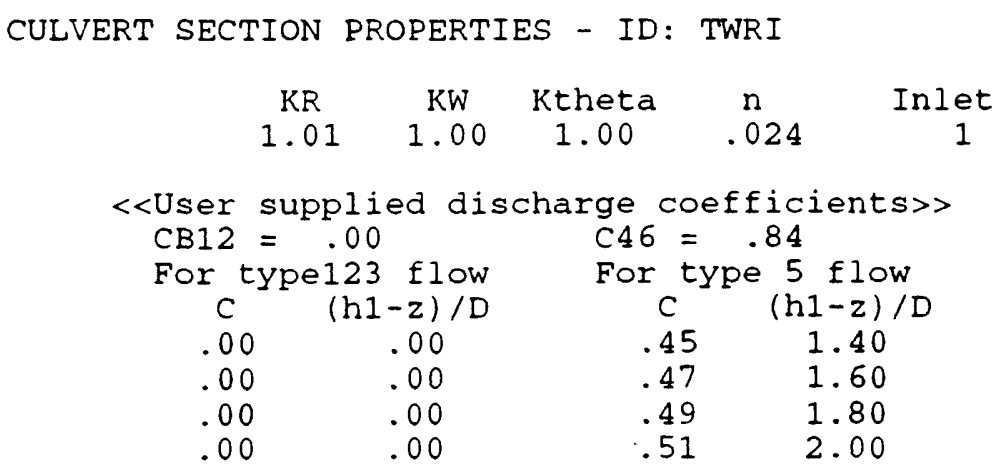

$\begin{array}{ccccc}\begin{array}{c}\text { Barrel } \\ \text { depth } \\ (\mathrm{ft})\end{array} & \begin{array}{c}\text { Area } \\ (\mathrm{sq} . \mathrm{ft})\end{array} & \begin{array}{c}\text { Top } \\ \text { Conveyance } \\ (\mathrm{cfs})\end{array} & \begin{array}{c}\text { idth } \\ \text { (ft) }\end{array} & \begin{array}{r}\text { Wetted } \\ \text { perimeter } \\ (\mathrm{ft})\end{array} \\ .33 & .0 & 18.1 & .00 & .0 \\ .67 & 2.8 & 79.6 & 3.59 & 3.7 \\ 1.00 & 4.1 & 187.5 & 6.99 & 5.2 \\ 1.33 & 6.2 & 342.1 & 6.80 & 6.4 \\ 1.67 & 8.6 & 542.3 & 7.45 & 7.5 \\ 2.00 & 11.2 & 786.5 & 8.00 & 9.4 \\ 2.33 & 13.9 & 1072.5 & 8.46 & 10.1 \\ 2.67 & 16.8 & 1397.6 & 8.84 & 10.9 \\ 3.00 & 19.8 & 1758.9 & 9.17 & 11.6 \\ 3.33 & 22.9 & 2153.2 & 9.43 & 12.3 \\ 3.67 & 26.1 & 2577.0 & 9.64 & 13.0 \\ 4.00 & 29.3 & 3026.7 & 9.80 & 13.7 \\ 4.33 & 32.6 & 3498.4 & 9.91 & 14.4 \\ 4.67 & 35.9 & 3987.8 & 9.98 & 15.0 \\ 5.00 & 39.3 & 4490.8 & 10.00 & 15.7 \\ 5.33 & 42.6 & 5002.8 & 9.98 & 16.4 \\ 5.67 & 45.9 & 5519.0 & 9.91 & 17.0 \\ 6.00 & 49.2 & 6034.3 & 9.80 & 17.7 \\ 6.33 & 52.4 & 6543.4 & 9.64 & 18.4 \\ 6.67 & 55.6 & 7040.6 & 9.43 & 19.1 \\ 7.00 & 58.7 & 7519.8 & 9.17 & 19.8 \\ 7.33 & 61.7 & 7974.4 & 8.84 & 20.6 \\ 7.67 & 64.6 & 8397.0 & 8.46 & 21.3 \\ 8.00 & 67.4 & 8779.3 & 8.00 & 22.1 \\ 8.33 & 69.9 & 9111.5 & 7.45 & 23.0 \\ 8.67 & 72.3 & 9381.4 & 6.80 & 23.9 \\ 9.00 & 74.5 & 9572.7 & 6.00 & 25.0 \\ 9.33 & 76.3 & 9660.0 & 4.99 & 26.2 \\ 9.67 & 77.7 & 9591.9 & 3.59 & 27.7 \\ 10.00 & 78.5 & 8981.7 & .00 & 31.4 \\ & & & & \end{array}$

Figure 24. CAP cutput for TWRI creek example problem using three-parameter table output. [ft, feet; sq.ft, square feet; cfs, cubic feet per second] 
Example using 3 parameter table output

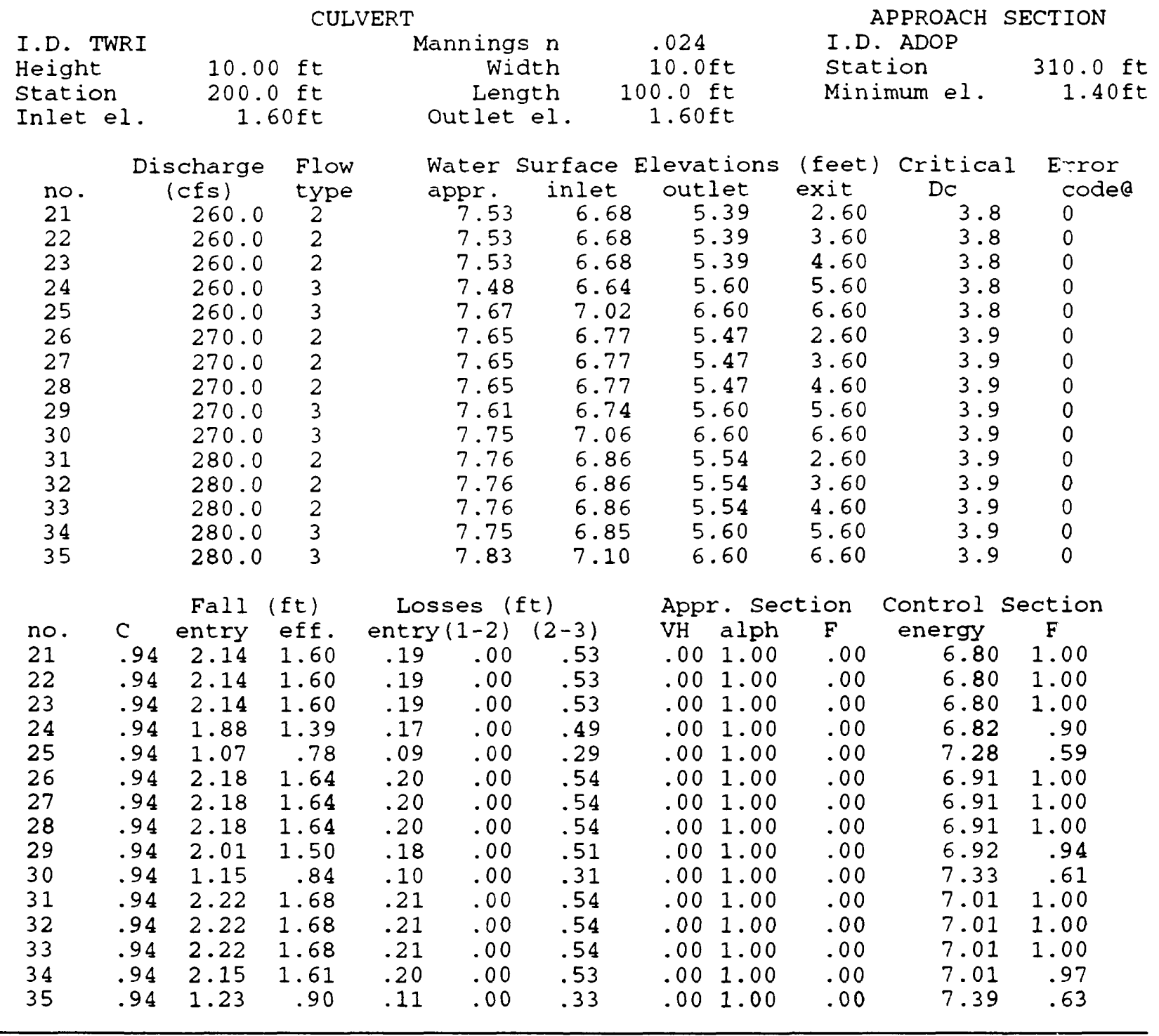

Abrevs. used: appr.-approach C-discharge coefficient eff.-effective VH-velocity head alph-velocity coefficient n-Manning's roughness coef. energy-specific energy F-Froude number entry, (1-2), (2-3)-part of reach

aEror codes: $-1,1-7$ Eatal error; 8-14 warning; 0 no error

Warning Messages-_.........

Figure 24. CAP output for TWRI creek example problem using three-parameter table outputcontinued. [ft, feet; sq.ft, cfs, cubic feet per second] 
Example using 3 parameter table output

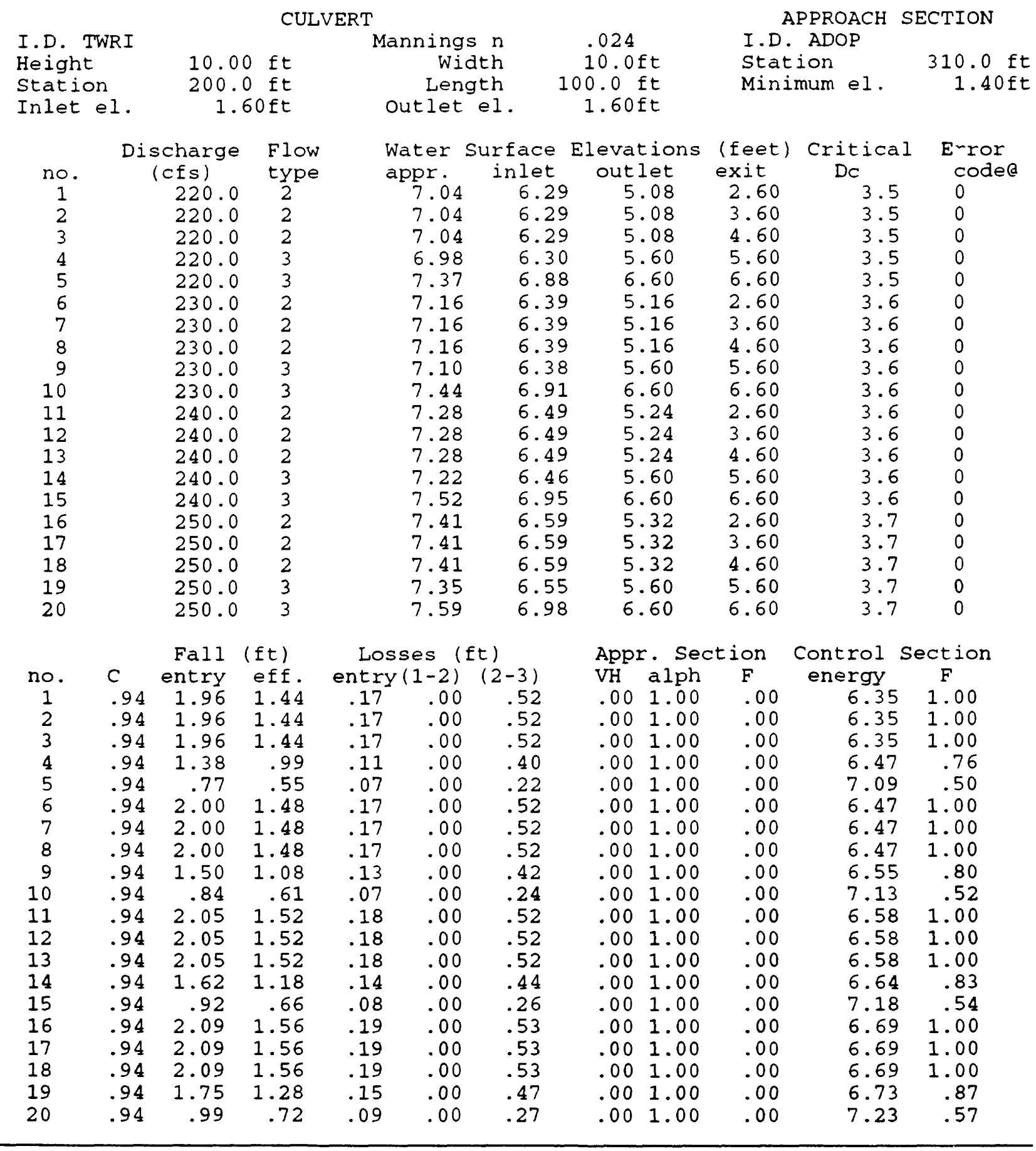

Abrevs. used: appr.-approach c-discharge coefficient eff.-effective $\mathrm{VH}$-velocity head alph-velocity coefficient n-Manning's roughness coef. energy-specific energy F-Froude number entry, (1-2), (2-3)-part of reach

aError codes: $-1,1-7$ fatal error; 8-14 warning; 0 no error

Figure 24. CAP output for TWRI creek example problem using three-parameter table outputcontinued. [ft, feet; sq.ft, cfs, cubic feet per second] 


\section{ERROR MESSAGES}

Error messages are printed to the screen and to the output file. Messages printed to the screen during program execution are usually the result of errors in the input file. Messiges printed to the output file are either warning messages, indicating potential problems, or fatal error messages for a particular combination of discharge and tailwater elevation.

\section{$\underline{\text { Input Error Messages }}$}

Input error messages are usually generated when data have been entered incorrectly into the input file or when the data array sizes exceed the defaults set in the program code. These messages are printed to the screen and with the print out of the input file(s) included ir the detailed report. Other messages are runtime messages generated by the compiler. The following is an alphabetized list of screen error messages that may be generated by the CAP during execution. Runtime messages generated by the compiler are not listed here and are dependent on the compiler used to produce the executable version of CAP. In the following messages, $n n$ is the number of array entries allowed by the program for that particular array.

\section{$n n$ allowable computation records, EXCEEDED}

Too many *PD records specified in input file. Enter only one *PD for the culvert analysis. $n n$ allowable discharge entries EXCEEDED

Number of discharges entered exceeds the array size. Reduce the number of discharges.

$n n$ allowable roughness depths, ----- EXCEEDED for ID

Number of roughness values entered exceeds the array sized for the cross-section ID listed.

Reduce the number of roughness depths.

$n n$ allowable roughness values, -----EXCEEDED for ID

Number of roughness values entered exceeds the array size for the cross-section ID listed.

Reduce the number of roughness values.

\section{$n n$ allowable tailwater entries -.-.--- EXCEEDED}

Number of tailwater depths entered exceeds the array size. Reduce the number of depths.

$n \boldsymbol{n}$ allowable $x, y$ coordinates, -.-.- EXCEEDED for ID

Number of coordinates entered exceeds the array size for the cross-section ID listed. Reduce the number of coordinates.

$n n$ allowable $\mathbf{x}, \mathrm{y}$ culvert coordinates, - EXCEEDED

Number of coordinates entered exceeds the array size for the culvert section. Reduce the number of coordinates.

\section{Approach section ID NOT FOUND IN FILE}

The program failed to find the approach ID entered in the file specified. A mistyped ID (either case or spelling) will not be found.

Approach section located incorrectly - FATAL

The approach section is not located upstream of the culvert inlet. Check reference distances for the culvert, approach section, and the culvert length. 
1.600

$\begin{array}{ccccccc}1.00 & 2.00 & 3.00 & 4.00 & 5.00 & & \\ 220 & 230 . & 240 . & 250 . & 260 . & 270 . & 280 . \\ 5.44 & 5.44 & 5.44 & 5.38 & 5.77 & & \\ 5.56 & 5.56 & 5.56 & 5.50 & 5.84 & & \\ 5.68 & 5.68 & 5.68 & 5.62 & 5.92 & & \\ 5.81 & 5.81 & 5.81 & 5.75 & 5.99 & \\ 5.93 & 5.93 & 5.93 & 5.88 & 6.07 & \\ 6.05 & 6.05 & 6.05 & 6.01 & 6.15 & \\ 6.16 & 6.16 & 6.16 & 6.15 & 6.23 & \end{array}$

Figure 25. Tabled output for TWRI creek example.

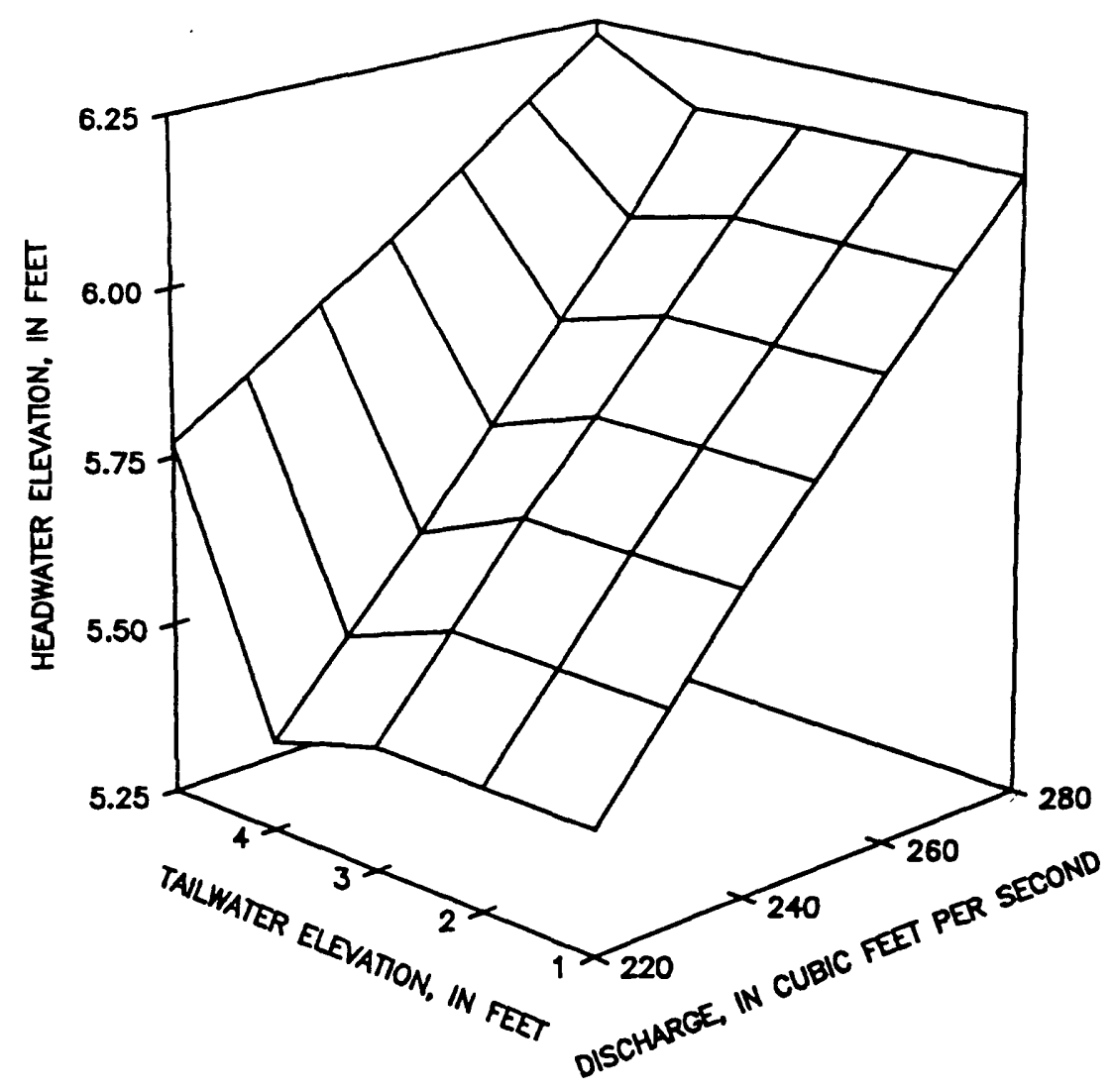

Figure 26. TWRI creek three-parameter rating surface. 
No *CF record, type 6 and 5 flows computed

No high head flow type specified. Type 6, the default, is used.

No *CQ record,

A *CQ record has not been entered. Discharges must be specified for culvert computations.

No ${ }^{*} \mathrm{CX}$ record,

A $*$ CX record has not been entered. Tailwater elevations must be specified for culvert computations.

No *C5 record,

A $*$ C5 record has not been entered. Discharge coefficients for type 4,5 and 6 flow must be specified.

Range on *PD swapped to ascending order

The minimum and maximum range on the *PD record were ordered incorrectly. The values were swapped. This is a warning message only and does not halt the program.

RATIO on *PD set to default of 1-.-.-.-.-.-

The value entered on the *PD record for RATIO was either not entered or less than or equal to zero. This is a warning message only and a default value of 1 is used by the program for RATIO.

$n n$ subarea breakpoints allowed. EXCEEDED for ID

Number of breakpoints entered exceeds the array size for the cross-section ID listed. Reduce the number of subareas.

THETA $<0$ or $>90$, default of 0 used

The angle for wingwalls entered on the ${ }^{*} \mathrm{C} 3$ record must be greater than or equal to 0 and less than or equal to 90 degrees.

$x, y$ coordinates are ordered funny -...- ID

Coordinates should be entered in counterclockwise order. If an enclosed section is beirg used, the first and last coordinate must be the same.

\section{Output File Messages}

Two types of error messages are printed to the output file; fatal messages and waring messages. Fatal messages are printed in the location where the computed values would have been printed. Warning messages are designated by a number in the error code column of the output and are printed at the end of the output after the warning messages heading. The following is a list of error code numbers and associate output error messages that can be written to the output file.

\section{-1, Root did not close to tolerance}

A tolerance, set in the program, is used to determine when the flow equation has been successfully solved. For this computation, the flow equation root did not close to the criteria specified in the program. 
Approach section located too close --WARNING

The approach section is located within one culvert height of the culvert entrance.

CB12 coefficient unreasonable FATAL

The coefficient, $\mathrm{CB} 12$, entered on the ${ }^{*} \mathrm{C} 1$ record is outside the range of valid discharg: coefficients (either greater than 0.98 or less than 0.85 ).

CP coefficients unreasonable -.---.-- FATAL

The coefficients entered on the ${ }^{*} \mathrm{C} 1$ record are outside the range of valid discharge coefficients (either greater than 0.98 or less than 0.65 ).

Culvert data incomplete, check data -- FATAL

The data in the input file is not sufficient to describe the culvert section and to run the program. The input file describing the culvert section must have a $\mathrm{CV},{ }^{*} \mathrm{CX},{ }^{*} \mathrm{CC},{ }^{*} \mathrm{CN}$, and either a $*$ CS or a CG record.

Culvert section ID NOT FOUND IN FILE

The program failed to find the culvert ID entered in the file specified. A mistyped ID (either case or spelling) will not be found.

C46 coefficient un reasonable ---.-.-- FATAL

The coefficient, $\mathrm{C} 46$, entered on the ${ }^{*} \mathrm{C} 5$ record is outside the range of valid discharge coefficients (either greater than 0.98 or less than 0.65 ).

C5 coefficients unreasonable -.......-. FATAL

The coefficients entered on the ${ }^{*} \mathrm{C} 5$ record are outside the range of valid discharge coefficients (either greater than 0.75 or less than 0.39 ).

Depth ratios for CP values funny -.... FATAL

The depth ratios entered on the ${ }^{*} \mathrm{Cl}$ record are not in increasing order.

Depth ratios for C5 values funny -..-. FATAL

The depth ratios entered on the ${ }^{*} \mathrm{C} 5$ record are not in increasing order.

Inconsistent no. of roughnesses \& roughness depths @ ID

If two roughness values per subarea are entered, the number of roughness depths should equal the number of roughnesses, otherwise, no depths should be entered.

Inconsistent no. of roughnesses and subareas for ID

Number of roughness values and subareas do not match. Number of entered roughnesses should be equal either to the number of subareas or to twice the number of subareas.

INLET code not valid, default of 1 used

The inlet code entered on the ${ }^{*} \mathrm{C} 3$ record must be either 1,2 , or 3 . See section on ${ }^{*} \mathrm{C}$ ? record.

KPROJ $>1$, default of 1 used

The adjustment for projecting entrances entered on the * $\mathrm{C} 3$ record must be less than or equal to 1 .

$K R<1$, default of 1 used

The adjustment for rounding entered on the ${ }^{*} \mathrm{C} 3$ record must be greater than or equal to 1 . KW $<1$, default of 1 used

The adjustment for beveling entered on the ${ }^{*} \mathrm{C} 3$ record must be greater than or equal tc 1 . NBBL, no. of barrels $<1$, default of 1 used

The number for NBBL is used for calculating the effects of webs on culvert properties. Enter the number of barrels per culvert. 
elevations used to compute the properties is too large. See the section on *PD record and the RATIO variable.

\section{7 , No solution type five flow}

The program is unable to compute the type 5 flow equations. Type 5 flow may not be applicable for these parameters. The root of the type 5 flow equation is not bracketed by type 5 flow criteria.

8, WARNING -- flow type $1 \& 3$ in barrel used type 1

The program has determined that barrel losses and length are such that type 1 flow will occur in the inlet section of the culvert. The approach water-surface elevation is computed using the type 1 flow equations.

9, WARNING -- No solution for type 3 inlet, assumed normal flow depth in inlet

The program was unable to find an appropriate solution for the inlet equation for type 3 flow. Because the culvert slope is mild, normal depth occurs in the inlet. Refer to the section on flow transitions for an explanation.

10, WARNING -- linearly interpolated between high head flows and type 2 insterd of type 3

The upstream water-surface elevation is between the lower limit for high head flows and the upper limit for the low head flows. Because the type 3 equation for tailwater control could not be solved, the type 2 equation for critical depth in the culvert outlet was used. This may reduce the upstream water surface elevation below what actually occur:

11, WARNING -- linearly interpolated between high head flows and critical depth flows The upstream water-surface elevation is between the lower limit for high head flows and the upper limit for the low head flows. The upstream water-surface elevation is interpolated between either type 1 and types 5 or 6 or type 2 and types 5 or 6 or type 3 and types 5 or 6 as suggested in Bodhaine. If the flow type is listed with a zern, critical depth is larger than the culvert height. Refer to the section on flow transitions for details.

12, WARNING -- flow did not meet high head criteria for type 5

The flow does not meet all the requirements for it to be a type 5 (sluice gate) flow. 13, WARNING -. culvert is flowing full and part full

If flow type is 34 , entrance is flowing as type 3 and exit as type 4 ; if flow type is 43 , entrance is flowing as type 4 and exit as type 3.

\section{SUMMARY}

The user's guide contains information on the culvert analysis program and examrles that demonstrate appropriate use of the program. The program uses the basic procedure described in the TWRI by Bodhaine on culverts with a few modifications to allow solutions to 1 ? computed between flow type transitions. Rating curves or rating surfaces describing the hydraulic behavior of the culvert can be plotted from the program results. The program can also be used to determine discharges for culverts from measured high-water marks. 
The upper and lower bounds of flow depths in the culvert computed by the program did not bracket a solution to the flow equation. This is a fatal error for that combination of discharge and tailwater elevation.

-4, Root not bracketed in approach section

The upper and lower bounds computed for the water-surface elevation in the approach did not bracket a solution to the flow equation. This is a fatal error for that combination of discharge and tailwater elevation. This error may result from a lack of spatial convergence. The water surface can not be approximated by a straight line betwee 7 the culvert inlet and the approach section successfully. A possible solution may be to translate the approach section closer to the inlet if the approach is located more than one culvert height upstream from the inlet.

\section{1, FAILED INTERPOLATION, -- for approach section properties}

The program was unable to interpolate needed values from the table of hydraulic propeties computed for the range of depth given on the *PD record. Check range of depths entered on *PD record and increase range. Range should be at least two times the culvert height. Depending on conditions in the approach section and the culvert erit, the range may need to be greater than two times the culvert height. Refer to the section on the *PD record.

\section{2, FAILED INTERPOLATION, -- for culvert properties}

The program was unable to interpolate needed values from the table of hydraulic propeties for the culvert section. Check that datum used in approach and culvert section descriptions are consistent.

\section{3, FAILED INTERPOLATION, -- for discharge coefficients}

The program was unable to interpolate needed values from the range of discharge coeff nients given. Expand range of $\left(h_{1}-z\right) / D$ versus discharge coefficients, or enter necessary discharge coefficients if none have been entered.

4, No solution type one flow ---SUPERCRITICAL FLOW at approach section

The program is unable to route the flow in the upstream direction. This is a fatal error and usually results when flow is supercritical in the approach. However, poor interpolation of approach section properties may result in this error. Setting RATIO greater than 1 , so that approach properties are computed more frequently at the lowest depths may eliminate this error.

\section{5, No solution type 2 or 3 flow ---SUPERCRITICAL FLOW at approach section}

The program is unable to route the flow in the upstream direction. This is a fatal error and usually results when flow is supercritical in the approach. However, poor interpolation of approach section properties may result in this error. Setting RATIO greater than 1, so that approach properties are computed more frequently ai the lowest depths may eliminate this error.

\section{6, DISCHARGE out of range of critical discharges}

The program estimates a first guess at the upstream water-surface elevation by computing critical discharges for the range of depths over which the approach-section properties are computed. This error may result if the range of depths over which the approach-section properties are computed is not large enough or if the intervals between water-surfane 


\section{REFERENCES CITED}

American National Standard Programming Language FORTRAN: American National Standards Institute, 1978, New York, N.Y.

Arcement, G.J., Jr., and Schneider, V.R., 1989, Guide for selecting Manning's roughness coefficients for natural channels and floodplains: U.S. Geological Survey, Water-Supply Paper 2339, 38p.

Barnes, Harry H., Jr., 1967, Roughness characteristics of natural channels, U.S. Geological Survey, Water-Supply Paper 1849, 213p.

Bodhaine, G.L., 1968, Measurement of peak discharge at culverts by indirect methods: IJ.S. Geological Survey, Techniques of Water-Resources Investigations, book 3, chapter A3, $60 \mathrm{p}$.

Chow, V.T., 1959, Open-channel hydraulics: New York, N.Y., McGraw-Hill Book Co., 680p.

Conte, S.D. and C. DeBoor, Elementary numerical analysis an algorithmic approach: New York, N.Y., McGraw-Hill Book Co., 432 p.

Hicks, D.M., and Mason, P.D., 1991, Roughness characteristics of New Zealand Rivers:

Wellington, New Zealand, Water Resources Survey, DSIR Marine and Freshwater, 329p.

Jarret, R.D., 1985, Determination of roughness coefficients for streams in Colorado: U.S. Geological Survey, Water-Resources Investigations Report 85-4004, 54p.

Matthai, H.F., Stull, H.E., and Davidian, J. (1970?), Preparation of input data for automatic computation of stage-discharge relations at culverts, unpublished report, U.S. Geological Survey.

Shearman, J.O., 1990, User's manual for WSPRO--a computer model for water-surface profile computations: U.S. Federal Highway Administration Report No. FHWA-IP-89-027, $187 \mathrm{p}$.

Shearman, J.O., W.H. Kirby, V.R. Schneider, and H.N. Flippo, 1986, Bridge waterways analysis model: research report: U.S. Federal Highway Administration Report No. FHWA/RD-86/108, 126p.

Thompson, D.B., and Rogers, T.D., Water surface profile computations-how many sections do I need?, Proceedings of the 1993 Hydraulic Conference, Vol. 1: New York, American Society of Civil Engineers, p. 791-796. 